\title{
MECHANICAL AND MICROSCOPIC INVESTIGATION \\ OF WHISKER-REINFORCED SILICONE RUBBER
}

by

\section{(C) Mark Weber}

A thesis submitted to the Faculty of Graduate studia:; in partial fulfillment of the requirements for tho degree of Master of Engineering

\author{
Department of Chemical Engineering \\ MCGill University \\ Montreal, Canada \\ September, 1989
}


MeChaNICAL AND MICROSCOPIC INVESTIGATION OF SILICONE RUBBER 


\section{ABSTRACT}

The fiber orientation and mechanical properties of a Franklin Fiber whisker reinforced silicone rubber were studied. The composites were molded using both transfer and compression molding. Processing parameters, such as sprue design, milling procedure, and mold temperature were varied to determine their effects on the orientation of the fibers and the tensile properties of the composite.

A novel image analysis system is used to determine fiber orientation. The fiber orientation is anisotropic and independent of sprue design and temperature, but dependent on the milling procedure. The tensile strength and elongation at break are isotropic for each composite, while the Young's modulus and tensile set are affected by fiber orientation. All properties are temperature dependent. The experimental young's moduli do not show agreement with theoretical predictions. 


\section{RESUME}

L'orientation des fibres et les propriétés mécanıquesi d'un caoutchouc silicone, renforcé avec des fibres Frankl in Fibu, ont été étudiés. Les composites ont été tabriques: on utilisant le moulage par transfert et le mouldue ful compression. Les paramètres du proces, commo la concentlull des carottes, le procédé de mélangeage sur roul e.sux, et l.1 température ont été variés pour déterminer lour elict 'ill l'orientation des fibres et les propriétés en tonsion.

Un nouveau systeme d'analyse est utilisé pour dótormım! l'orientation des fibres. L'orientation est ansutrop" w indēpendante de 1 a conception des cirotess it il. 1.1 température, mais dépendante sur le procédé dr mélamunug. ',u rouleaux. La résistance à la traction et l'allonrument il la rupture sont isotropes pour chaque composite, mils; 1. mmlu. d'young et le recouvrement ēlastique sont ilfectr:; pir l'orientation des fibres. Une élévation de temprírutur. (..1u, une réduction des propriétés en tension. Ler; récult.1t, pour le module d'Young ne concordent pas avec les prédiet ion', thēoriques. 


\section{ACKNOWLEDGEMENTS}

I would like to express my gratitude to my research supervisor, Prof. M.R. Kamal, for his guidance, support, and encouragement throughout this project.

In addition, I wish to thank:

- The Lord corporation for their financial support and supply of materials and equipment used in this work, and especially Dr. K.K. Tay of Lord for his invaluable help and guidance.

- The machine shop personnel, both at MCGill and at Lord, for the construction of several pieces of equipment used in the project.

- Dr. A. Turgut Mutel for his tremendous assistance and Inspiration in all phases of the project, particularly with the computer programming.

- Mr. Guenter Lohfink for his helpful discussions on the theory of rubber and his photographic assistance.

- Mossrs. Bryn Hird and Dimitri Kolovos for their performance of some of the experimental work.

- Messrs. Philip Bates, Taras Broadhead, Patrick Brousseau, Burke Nelson, and Tony Samurkas for their friendship.

- The Chemical Engineering Department, NSERC, and the Ministere de l'Education, Gouvernement du Quebec, for their financial assistance.

- My parents and family for being there.

- Miss Christine Bryce for her encouragement, support, and Eriendship. 


\title{
TABLE OF CONTENTS
}

\begin{abstract}
. . . . . . . . . . . . . . . . . . . . 1
RESUME . . . . . . . . . . . . . . . . . . . . . $1 \mathrm{i}$

ACKNOWLEDGEMENTS • . . . . . . . . . . . . . . . . . 111

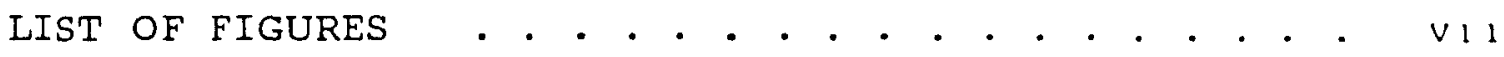

LIST OF TABLES • . . . . . . . . . . . . . . . . . $\times 11$
\end{abstract}

\section{Chapter}

1. INTRODUCTION . . . . . . . . . . . . . . . . . . 1

1.1. Rubber . . . . . . . . . . . . . . 1

1.1.1. Silicone Rubber . . . . . . . .'

1.2. Reinforcement . . . . . . . . . . . .

1.2.1. Continuous cord Reinforcement . . ',

1.2.2. Particulate Fillers . . . . . ,

1.2.3. Short Fibers . . . . . . . . . /

1.2.3.1. Whiskers . . . . .

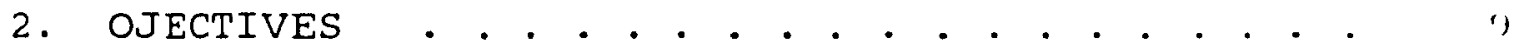

3. LITERATURE REVIEW . . • . . . • . . . . . . . . 11)

3.1. Reinforced Rubber . . . . . . . . . . 11)

3.1.1. Theory of Reinforcement . . . . 11

3.1.2. Whisker Composites . . . . . . 1\%

3.2. Processing and Molding of Rubber Compoistr..; If,

3.2.1. Compression Molding . . . . . I,

3.2.2. Injection and Transfer Molding . . 1/ 
3.3. Mechanical Properties of Molded Rubber Composites . . . . . . . . . . . . . 18

3.3.1. Effect of Processing Parameters . 24

4. EXPERIMENTAL . . . . . . . . . . . . . . 28

4.1. Materials ............ . 28

4.2. Molding Techniques ......... 30

4.2.1. Transfer Molding ....... . 30

4.2.1.1. Molding Conditions .. 30

4.2.2. Compression Molding . . . . . 31

4.2.2.1. Molding Conditions . . 33

4.3. Sample Analysis and Testing . . . . . . 34

4.3.1. Orientation Analysis . . . . . 34

4.3.1.1. Microtome Specimen
Preparation . . . . 34

4.3.1.2. Microtoming Procedure . 37

4.3.1.3. Image Aralysis . . . . 39

4.3.2. Tensile Tests ......... 40

$\because$ EXPERIMENTAL RESULTS AND DISCUSSION . . . . . 45

5.1. Fiber Orientation and Length Results . . 45

5.1.1. Transfer Molded Samples . . . . 45

5.1.2. Compression Molded Samples . . . 64

5.1.3. Comparison Between Transfer and
Compression Moldjng . . . . 82

5.2. Tensile Test Results . . . . . . . . 82

5.2.1. Transfer Molded Samples .. . . 83

5.2.2. Compression Molded Samples... . 94

5.2.3. Comparison Between Transfer and
Compression Molding . . . . . 98 
5.2.4. Comparison Between Experimental Data and Theoretical predictions . . 101

5.2.5. Effect of Franklin Fibers on Tensile properties . . . . . 105

5.3. Tensile set Results . . . . . . . . . 105

5.3.1. Transfer Molded Samples . . . . 106

5.3.2. Compression Molded Samples . . . 109

5.3.3. Comparison Between Transfer and Compression Molding . . . . . . 109

6. CONCLUSION AND RECOMMENDATIONS • . . . . . . . . 116

6.1. Conclusions . . . . . . . . . . . . . 116

6.2. Recommendations for Future Work . . . . 118 REFERENCES . . . . . . . . . . . . . . . . . 1.1) 
LIST OF EIGURES

FIGURE

1.1. Comparison Between Natural and Silicone Rubber structures. . . . . . . . . . . . . . . . .

3.1. Orientation of Nylon Fibers in an Injection Molded Composite. . . . . . . . . . . .

3.2. Effect of Fiber Concentration on Elongation at Break $(\Delta)$ and Young's Modulus (O). . . . .

3.3. Effect of Fiber Concentration on Tensile Strength. . . . . . . . . . . . . . .

3.4. Effect of Fiber orientation on Tensile Strength. . . . . . . . . . . . . . .

3.5. Effect of Fiber orientation on Young's Modulus.

3.6. Comparison of $300 \%$ Modulus for Compression and Injection Molded Carbon Black Composites. .

3.7. Comparison of Tensile strength for Compression and Injection Molded Carbon Black Composites.

3.8. Dependence of Composite Physical Properties on Cure Temperature.

4.1. Sprue Dimensions. . . . . . . . . . . . .

4.2. Microtome Locations for Transfer Molded Samples.

4.3. Microtome Locations for Compression Molded Samples.

4.4. Microtomed Slice as Seen Through the Microscope.

4.5. Microtomed slice as Seen on the Video Screen.

4.6. Digitized Representation of Microtomed Slice.

4.7. Microtome Slice as Seen Through the Microscope.

4.8. Microtome slice as seen on the Video screen.

4.9. Digitized Representation of Microtomed slice. 
4.10. Dimensions of ASTM D638-87b Die V Tensile Test Die. . . . . . . . . . . . . . . .

5.1. Orientation and Length Distributions for Samples Molded with Converging Sprues at $163^{\circ} \mathrm{C}$ (Microtome Location 1). . . . . . . . . . . 46

5.2. Orientation and Length Distributions for Samplo: Molded with Converging Sprues at $163^{\circ} \mathrm{C}$ (Microtome Location 2).

5.3. Orientation and Length Distributions for Samples; Molded with Converging Sprues at $163^{\circ} \mathrm{C}$

(Microtome Location 3).

5.4. Orientation and Length Distributions for Samples: Molded with Converging Sprues at $163^{\circ} \mathrm{C}$

(Microtome Location 4). . . . . . . . . .

5.5. Orientation and Length Distributions for Samples Molded with Converging Sprues at $163^{\circ} \mathrm{C}$

(Microtome Location 5). . . . . . . . . . 50

5.6. Orientation and Length Distributions for Sample:; Molded with Converging Sprues at $163^{\circ} \mathrm{C}$ (Microtome Location 6). . . . . . . . . .

5.7. Orientation and Length Distributions for Samples Molded with Converging sprues at $163^{\circ} \mathrm{C}$ (Microtome Location 7). . . . . . . . . 52

5.8. Orientation and Length Distributions for Sample:; Molded with Converging Sprues at 204 " $\mathrm{C}$ (Microtome Location 3). . . . . . . . . . t, t4

5.9. Orientation and Length Distributions for Samples; Molded with Converging Sprues at $204^{\circ} \mathrm{C}$ (Microtome Location 4).

5.10. Orlentation and Length Distributions for Samplras Molded with Converging Sprues at $204^{\text {" }} \mathrm{C}$ (Microtome Location 5).

5.11. Orientation and Length Distributions for Samples; Molded with Straight sprues at $163^{\circ} \mathrm{C}$

(Microtome Location 3).

5.12. Orientation and Length Distributions for Samplac: Molded with straight sprues at $163^{\circ} \mathrm{C}$ 
5.13. Orientation and Length Distributions for Samples Molded with Straight Sprues at $163^{\circ} \mathrm{C}$ (Microtome Location 5). . . . . . . . . .

5.14. Orientation and Length Distributions for Samples Molded with Straight Sprues at $204^{\circ} \mathrm{C}$ (Microtome Location 3). . . . . . . . .

5.15. Orientation and Length Distributions for Samples Molded with straight Sprues at $204^{\circ} \mathrm{C}$

(Microtome Location 4). . . . . . . . .

3.16. Orientation and Length Distributions for Samples Molded with Straight Sprues at $204^{\circ} \mathrm{C}$ (Microtome Location 5). . . . . . . . .

b.17. Orientation and Length Distributions for Controlled Milling Samples Molded at $163^{\circ} \mathrm{C}$ (Microtome Location 1). . . . . . . . . . .

'.13. Orientation and Length Distributions for Controlled Milling Samples Molded at $163^{\circ} \mathrm{C}$ (Microtome Location 2). . . . . . . . . .

3.19. Orientation and Length Distributions for Controlled Milling Samples Molded at $163^{\circ} \mathrm{C}$ (Microtome Location 3). . . . . . . . . .

'.20. Orientation and Length Distributions for Controlled Milling Samples Molded at $163^{\circ} \mathrm{C}$ (Microtome Location 4).

'..21. Orientation and Length Distributions for Controlled Milling Samples Molded at $163^{\circ} \mathrm{C}$ (Microtome Location 5).

5.22. Orientation and Length Distributions for Controlled Milling Samples Molded at $163^{\circ} \mathrm{C}$ (Microtome Location 6).

5.23. Orientation and Length Distributions for Controlled Milling Samples Molded at $163^{\circ} \mathrm{C}$ (Microtome Location 7). . . . . . . . .

5.24. Orientation and Length Distributions for Controlled Milling Samples Molded at $204^{\circ} \mathrm{C}$ (Microtome Location 2). . . . . . . . . .

3.25. Orientation and Length Distributions for Controlled Milling Samples Molded at $204^{\circ} \mathrm{C}$ (Microtome Location 3) 
5.26. Orientation and Length Distributions for

Random Milling Jamples Molded at $163^{\circ} \mathrm{C}$

(Microtome Location 1). . . . . . . . . .

5.27. Orientation and Length Distributions for

Random Milling Samples Molded at $163^{\circ} \mathrm{C}$

(Microtome Location 2) . . . . . . . . . 76

5.28. Orientation and Length Distributions for

Random Milling Samples Molded at $163^{\circ} \mathrm{C}$

(Microtome Location 3) . . . . . . . . . .

5.29. Orientation and Length Distributions for

Random Milling Samples Molded at $163^{\circ} \mathrm{C}$

(Microtome Location 4) . . . . . . . . . 13

5.30. Orientation and Length Distributions for

Random Milling Samples Molded at $163^{\circ} \mathrm{C}$

(Microtsme Location 5). . . . . . . . . . 70

5.31. Orientation and Length Distributions for

Ranctom Milling Samples Molded at $163^{\text {"C }}$

(Microtome Location 6) . . . . . . . . . . . 86)

5.32. Orientation and Length Distributions for

Random Milling Samples Molded at $163^{\circ} \mathrm{C}$

(Microtome Location 7) . . . . . . . . . . 81

5.33. Tensile Test Results for Samples Moldad with

Converging Sprues at $163^{\circ} \mathrm{C}$. . . . . . . . . . 34

5.34. Tensile Test Results for Samples Molded with

5.35. Tensile Test Results for Samples Molded with
Straight Sprues at $163^{\circ} \mathrm{C}$. . . . . . . . . \% / $^{.}$

5.36. Tensile Test Results for Samples Molded with

straight sprues at $204^{\circ} \mathrm{C}$. . . . . . . . . . 38

5.37. E' for Sample Molded at $163^{\circ} \mathrm{C}$. . . . . . . 'g0

5.38. E" for Sample Molded at $163^{\circ} \mathrm{C}$. . . . . . . '0)

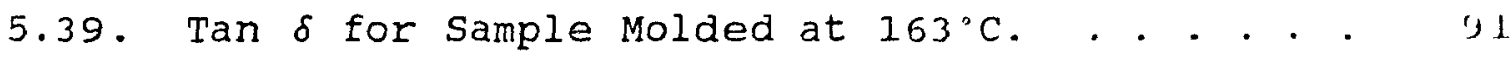

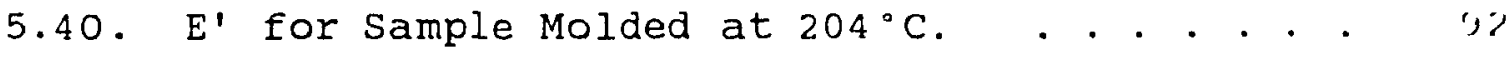

5.41. E" for Sample Molded at $204^{\circ} \mathrm{C} . \quad . .+. .+. ~ 9 \%$

5.42. Tan $\delta$ for Sample Molded at $204^{\circ} \mathrm{C} . \quad . .+. .93$ 
5.43. Tensile Test Results for controlled Miling Samples Molded at $163^{\circ} \mathrm{C}$. . . . . . . . .

5.44. Tensile Test Results for Controlled Milling Samples Molded at $204^{\circ} \mathrm{C}$. . . . . . . .

5.45. Tensile Test Results for Random Milling Samples Molded at $163^{\circ} \mathrm{C}$. . . . . . . . .

5.46. Tensile set Results for Samples Molded with Converging Sprues at $163^{\circ} \mathrm{C}$. . . . . . . .

5.47. Tensile set Results for Samples Molded with Converging sprues at $204^{\circ} \mathrm{C}$.

5.48. Tensile set Results for Samples Molded with

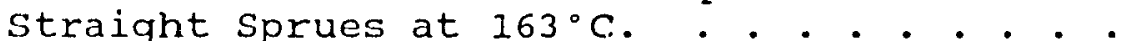

5.49. Tensile set Results for Samples Molded with straight Sprues at $204^{\circ} \mathrm{C}$. . . . . . . . .

5.50. Tensile Set Results for Controlled Milling Samples Molded at $163^{\circ} \mathrm{C}$. . . . . . . . .

5.51. Tensile Set Results for Controlled Milling Samples Molded at $204^{\circ} \mathrm{C}$. . . . . . . . .

5.52. Tensile set Results for Random Milling Samples Molded at $204^{\circ} \mathrm{C}$. 


\section{LIST OF TABLES}

TABLE

1.1. The Reinforcement of Natural Rubber with Particulate Silica. . . . . . . . . . . 6

1.2. The Reinforcement of Natural Rubber with Silk Fiber. . . . . . . . . . . . . . . . 6

3.1. Typical Chemical Analysis of Franklin Fiber. 14

3.2. The Reinforcement of polyolefins with prankl in Fiber. . . . . . . . . . . . . . . 14

3.3. Composition of a Bulk Molding Compound. . . . 15

3.4. Replacement of Glass Fiber with Franklin Fiber in a Bulk Molding Compound. . . . . . is

4.1. Silicone Rubber Properties. . . . . . . . . . 29

4.2. Franklin Fiber Properties. . . . . . . . . . 29

4.3. Composite Formulation. . . . . . . . . . .

5.1. Anisotropy Ratios for Molded Samples. . . . 100

5.2. Comparison Between Halpin-Tsai Modulus
Predictions and Experimental Values. . . . 102

5.3. Prediction of Young's Modulus for Componite
with Fiber orientation Angle $\theta . \quad . \quad . \quad . \quad . \quad . \quad . \quad 104$ 


\section{INTRODUCTION}

Reinforced rubber composites are of interest due to their combination of the elasticity of the rubber and the strength and stiffness of the reinforcement. These composites find use as automobile parts, tires, belts, hoses, and footwear. The reinforcement is either continuous cords, particulate fillers, or short fibers. Some background on both rubber and reinforcement will be given in this section.

\subsection{Rubber}

According to Flory (1), a rubber is capable of sustaining large deformations without rupture and of recovering spontaneously to very nearly its original dimensions after removal of the applied stress. Rubber consists of long polymer chains which normally exhibit a random configuration. When stress is applied, the chains change their configuration to accomodate the deformation. Rubber also exhibits a network stricture which consists of physical and chemical crosslinks. The physical crosslinks are not permanent and allow chain slippage. The chemical crosslinks are a result of vulcanization, which leads to the formation of a permanent network structure. This structure contributes to rubber elasticity and to the tendency of rubber to recover its shape after deformation (2). 
Many types of rubber are used as the matrix component in the composite system. The material of interest in this work is silicone rubber. Warrick et al. (3) have written an extensive review of silicone rubber, its composition, vulcanization, reinforcement, analysis, properties, and uses. The relovent properties of silicone rubber are discussed below.

\subsubsection{Silicone Rubber (4)}

Silicone rubber exhibits good thermal stability, resistance to ozone attack, and excellent flexibility. 'Ihesc proportios; are mainly due to its molecular structure, which 1 s compresd to the structure of natural rubber in Figure 1.1. Natural rubber has a backbone of carbon-carbon linkages, whereas the backbone of the silicone rubber consists of silicon-oxycun bonds. This silicon-oxygen bond is also found in matarials such as quartz, glass, and sand, and gives the rubber it:; thermal stability. The organic side-chains, mothyl groups in this case, provide the excellent flexibility found in silicono rubber. This type of silicone rubber with methyl side chain: is designated MQ by the American Society for Testing and Materials (ASTM) .

Natural rubber also contains double bonds within the backbone, whereas the silicon rubber backbone consists solely of singlr. bonds. These sites of unsaturation in the natural rubbrer are susceptible to ozone attack, which can occur dur to the 


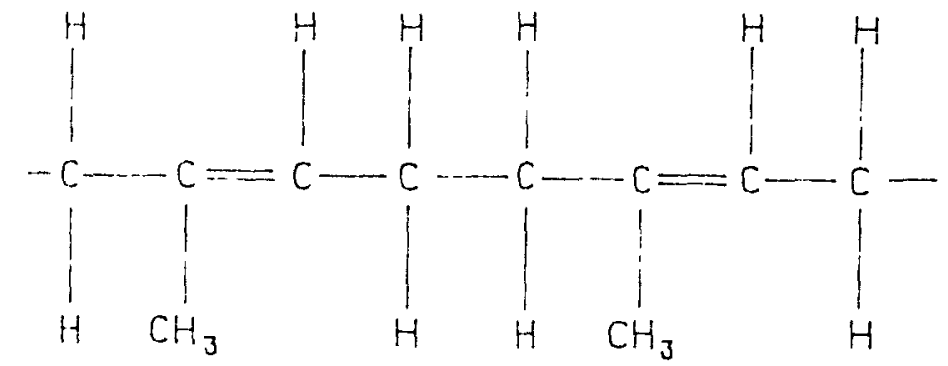

Natural Rubber

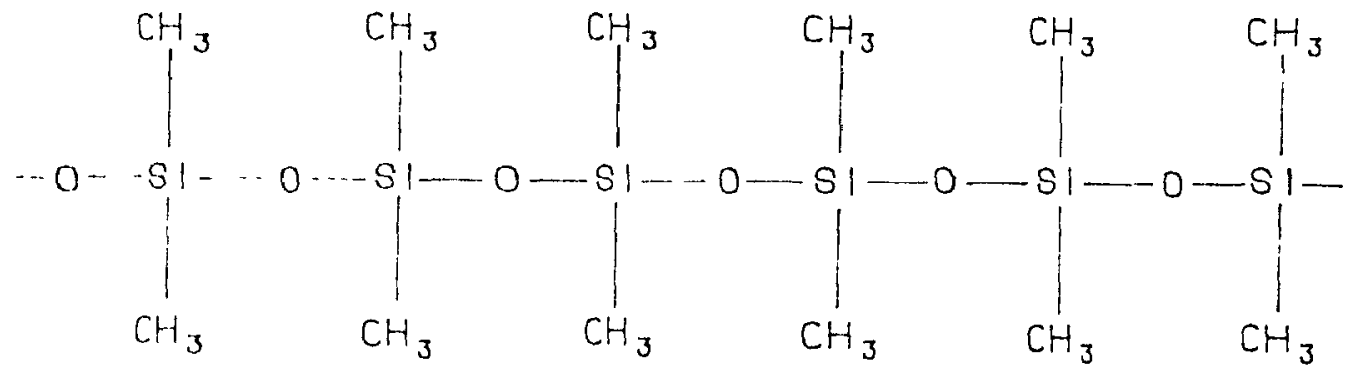

SIII cone Rubber (MQ Type)

Figure 1.1. Comparison Between Natural and Silicone Rubber Structures. 
environment or electrical fields. Since there are no double bonds in the silicone rubber chain, this rubber is extromoly resistant to ozone.

Silicone rubber is known to contain a high freo volume fraction and its crosslinked network is found to be rolat ively weak (3). Therefore, silicone polymers respond dramatically to reinforcement. For many commercial application, thr reinforcement of silicone rubber is a necessity.

\subsection{Reinforcement}

The reinforcement of both thermoplastics and rubber roilult: in mechanical and thermal property improvement. Rubur possesses a low modulus and high elasticity, and thrim properties give rubber an advantage over thermopla,t, $\ldots$; in many instances. However, certain rubber application, reruru" greater stiffness and less elasticity. Therefore, thr ruhrr is reinforced to achieve these properties. Continuous corls:, particulate fillers, and short fibers are commonly 11\%ril a'; reinforcement.

The tensile modulus, tear strength, and compression set are all increased with the addition of either particulate filler: or short fibers. The tensile strength and elongation at braik. are enhanced by the addition of particulate filler, whereds the addition of short fibers has a detrimental effect on both 
of these properties. The decrease in strength with short fiber reinforcement occurs due to the reduction in elongation at break, in spite of the substantial increase in tensile modulus. Short fiber composites are anisotropic, due to the anisotropic nature of the fibers, resulting in mechanical properties which are dependent on the orientation of the fibers. The properties are improved to a greater degree when the fibers are aligned in the test direction, rather than transverse to testing, although property enhancement is still realized in the transverse direction. Tables 1.1 (5) and 1.2 (6) demonstrate the effect of reinforcing natural rubber with particulate fillers and short fibers, respectively.

A:; mentioned previously, there exist three main types of rubber reinforcement. They are continuous cords, particulate tillers, and short fibers. Each is discussed in some detail below.

\subsubsection{Continuous cord Reinforcement}

Continuous cords have been used extensively as a reinforcement, particularly for tires. Continuous cords absorb the loads applied to the composite efficiently, and the composite retains its flexibility, especially in the direction normal to the fibers, because the reinforcement does not alter the rubber properties on a microscopic scale. The cords can also be placed into any desired orientation pattern, 
Table 1.1. The Reinforcement of Natural Rubber with Particulate Silica.

\begin{tabular}{|l|c|c|}
\hline \multicolumn{1}{|c|}{ Silica, phr } & 0 & 20 \\
\hline Tensile strength, MPa & 1.6 & 21.9 \\
Modulus 300\%, MPa & - & 2.7 \\
Elongation at break, $\%$ & 230 & 640 \\
Tear strength, kN/m & 35.3 & 46.0 \\
Compression set, $\%$ & 35 & 42 \\
\hline
\end{tabular}

Table 1.2. The Reinforcement of Natural Rubber with silk: Fiber.

\begin{tabular}{|l|c|c|c|}
\hline Silk fiber, phr & $\begin{array}{l}\text { Fiber } \\
\text { orientation }\end{array}$ & 0 & 20 \\
\hline Tensile strength, MPa & $\mathrm{L}$ & 21.98 & 11.70 \\
& $\mathrm{~T}$ & 21.21 & $6.9 \%$ \\
Modulus 5\%, MPa & $\mathrm{L}$ & 0.10 & 2.35 \\
& $\mathrm{~T}$ & 0.10 & 0.55 \\
Elongation at break, $\%$ & $\mathrm{~L}$ & 660 & 30 \\
& $\mathrm{~T}$ & 650 & 320 \\
Tear strength, kN/m & $\mathrm{L}$ & 31.1 & 57.5 \\
& $\mathrm{~T}$ & 31.4 & 60.2 \\
Compression set, $\%$ & $\mathrm{~L}$ & 38 & 63 \\
& $\mathrm{~T}$ & 5.2 \\
\hline
\end{tabular}

$L=$ Longitude direction

$\mathrm{T}=$ Transverse direction 
so as to optimize mechanical properties. Though continuous cords increase the strength and modulus, they impart significant anisotropy to the composite. This must be taken into account when using continuous cords as a reinforcement.

\subsubsection{Particulate Fillers}

'Ihe mechanical properties of rubber can be improved by the addition of particulate fillers, such as carbon black or silica. The fillers redistribute the stresses and form crosslinks via filler-elastomer bonds, thus causing increases in modulus and strength. Since fillers are essentially spherical, the filler-rubber composite is much more isotropic than either cord-rubber or short fiber-rubber composites. However, it cannot match these other composites in strength and modulus.

\subsubsection{Short Fibers}

Short flber composites exhibit properties intermediate between continuous cord and particulate filler composites. Short fiber composites are weaker than continuous fiber composites, but stronger than filler-reinforced rubber ( 7 ). Although they are not as strong as cords, they allow easier composite fabrication and improved overall economics. Also, the properties of short fiber-reinforced materials are less anisotropic than cord composites, although not to the extent 
of particulate composites ( 8 ).

\subsubsection{Whiskers}

There are a multitude of short fibers which have found usie in short fiber-rubber composites. Glass, carbon, nylon, cellulose, aramid, and silk fibers are just a few eximpla:i. Another type of short fiber reinforcement is the whisker al. microfiber. Whiskers are very small, smaller than a norm.1 short fiber, but they possess equal or greater strength. 'l'hl:: is due to the fact that whiskers are perfect single cry:it.11), and contain fewer defects than short fibers. A whisker would theoretically act as a combination of a particulate filler and a short fiber, giving the strength of a short $t$ iber and the isotropic characteristics of a particulate filler, althugh a certain degree of anisotropy would still exist. It $1:$ thic; combination of strength and size that makes whisker. in attractive reinforcement for rubber. 


\section{OBJECTIVES}

The present project represents an initial experimental effort to aid in the understanding of the processing and mechanical behavior of microfiber-reinforced rubber composites and to relate this behavior to the state of fiber orientation in the composites. More specifically, the objectives of this project are:

1. To produce composites $c$ sting of silicone rubber and Franklin Fiber whiskers (microfibers) by both transfer and compression molding.

2. To evaluate the feasibility of controlling microfiber orlentation by manipulating the sprue design in transfer molding or the milling procedure in compression molding.

3. To develop experimental and image analysis techniques for evaluation of microfiber orientation.

i. To evaluate the relationships between orientation of the microfibers, processing conditions, and mechanical behavior of the composites. 


\section{LITERATURE REVIEW}

\subsection{Reinforced Rubber}

\subsubsection{Theory of Reinforcement}

The reinforcement of polymeric materials rosults in a partition of an applied stress between the matrix and tho reinforcement. The properties of the composite $6,1 n$ bu predicted, given the properties of the constituents, by usim theoretical relations. Such relations include the Halpin-l's:ul equations (9), which predict the mechanical propertic:; uf cord, particulate, and short fiber reinforced polymers. Fis continuous cord reinforcement, the rule of mixturcs applari, and the composite Young's modulus in the longltudinal direction is (10):

$$
E_{c}=E_{f} \phi_{f}+E_{m} \phi_{m}
$$

where $E$ is the Young's modulus, $\phi$ is the volume fraction of the specified phase, and $c, f$, and $m$ refer to the compoisits, fiber phase, and matrix phase, respectively. In the transverse direction, the composite modulus is (10):

$$
\mathrm{E}_{\mathrm{c}}=\mathrm{E}_{\mathrm{m}}\left(1+2 \phi_{\mathrm{f}}\right) / \phi_{\mathrm{m}}
$$

For these equations, it is assumed that tho cord: wrs perfectly aligned, well bonded, regularly spaced, ind unidirectional. 
For particulate reinforced materials, one composite Young's modulus is predicted by the Halpin-Tsai equation, due to the isotropic nature of particulate fillers. For rigid, spherical, isotropic, and randomly dispersed particles, the predicted composite Young's modulus is (10):

$$
E_{r}=E_{m}\left(1+2 C \phi_{f}\right) /\left(1-C \phi_{f}\right)
$$

where: $C=\left(E_{\mathrm{f}} / E_{\mathrm{m}}-1\right) /\left(E_{\mathrm{f}} / E_{\mathrm{m}}+2\right)$

The composite modulus for short fiber composites can also be predicted using the corresponding Halpin-Tsai equation. The anisotropy of the reinforcing fibers results in a directiondopendent composite modulus. The longitudinal young's modulus $15(10):$

$$
E_{\mathrm{I}}=E_{\mathrm{m}}\left(1+2(\mathrm{~L} / \mathrm{D}) \mathrm{n}_{\mathrm{L}} \phi_{\mathrm{f}}\right) /\left(1-\mathrm{n}_{\mathrm{L}} \phi_{\mathrm{f}}\right)
$$

where: $n_{1}=\left(E_{\mathrm{f}} / \mathrm{E}_{\mathrm{m}}-1\right) /\left(\left(E_{\mathrm{f}} / \mathrm{E}_{\mathrm{m}}\right)+2(\mathrm{~L} / D)\right)$

and $L / D$ is the aspect ratio of the fibers. In the transverse direction, the Young's modulus is predicted to be (10):

$$
E_{T}=E_{1 n}\left(1+2 n_{T} \phi_{f}\right) /\left(1-n_{T} \phi_{E}\right)
$$

where: $n_{T}=\left(E_{:} / E_{m}-1\right) /\left(\left(E_{\mathrm{f}} / E_{\mathrm{m}}\right)+2\right)$

The assumptions made in deriving the above equations are that the fibers are strongly aligned in the test direction, well bonded, regularly spaced, and have a uniform length.

For well-bonded short fibers strongly oriented in the direction of an applied stress, a tensile stress is generated In the fiber due to shear stresses applied through the matrix. 
This transfer of the applied load to the fibers occurs at the fiber ends where the shear stresses are at a maximum. The matrix shear stresses decrease along the length of the fiber and are zero at the midlength. The tensile stresses in the fiber increase along the fiber length, starting from a small value at the end. They are given by the following rolation (8):

$$
\sigma_{f}(L)=2 / R \int_{0}^{L} \tau(s) d s
$$

where $L$ and $\Omega$ are the length and radius of the fiber, respectively, and $\tau$ is the local position-dependent shrur stress in the matrix. The fiber tensile stressns evontually either reach a peak when the fiber strength is roachod, which causes fiber fracture and composite failure, or platoru whon the matrix shear deformation becomes zero.

\subsubsection{Whisker composites}

Whiskers combine strength and small size to offer groul reinforcement and reduced anisotropy. one typr. uf commercially available whiskers is Franklin Fiber. It lis a calcium sulfate whisker fiber, available in elther ar anhydrous or hemi-hydrate form. Franklin Fiber is produstal by hydrothermal synthesis, drying, and heating, whereby g/t'um is converted to either the hemi-hydrate or anhydrous forms of calcium sulfate as single crystal whisker fibers. A typlcal chemical analysis of both forms of Frantin Fiber le given in 
Table 3.1 (11)

Franklin Fiber whiskers have been used to reinforce plastics and show great promise. Table 3.2 demonstrates the effect of adding $30 \%$ Franklin Fiber (FF) to both polypropylene (PP) and high density polyethylene (HDPE) (11). Improvements to properties under both tension and flexure were realized. Franklin Fibers were also used as a partial replacement for glass fiber. A bulk molding compound, whose composition is given in Table 3.3 , was modified by replacing $25 \%$ of the glass fibers with Franklin Fibers (11). As shown in Table 3.4, this modified composite was found to be superior to the $100 \%$ glass fiber composite in tension and in flexure. Franklin Fiber has been found to be most effective when used in conjunction with another type of short fiber.

Although Franklin Fiber has been used to reinforce plastics, there is no published information on the reinforcement of rubber with Franklin Fiber. However, it has been recommended as a potentially advantageous reinforcing material for rubber for certain applications (12), especially when high heat resistance, low thermal conductivity, improved surface texture, lower cost, and improved fatigue and flex Iife are desired. 
Table 3.1. Typical Chemical Analysis of Franklin Fiber.

\begin{tabular}{|l|c|c|}
\hline Compound & $\begin{array}{c}\text { Amount in An- } \\
\text { hydrous Form (\%) }\end{array}$ & $\begin{array}{c}\text { Amount in Hemi- } \\
\text { Hydrate Form (\%) }\end{array}$ \\
\hline $\mathrm{CaSO}_{4}$ & 97.68 & $70-50$ \\
$\mathrm{CaSO}_{4}-1 / 2 \mathrm{H}_{2} \mathrm{O}$ & - & $30-50$ \\
$\mathrm{CaSO}_{4}-2 \mathrm{H}_{2} \mathrm{O}$ & - & Negligible \\
$\mathrm{CaCO}_{3}-\mathrm{MgCO}_{3}$ & 1.27 & 1.27 \\
$\mathrm{SiO}_{2} \&$ insolubles & 0.13 & 0.13 \\
$\mathrm{Fe}_{2} \mathrm{O}_{3} \& \mathrm{Al} \mathrm{O}_{3}$ & 0.31 & 0.31 \\
$\mathrm{ph}(10 \%$ slurry & 10.4 & 8.2 \\
\hline
\end{tabular}

Table 3.2. The Reinforcement of polyolefins with frrmtilin Fiber.

\begin{tabular}{|c|c|c|c|c|}
\hline Sample & $\begin{array}{c}\text { Tens. Str. } \\
\text { (MPa) }\end{array}$ & $\begin{array}{c}\text { Tens. Mod. } \\
\text { (MPa) }\end{array}$ & $\begin{array}{l}\text { Flex. Str. } \\
\text { (MPa) }\end{array}$ & $\begin{array}{c}\text { Flox. Mrorl. } \\
\text { (MPa) }\end{array}$ \\
\hline $100 \% \mathrm{PP}$ & 35.7 & $1.37 \times 10^{3}$ & 46.9 & $1.53 \times 10^{2}$ \\
\hline $30 \% \mathrm{FF} / 70 \% \mathrm{PP}$ & 31.6 & $2.36 \times 10^{3}$ & 51.6 & $3.93 \times 10^{\circ}$ \\
\hline $100 \% \mathrm{HDPE}$ & $22 \cdot 3$ & $8.69 \times 10^{2}$ & 25.8 & $9.70 \times 10^{\circ}$ \\
\hline $30 \% \mathrm{FF} / 70 \% \mathrm{HDPE}$ & 18.7 & $1.50 \times 10^{\circ}$ & 28.9 & $2.13 \times 10$ \\
\hline
\end{tabular}

$\mathrm{PP}=$ Polypropylene

HDPE $=$ High Density Polyethylene 
Table 3.3. Composition of a Bulk Molding Compound.

\begin{tabular}{|l|c|}
\hline \multicolumn{1}{|c|}{ Material } & Weight $\%$ \\
\hline Calcium Carbonate & 55.0 \\
Polyester Resin & 28.1 \\
Glass Fiber & 15.6 \\
Zinc Stearate & 1.0 \\
Other & 0.3 \\
\hline
\end{tabular}

Table 3.4. Replacement of Glass Fiber with Franklin Fiber in a Bulk Molding Compound.

\begin{tabular}{|c|c|c|c|c|}
\hline Sample & $\begin{array}{c}\text { Tens. Str. } \\
\text { (MPa) }\end{array}$ & $\begin{array}{c}\text { Tens. Mod. } \\
\text { (MPa) }\end{array}$ & $\begin{array}{c}\text { Flex. Str. } \\
\text { (MPa) }\end{array}$ & $\begin{array}{c}\text { Flex. Mod. } \\
\text { (MPa) }\end{array}$ \\
\hline $100 \%$ Glass (G) & 31.9 & $4.67 \times 10^{3}$ & 53.8 & $8.83 \times 10^{3}$ \\
$75 \% \mathrm{G} / 25 \% \mathrm{FF}$ & 40.1 & $5.13 \times 10^{3}$ & 70.5 & $9.65 \times 10^{3}$ \\
\hline
\end{tabular}

$\mathrm{G}=$ Glass fiber

$\mathrm{FF}=$ Franklin Fiber 


\subsection{Processing and Molding of Rubber Composites}

The fabrication of rubber composites is usually achieved by a combination of mixing and molding. For certain molding processes, a milling stage precedes the molding oporation. Compression, injection, and transfer molding are all commonly used in the rubber industry, and the fundamental anpert:; 11 each of these will be presented in this section.

\subsubsection{Compression Molding}

Before a rubber composite can be compression molded, it inust be roll milled. The milled sheet is then compression molderl to the desired shape. The milling stage has a $g 1 \mathrm{gn} 1110,1 \mathrm{~m}$ impact on the mechanical properties of the composito, (1we tu) its effects on orientation and breakage of the fur... Milling causes uniaxial orientation due to extensiondl for.... in the mill direction. Therefore, the orientatuon of thr fibers in a composite may be increased by increasing tho tot.ul strain. This may be achieved by decreasing thr o.tl :,pur.. between the rolls or increasing the thickness of thr shr.r.t. Changing the roll speed or increasing the number of pras:c..., of the sheet through a constant gap space has no effoct (1:).

The breakdown of fibers in the milling process has a largr: effect on the mechanical properties of the composite. Iho greater the aspect ratio of the fibers, the greater the ef fuct 
of the reinforcement. Flexible fibers with good fatigue strength, such as polyamide, undergo little breakdown, and retain a high aspect ratio. However, the flexibility of such fibers inakes them difficult to orient. Rigid fibsrs with poor fatigue properties, such as glass, undergo significant breakdown; however, they can exhibit better orientation because of their rigidity (14).

After milling, the composite sheet is molded. The flow during compression molding can cause a change in the orientation of the tibers from that induced by milling (15). Also, residual stresses can be introduced into the part if complete relaxation of flow stresses is not achieved after closing of the mold (16). Therefore, flow in the mold must be minimized to avoid reorientation of the fibers and to reduce stresses resulting from flow.

\subsubsection{Injection and Transfer Molding}

Injection and transfer molding are very similar, as, in each case, the rubber is fed under pressure through a sprue into a heated and closed mold cavity. One significant difference betweon them is in the melting of the material. The melting is achieved in transfer molding solely by the heating of the material. In the injection molding process, both heating and shearing cause melting. The shearing is achieved with the use of a rotating screw. The combination of heating and shearing 
is more effective in melting the material, giving injection molding a faster cycle than transfer molding, and reducing cure time considerably. However, the shearing induced by the screw results in increased fiber breakage, as compared to transfer molding.

Both injection and transfer molding cause significunt anisotropy, much more than is caused by compression moldiny. This is due to the substantial flow induced by injection and transfer molding. The flow is non-uniform in injection and transfer molding, resulting in non-uniform fiber oriontut lon and non-uniform mechanical properties. A typical cxamplo sl the anisotropy in fiber orientation found in injection molded samples is shown in Figure 3.1 for a nylon fiber compositt. molded with a center gated disk mold (17). The fibors have a circumferential orientation due to compressional flow. A:. the melt enters the mold, it decelerates, creating a noust. $1 \mathrm{ve}$ velocity gradient. This causes a compression in the rullul direction and an extension in the hoop direction, rotating the fibers to create circumferential orientation (18).

3.3. Mechanical properties of Molded Rubber Compos: it w;

The reinforcement of rubber with short fibers typicilly cild:..., a decrease in elongation at break with an increasse in $f$ thr.er concentration. The initial decrease is nearly logarithmic until a certain fiber loading, after which the elongation at 


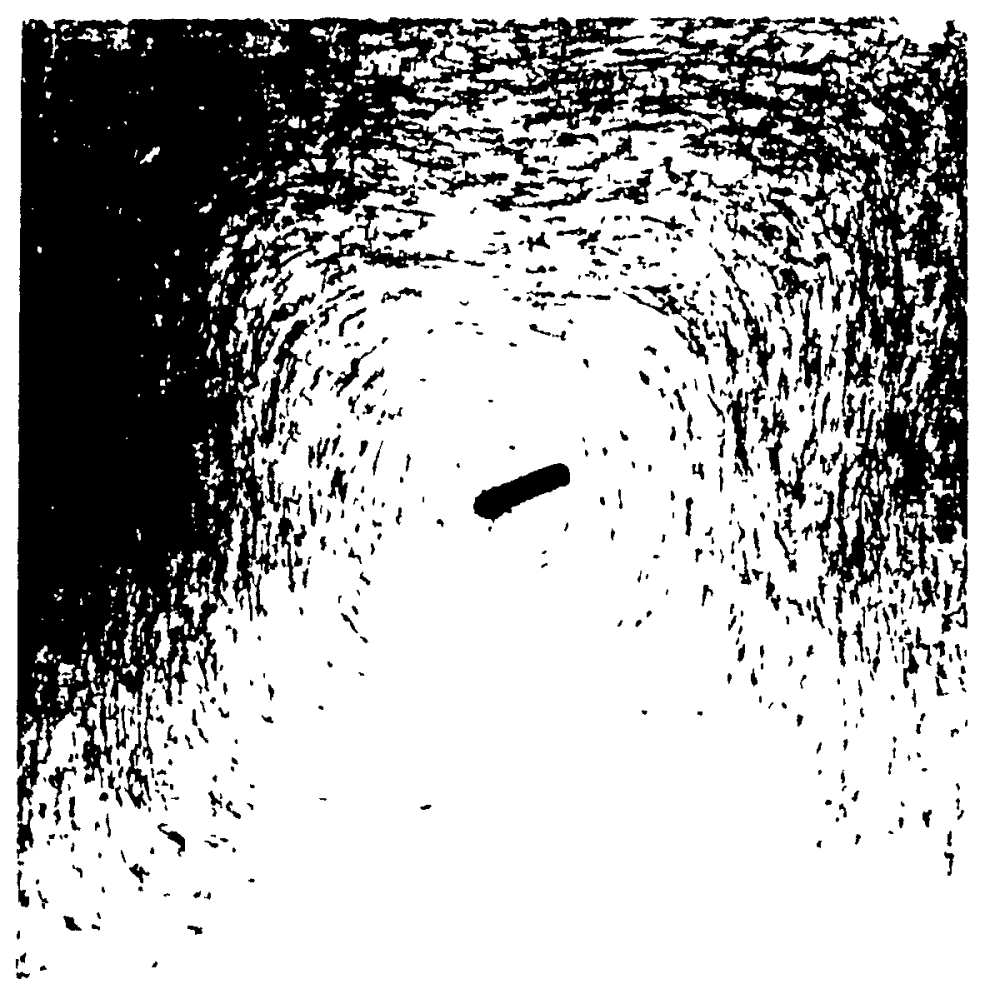

Figure 3.1. Orientation of Nylon Fibers in an Injection Molded Composite. 
break decreases slowly, and then plateaus. These nbservations are shown in Figure 3.2 (19) for a cellulose fiber composite. The Young's modulus is increased as the concentration of fibers is increased. At low fiber loadings the increase is: small, but, above some critical point, it increases almosit linearly with concentration, as shown in Figure 3.2 (20) 10 r a cellulose fiber composite. The tensile strength of a sholt fiber-rubber composite is influenced by the combinou ef furt of the elongation at break and Young's modulus, as scen in Figure 3.3 (20) for a cellulose fiber composite. Initially, the sharp decline in elongation at break dominatos over th" slight increase in Young's modulus, and the tonsile stremuth decreases until some critical concentration. As the lubr concentration is increased beyond this point, its effert un elongation at break decreases, while its relation with Youny':; modulus still follows an approximately linear increasc. "lh" combined effect of these leads to an increase in tunnilu strength with increasing fiber concentration. In gonor.l, the critical fiber concentration needed to obtain an initial increase in tensile strength is approximately 10\% tiber: by volume. A fiber concentration of at least $25 \%$ by volume $1 \because$ needed to achieve composite tensile strength equal to that of the matrix.

The orientation of the fibers in the composite has a significant impact on the mechanical properties. The variation of tensile strength and Young's modulus with fiber 


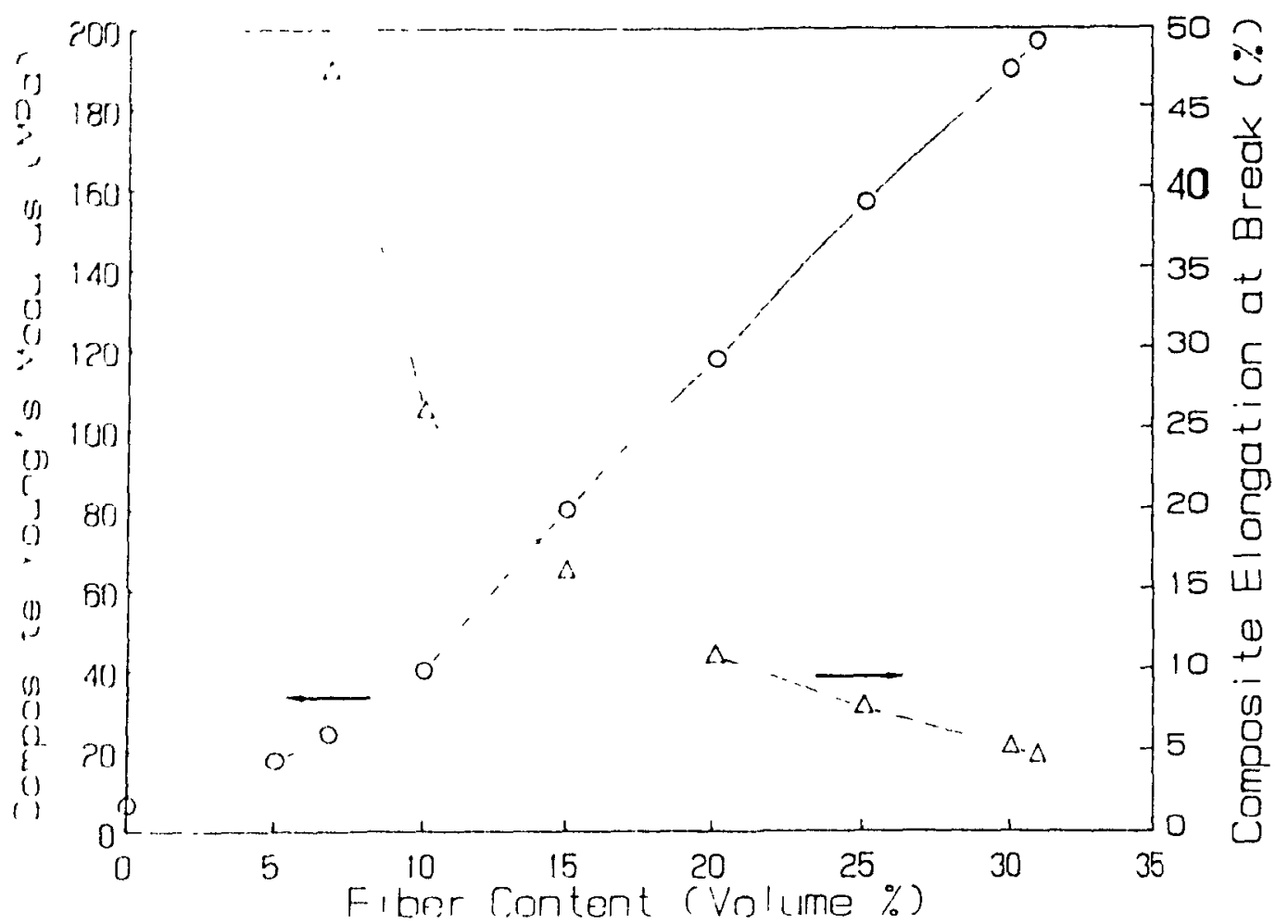

Figure 3.2. Effect of Fiber concentration on Elongation at Break $(\Delta)$ and Young's Modulus (O).

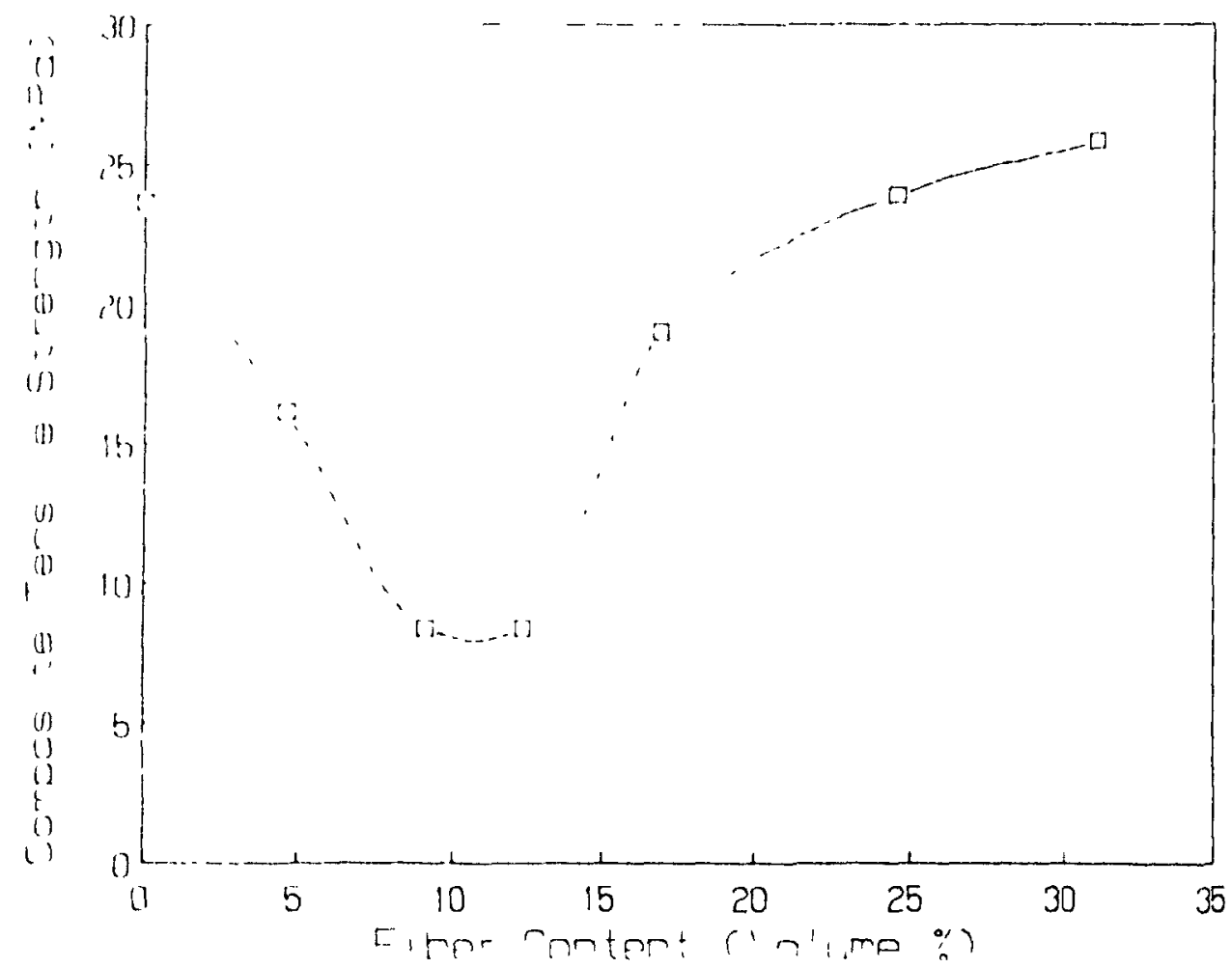

Figure 3.3. Effect of Fiber Concentration on Tensile strength. 
orientation is shown in Figures 3.4 (19) and 3.5 (19), respectively. The tensile strength and Young's modulus achieve their maximum values when the fibers are aligned parallel to the direction of testing. When the fiber:s are aligned perpendicular to the test direction, the strength and modulus values are at their lowest, since the fibers; ab:sorb less of the applied load when they are transversely oriented. When the fibers are aligned at an angle between these two extremes, the tensile modulus of the composite cin be calculated using the following relation (21):

$$
1 / E_{\theta}=\cos ^{2} \theta / E_{L}+\sin ^{2} \theta / E_{T}
$$

where $E_{\theta}$ is the modulus of the composite wherein the 1iber:; deviate from the test direction by the angle $\theta, E_{1}$ the longitudinal (test direction) composite modulus $(\theta=0 "$, , and $E_{\mathrm{T}}$ the transverse composite modulus $\left(\theta=90^{\prime}\right)$. Equation ( 7$)$ is applicable for unidirectional composites. The tensile modulus is very sensitive to orientation, as shown in firure 3.5, so it is often used as a means of determining anisotropy (22)

The milling stage in compression molding and the flow in injection and transfer molding cause fiber orientation. Thi: results in anisotropic mechanical properties, especially for injection and transfer molded samples due to the strong alignment of the fibers. This anisotropy in mechanicial properties is seen even in particulate filler composites, where the reinforcement is isotropic, due to the stretching 


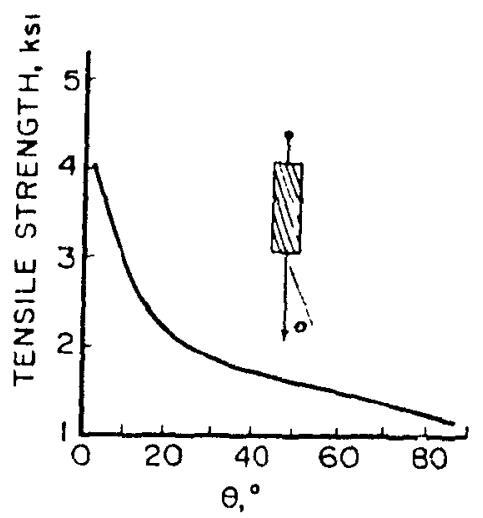

Figure 3.4. Effect of Fiber Orientation on Tensile strength.

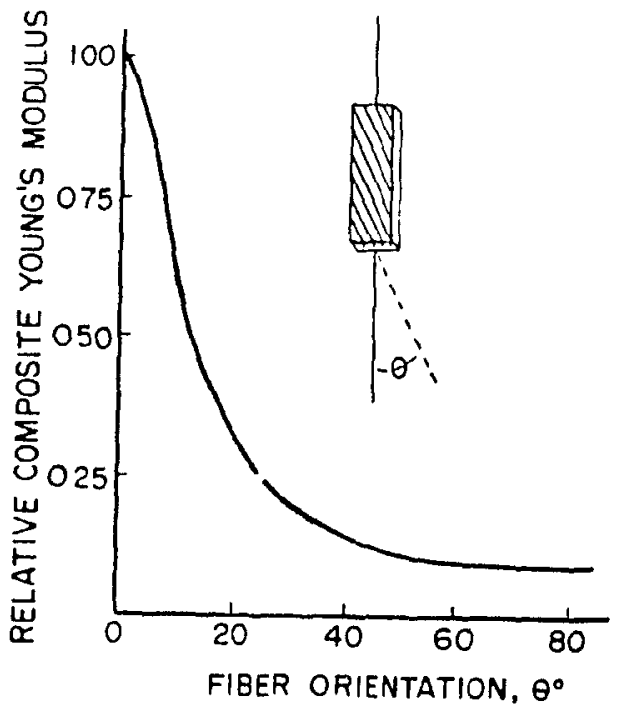

Figure 3.5. Effect of Fiber Orientation on Young's Modulus. 
and alignment of the rubber chains $(17,23)$.

Figures 3.6 and 3.7 compare the effects of injection and compression molding on the $300 \%$ modulus and tensile strength, respectively, for a carbon black reinforced rubber (17). 'lhe anisotropy was greater for the injection molded samples: as expected, although the difference between propertios monsural along the mold flow lines and transverse to the mold tlow Iines was only about $15 \%$. The anisotropy is greater for short fiber composites than particulate composites, due to the anisotropy of the short fibers. However, the eftect of short fiber orientation on the mechanical properties ol injection or transfer molded rubber composites has not born itudied extensively.

\subsubsection{Effect of Processing parameters}

The processing parameter that has been extensively studlud i: the molding temperature. The efficiency of the molding process may be improved by increasing the molding tompcrature, which causes a reduction in the cure time, thereby roducing the cycle time. However, it also causes less efficient cror:linking. Since the time for cross-linking is decreascd, luwer crosslinks are formed. When molding at high tempordtures, care must be taken to avoid premature vulcanization, or scorch, of the material. When a material is scorcherl, $1 t$ contains local strains due to insufficient relaxation time. 


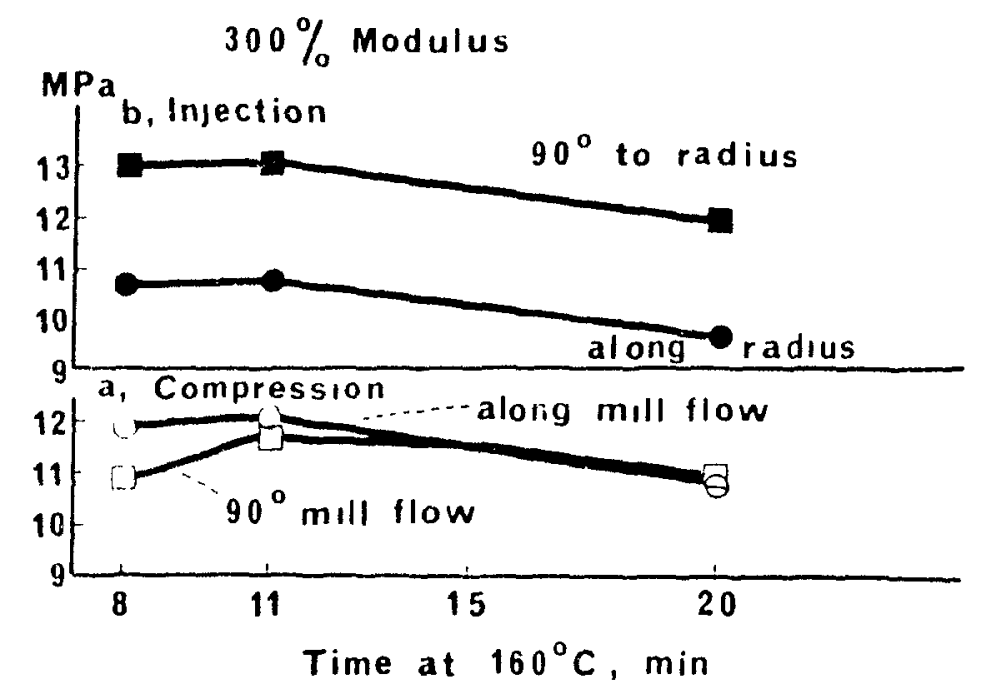

Figure 3.6. Comparison of $300 \%$ Modulus for Compression and Injection Molded Carbon Black Composites.

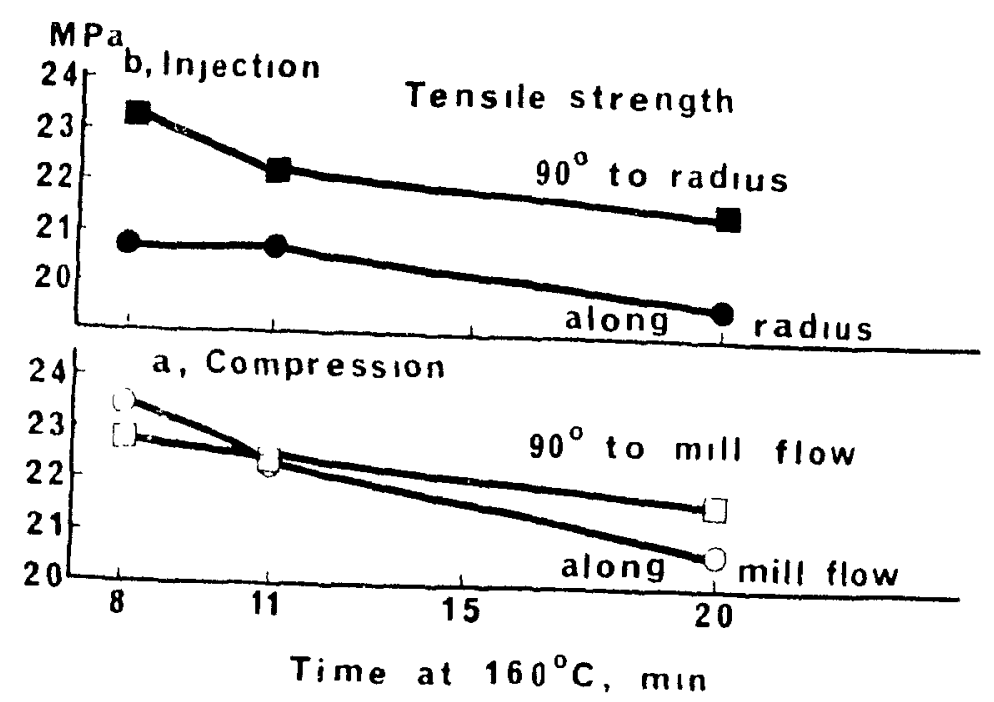

Figure 3.7. Comparison of rensile strength for compression and Injection Molded Carbon Black Composites. 
This results in a decrease in the elasticity of the rubber and causes poor mechanical properties.

The effect of an increase in mold temperature on mouranical properties of a carbon black reinforced rubber is shown in Figure $3.8(17)$. The properties were rated at a maximum of loo at $160^{\circ} \mathrm{C}$ and decreased as the temperature was increasid. While the increase in mold temperature caused a decrease in mechanical properties, it did not siynificantly alter the anisotropy ratios of the injestuon and compression molded samples. 


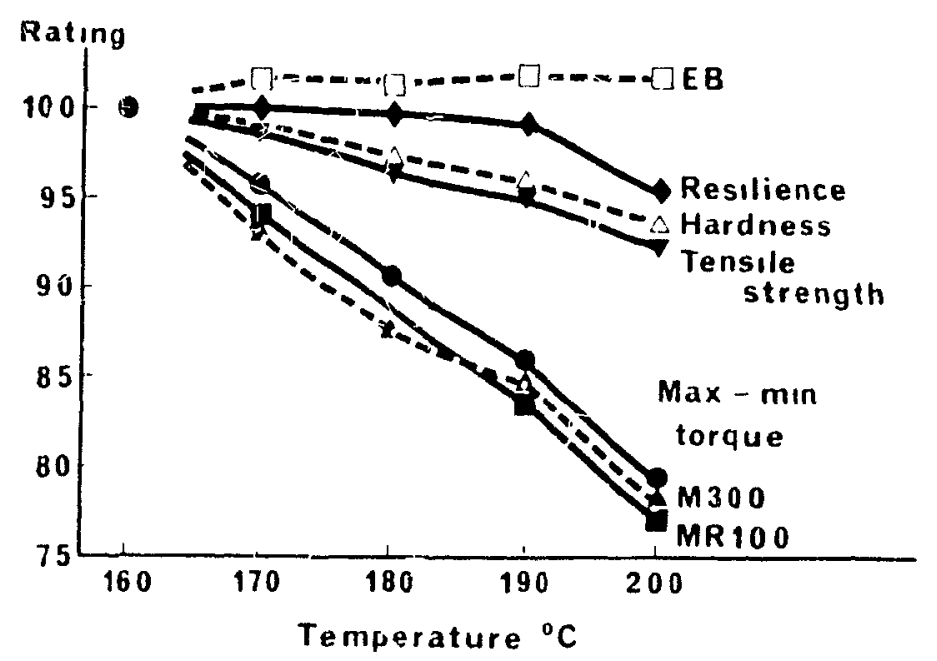

Figure 3.8. Dependence of Composite Physical properties on Cure 'Temperature.

$\mathrm{EB}=$ Elongation at Break

M300 $=300 \%$ Modulus

MRI00 = Relaxed Modulus $(100 \%)$ 


\section{EXPERIMENTAL}

For this project, a silicone rubber-whisker composite wa:s studied to determine the effect of different molding operations and processing parameters on fiber orientation and mechanical properties. The experimental procedure usid to accomplish this is given in this section.

\subsection{Materials}

The materials used in this project were Silastic 350 silicom rubber with methyl-vinyl side chains (VMQ type), manufactur od by Dow Corning, and Franklin Fiber whiskers, manufacturnd by the United States Gypsum Company. The fibers had an aspor.t: ratio of 30 ( $L=60$ microns, $D=2$ microns), as speciticed by the manufacturer. The physical properties of the unreintorced rubber and the fibers are given in Tables 4.1 (24) and 4.2 (11), respectively. An epoxy silane coupling agent was usicd to improve the bond between the fibers and the rubber. I'tus: composition of the $\mathrm{mix}$ is shown in Table 4.3 . The original mixing and millirig of the rubber and fibers was carricd out by the Lord corporation at their plant in Erie, Pennsylvania. After mixing, the rubber-fiber composite was milled to ensure proper dispersion of the fibers. The mixed and millod composite was then shipped to the Lord Research contrer in Cary, North Carolina in twenty kilogram blocks for molding. 
Table 4.1. Silicone Rubber Properties.

\begin{tabular}{|c|c|c|c|c|c|}
\hline Rubber & $\begin{array}{c}\text { Spec. } \\
\text { Gravity } \\
\text { at } 25^{\circ} \mathrm{C}\end{array}$ & $\begin{array}{c}\text { Tensile } \\
\text { Strength } \\
(\mathrm{MPa})\end{array}$ & $\begin{array}{c}\text { Elongation } \\
\text { at Break } \\
(\%)\end{array}$ & $\begin{array}{c}\text { Modulus } \\
100 \% \\
(\mathrm{MPa})\end{array}$ & $\begin{array}{c}\text { Tear } \\
\text { Strength } \\
(\mathrm{kN} / \mathrm{m})\end{array}$ \\
\hline Silastic 35U & 1.13 & 8.14 & 800 & 0.83 & 19.3 \\
\hline
\end{tabular}

'Table 4.2. Franklin Fiber Properties.

\begin{tabular}{|l|c|c|c|c|c|c|}
\hline Fibers & L & D & $\begin{array}{l}\text { Aspect } \\
\text { Ratio }\end{array}$ & $\begin{array}{c}\text { Spec. } \\
\text { Gravity }\end{array}$ & $\begin{array}{c}\text { Tensile } \\
\text { Strength } \\
(\mu \mathrm{m})\end{array}$ & $\begin{array}{r}\text { Elastic } \\
\text { Modulus } \\
(\mu \mathrm{m})\end{array}$ \\
\hline Franklin & 60 & 2 & 30 & 2.96 & $2.07 \times 10^{3}$ & $1.79 \times 10^{5}$ \\
\hline
\end{tabular}

'I'able 4.3. Composite Formulation.

\begin{tabular}{|l|c|c|}
\hline \multicolumn{1}{|c|}{ Compound } & phr & weight $\%$ \\
\hline Silastic 35U rubber (VMQ type) & 100 & 93.4 \\
Franklin Fibers (anhydrous type) & 6 & 5.6 \\
Dicumyl peroxide (40\% dispersion) & 1.05 & 1.0 \\
\hline
\end{tabular}




\subsection{Molding Techniques}

Two molding techniques were used for this project: transiter molding and compression molding. All molding was carrica out at the Lord Research center using their facilitics.

\subsubsection{Transfer Molding}

An Injectamatic transfer molding machine, manufactured by Hydratecs Inc., was used. The mold was first allowed to heut to the desired temperature, which was measurod by "I thermocouple located at the outer surface of the mold. Whin the temperature was reached, a one hundred gram slab of the rubber-fiber mixture which had been cut from the blork with scissors was inserted into the transfer pot. 'The pro:i:; wil: closed until the force reached $8.24-8.93 \mathrm{MPa}(1200-1300$ psi). The rubber was then cured and a $15 \mathrm{~cm} \times 15 \mathrm{~cm}$ (6, in $\%$ 6 in) sheet resulted. Miller-stephenson MS 136 mold rrln., agent was used to ensure that the cured shoct w.1: $[\cdot 1: 11$ ly removed from the mold. Ten samples were made for cach moldim condition.

\subsubsection{Molding Conditions}

The variables which were manipulated in the experiment wr: the mold temperature and the sprue design. Two different molr temperatures were used: $163^{\circ} \mathrm{C}\left(325^{\circ} \mathrm{F}\right)$ and $204^{\circ} \mathrm{C}\left(400^{\circ} \mathrm{F}\right)$. Ihr. 
corresponding cure times were 25 minutes and 6 minutes, respectively. Three sprue designs were compared: converging sprues, diverging sprues, and straight sprues. These are shown in Figure 4.1. Molding was carried out at each temperature for the three geometries.

\subsubsection{Compression Molding}

Before the rubber-fiber mixture could be compression molded, it was milled in order to obtain sheets of approximately $2 \mathrm{~mm}$ thickness. The milling was carried out using a Nerpco Inc. roll mill, which was equipped with a sterltronic temperature controller. For the milling, the roll temperature was $42^{\circ} \mathrm{C}$, the front roll speed was $10 \mathrm{rpm}$, and the back roll speed was 17 rpm. The gap between the rolls was adjusted to approximately $2 \mathrm{~mm}$.

'I'wo procedures were followed in the milling of the samples, in order to obtain sheets with different levels of orientation. In an effort to obtain random fiber orientation, the rubber-fiber mixture was passed through the mill at least Iive times in the same direction. The sheet was removed from the mill and placed back between the rolls in exactly the same direction as in the previous pass. The sheet was not turned over or reversed, and the mill parameters were kept constant. This was repeated six to eight times per milled sheet. The sumples were labelled "random milling". In the second 


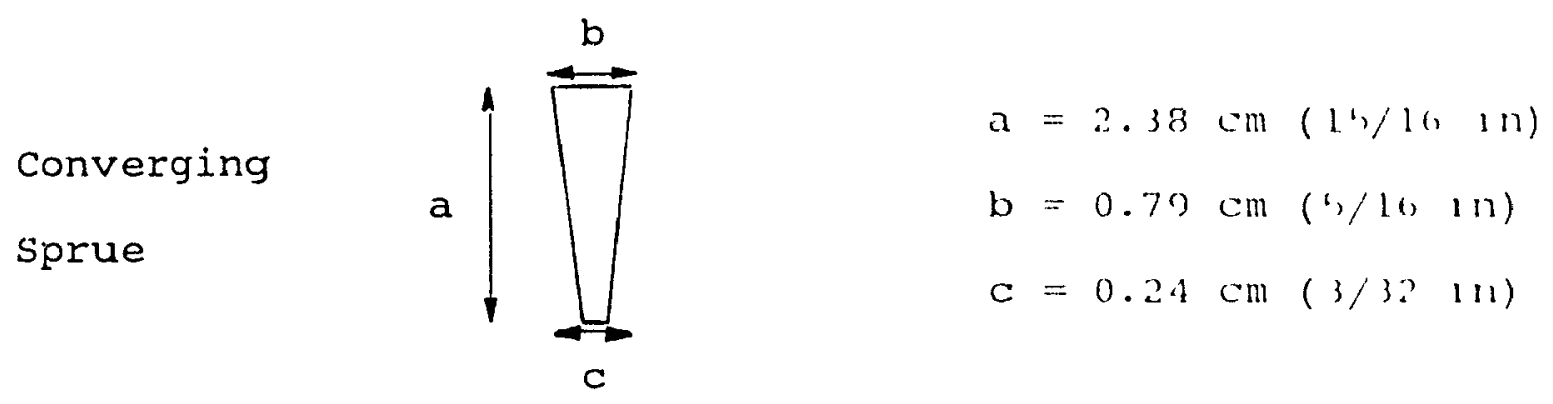

Diverging

sprue

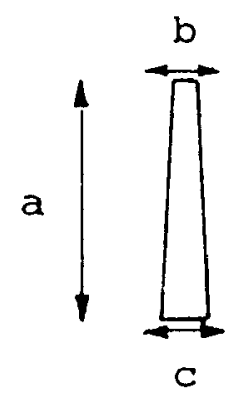

$$
\begin{aligned}
& a=2.38 \mathrm{~cm}(13 / 11,11) \\
& b=0.24 \mathrm{~cm}(3 / 3,1 \mathrm{n}) \\
& c=0.48 \mathrm{~cm}(3 / 16,11)
\end{aligned}
$$

straight

Sprue

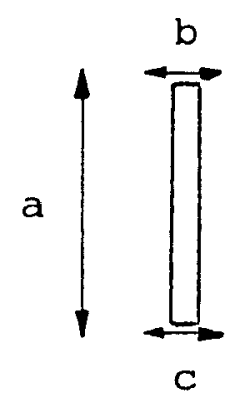

$$
\begin{aligned}
& a=2.38 \mathrm{~cm}(15 / 16,1 n) \\
& b=0.24 \mathrm{~cm}(3 / 32111) \\
& c=0.24 \mathrm{~cm}(3 / 31 \mathrm{n})
\end{aligned}
$$

Figure 4.1. Sprue dimensions. 
milling procedure, an attempt was made to increase the level of orientation in the milling direction by increasing the strain. The sheet was milled, folded in half, and milled again. This was repeated two to four times per sheet. These samples were labelled "controlled milling".

For the compression molding, a Pasadena Hydraulics Inc. compression molding machine was used. The machine and the mold were heated electrically to the desired cemperature which was measured by thermometers placed on the outer surface of the platens. The milled sheets were cut into $15 \mathrm{~cm} \times 15 \mathrm{~cm}$ (6) in $x \sigma$ in) squares with scissors in order to fit exactly Into the mold cavity. Once the temperature was attained, the mold was removed, and a square was placed in the mold cavity. 'The mold was closed and placed between the platens of the machine. The press was closed and opened three times to cnsure that no air was trapped in the mold. Subsequently, the applied weight was increased to $6804 \mathrm{~kg}(7.5$ tons) and the sheet was allowed to cure. A $15 \mathrm{~cm} \times 15 \mathrm{~cm}$ ( 6 in $\times 6$ in) sheet resulted. Ten samples were molded for each condition.

\subsubsection{Molding conditions}

'The variables that were investigated were the molding tcmperature and the orientation of the fibers, which was described above. Three different temperatures were used: $103^{\circ} \mathrm{C}\left(325^{\circ} \mathrm{F}\right), 180^{\circ} \mathrm{C}\left(356^{\circ} \mathrm{F}\right)$, and $204^{\circ} \mathrm{C}\left(400^{\circ} \mathrm{F}\right)$. The 
corresponding cure times were 25 minutes, 7 minutes, and is minutes, respectively. At each temperature, samples with both controlled and random orientation were molded. Due to time constraints, only the sheets molded at $163^{\circ} \mathrm{C}$ and $204^{\circ} \mathrm{C}$ werc studied.

\subsection{Sample Analysis and Testing}

\subsubsection{Orientation Analysis}

The orientation of the fibers in the molded sumple:; wil:; determined using microtoming and image analysis techmiguen: Each is discussed in detail in the following section:.

\subsubsection{Microtome Specimen Preparation}

The specimens that were to be microtomed were chosen $1 \mathrm{rm}$ several positions in the sample so as to obtuin .1 representative description of the fiber orientation throughout the sample. Figures 4.2 and 4.3 show the locations chosirn 1 or analysis of the transfer and compression molded simpl..., respectively. At each location, sections were cut in thrur planes: depth, longitude, and transverse. The longltudinill and transverse planes are shown in Figures 4.2 and 4.3 , whilr. the depth plane is in the sample thickness direction. Thr. compression molded samples with controlled orientation wrere milled so as to obtain strong orlentation in the mill. 

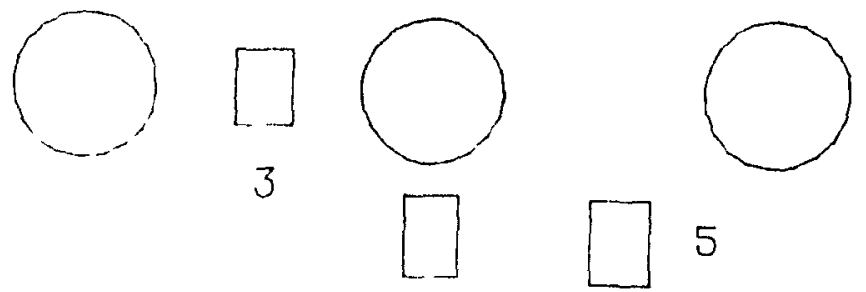

5

4

$] ?$

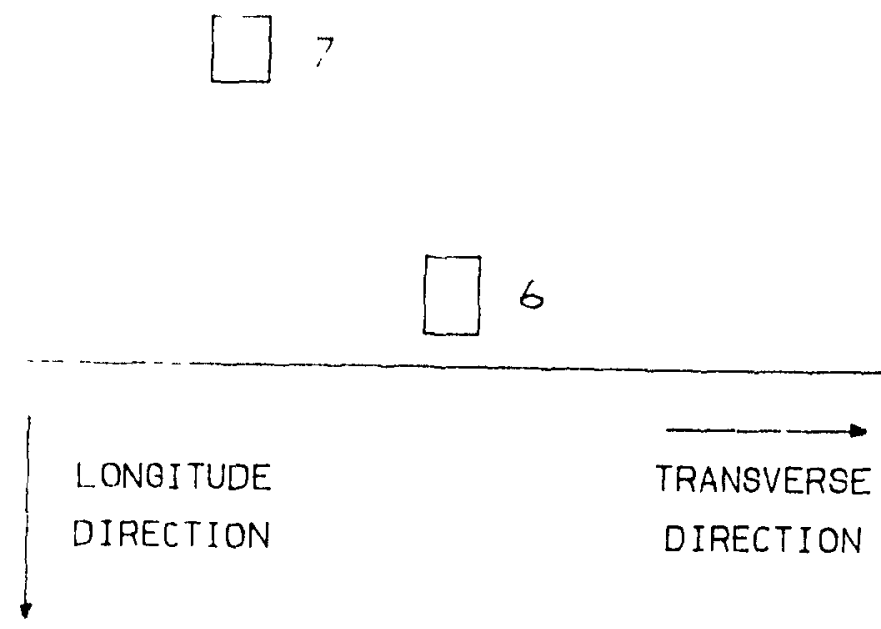

Figure 4.2. Microtome Locations for Transfer Molded Samples. 


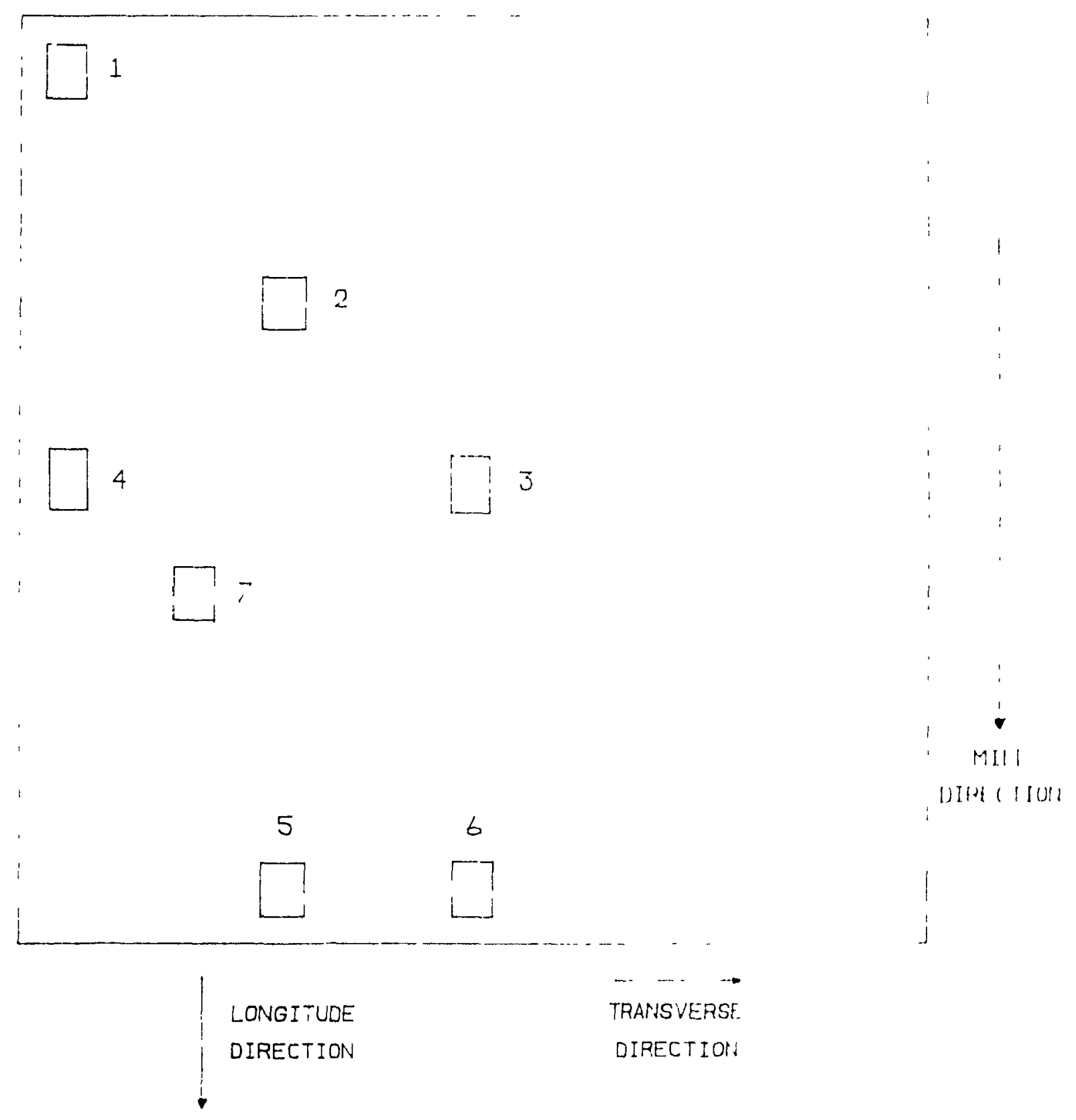

Figure 4.3. Microtome Locations for Compression Molded Samples. 
direction. This direction is shown in Figure 4.3.

The sample sheets were placed on a flat surface and the sections were cut using a sharp blade. The sections were approximately $6 \mathrm{~mm}$ in length and $3-4 \mathrm{~mm}$ in width. The thickness of each cut specimen was measured using a Mitutoyo micrometer and recorded. Once the cutting was completed, the sections were bonded onto black pure gum rubber stoppers. The top and bottom surfaces of the stoppers were roughened with sand paper and cleaned with acetone. One section was bonded onto each surface using silastic 732 RTV adhesive from Dow corning. The stoppers were left at ambient conditions for 24 hours to ensure full curing of the adhesive. After this period, the samples were ready for microtoming.

\subsubsection{Microtoming Procedure}

The sections were microtomed using a sliding Reichert microtome, model $\mathrm{OME}$, and a Lipshaw surgical steel blade. Due to the rubbery nature of the samples, the microtoming was done under cryogenic conditions using liquid nitrogen. The rubber stopper was placed in a $15 \mathrm{~cm}$ x $15 \mathrm{~cm}$ two-ply sheet of aluminum foil and the foil was folded around the sides of the stopper to encase the stopper and leave only the specimen exposed. This arrangement was placed in the microtome assembly and the holding screw was tightened. The microtome blade was placed in its slot at a set angle of $15^{\circ}$ and the 
screws tightened. The stopper was then adjusted using the positioning screws so that the top surface of the specimen was parallel to the blade.

After the adjustments were completed, the aluminum loil wa:; folded up so as to enclose the specimen in a "cup". "lhe liquid nitrogen was poured out of a dewer and into tho "cup", freezing the specimen. Once the liquid nitrogen evaporated below the upper surface of the specimen, the sides of the "cup" were folded down and the microtome blade was brought forward. After each pass of the blade the height of the specimen was raised by five microns using the dial on the side of the microtome until a slice of the specimen was obtainfu. The slice was placed on a microscope slide which was; wetted with Resolve, a low viscosity microscope immersion oll 1 rom Stephens scientific. The sides of the aluminum foil were folded up again and the process repeated. Onc silice wis obtained per liquid nitrogen application and fjve slice:; wrre placed on each slide. After five slices, a cover glas, wa: placed on the slide and taped down.

For the depth slices, ten layers, beginnang at the stin luyr and proceeding to the core, were cut in order to obtain as much information as possible about the sampies using a reasonable number of slices. Since the samples vere approximately $2 \mathrm{~mm}$ thick, the distance from skin to core wis 1000 microns. The ten layers were therefore approximately 
100 microns apart, so after the slices at one layer were obtained, a $100 \mathrm{micron}$ thick section of material was cut off. The slices at the next layer were then microtomed. To ensure that each layer provided one good specimen, two consecutive silices were cut. In total, twenty slices, each with a thickness of 5 microns, were obtained for each microtome location. The thickness of the depth section was measured after microtoming was completed and subtracted from the thickness before microtoming. This figure was then compared to the amount that was assumed to be cut off for each layer to ensure that the thicknesses were as accurate as possible.

\subsubsection{Image Analysis}

'The microstructure of the composites was observed and analyzed using an image analysis technique. The microscope slides were placed under a Leitz Laborlux s optical microscope which was equippera with a Sony $\mathrm{XC}-38 \mathrm{miniature}$ video camera. The image seen by the camera was frame grabbed by a PIP 1024 video digltiser board from Matrox Electronic systems Ltd. which was loukd into a Hewlett Packard Vectra microcomputer. The image was then displayed on a NEC Multisync monitor and enhanced and throsholdod. A computer program was used to locate the fibers und analyze their length and orientation.

Ihe accuracy of this image analysis system was tested by comparing photographs of the image seen through the microscope 
with the image captured by the video camera and the digitized representation of the slice. Figure 4.4 shows the strongly oriented microtomed slice as seen trirough the microscope, Figure 4.5 shows the slice as seen on the video screen, and Figure 4.6 gives the digitized version of the image. There is good agreement between the Figures, demonstrating the accuracy of the image analysis system for a strongly oriented layer. The system was also tested using a soction that hud random orientation and a large number of fibers. Ihe result:; are shown in Figures 4.7 through 4.9 in the same sequence a: above. Even for a randomly oriented layer wlli " high concentration of fibers, the system proved accurate.

\subsubsection{Tensile Tests}

The Instron tensile tester was used to test the tensila strength, elongation at break, Young's modulus, and trinsile: set of the samples, as per ASTM test D 412-87. I'h is j:, the standard test method for rubber properties in tensiun. Dumbbell sections were cut from the samples, but not ircording to the specifications of ASTM test D 412-37, dure to the lirt that only a limited amount of material was available lor testing and it was desired to obtain as much informution as possible.

It was decided to use specimens of the size glven in Airlu tert D 638-87b, which is the standard test method for tensils. 


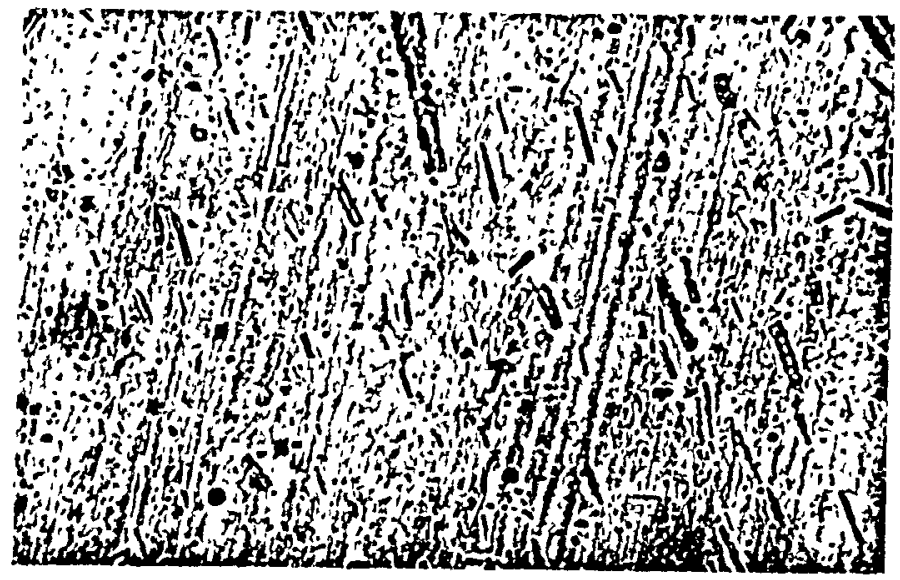

Figure 4.4. Microtomed slice as seen Through the Microscope.

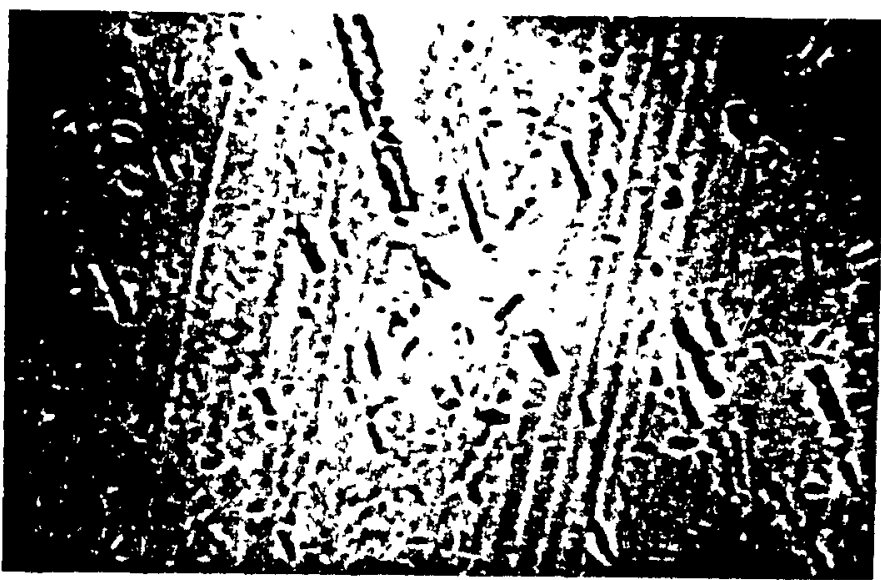

Figure 4.5. Microtomed Slice as Seen on the Video Screen.

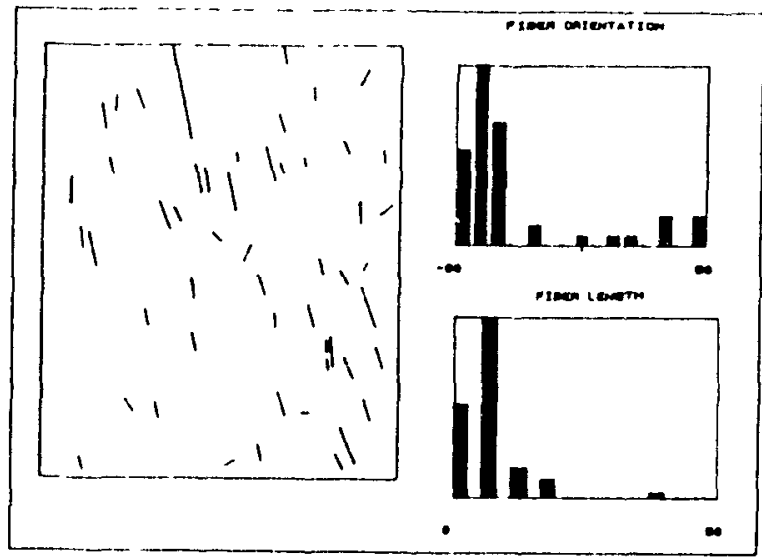

Figure 4.6. Digitized Representation of Microtomed Slice. 


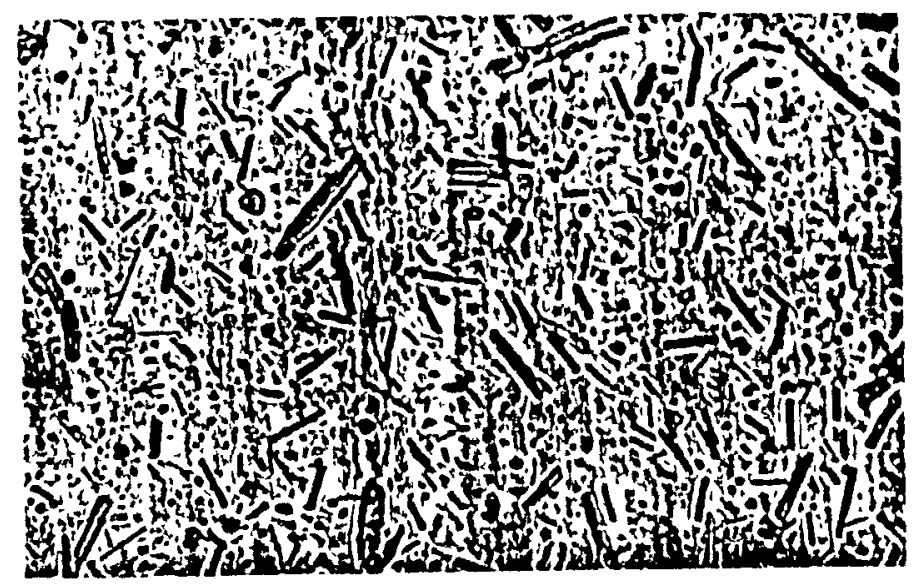

Figure 4.7. Microtomed slice as seen Through the Microscope.

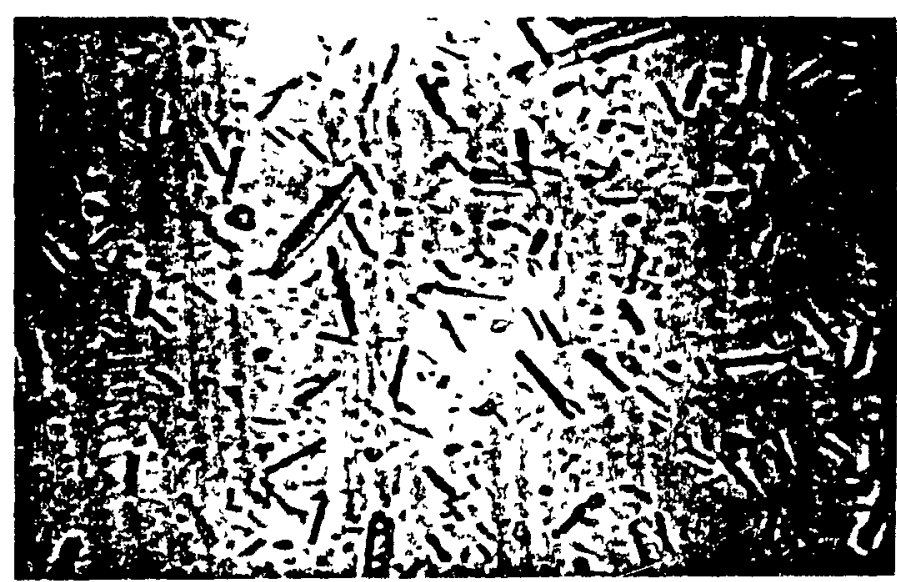

Figure 4.8. Microtomed slice as Seen on the video irindil.

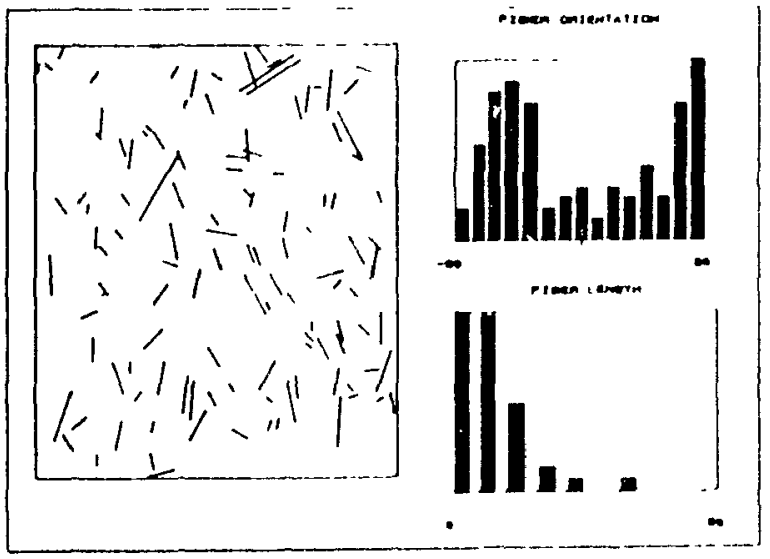

Figure 4.9. Digitized Representation of MLcrotomred : 114. 
properties of plastics. The type $V$ tension test specimen was selected. A sketch of this specimen is given in Figure 4.10 . specimens were cut from the molded samples at several locations, using a type $V$ die made in the departmental workshop.

l'esting was carried out as per ASTM D 412-87 using the Instron Mechanical. Tester, model 1123. The cut specimens were conditioned at room temperature for at least three hours prior to testing. Test marks were drawn on the samples according to the gage length given in ASTM D 638-87b for die V. The $\because 1$ osshead speed for all tests was $500 \mathrm{~mm} / \mathrm{min}$. Pneumatic grips wre used to prevent slippage of the sample during stretching. 'The clongation for the tensile set was $500 \%$ 


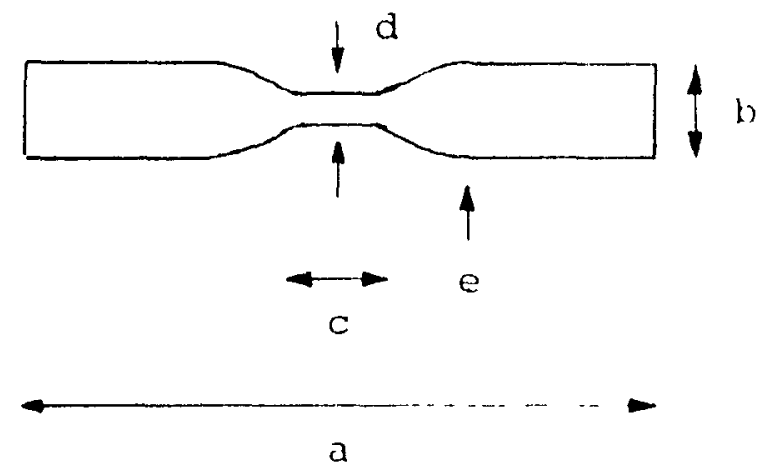
a (overall length) $=63.5 \mathrm{~mm}(2.5 \mathrm{ln})$
$\mathrm{b}$ (overall width) $=9.53 \mathrm{~mm}(0.375 \mathrm{ln})$
$c$ (length of narrow section) $=9.53 \mathrm{~mm}(0.3 \%$, in)
$\mathrm{d}$ (width of narrow section) $=3.18 \mathrm{~mm}(0.126, \mathrm{in})$
$e$ (radius of fillet) $=12.7 \mathrm{~mm}(0.50 \mathrm{in})$

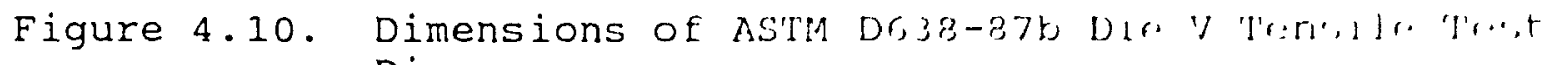
Die. 


\section{EXPERIMEITAL RESULTS AND DISCUSSION}

\subsection{Fiber orientation and Length Results}

The fiber orientation and length distributions were determined by the use of the image analysis computer program. Five depth locations were studied for both the transfer and compression molded samples. These locations included the skin and core layers, as well as three intermediate layers. The three layers were chosen after viewing a longitudinal slice of the sample and noting the levels at which variations in fiber orientation occurred. An orientation function of the form $(25):$

$$
\mathrm{f}=0.5\left[3<\cos ^{2} \theta>-1\right]
$$

was calculated for each layer. A value of 1.0 denotes longitudinal fiber orientation, while a value of -0.5 Indicates transverse fiber orientation. Random fiber orlentation is given by a value of 0 .

\subsubsection{Iransfer Molded Samples}

l'he results for the samples that were transfer molded with converging sprues at $163^{\circ} \mathrm{C}$ are given in Figures 5.1 through 5.7. These results indicate a circumferential fiber orientation within the sample at the core level. This was expected due to the decrease in velocity as the material travels downstream in the mold cavity. This negative velocity 
l Longitude

Direction $\longrightarrow$ Transverse

Direction
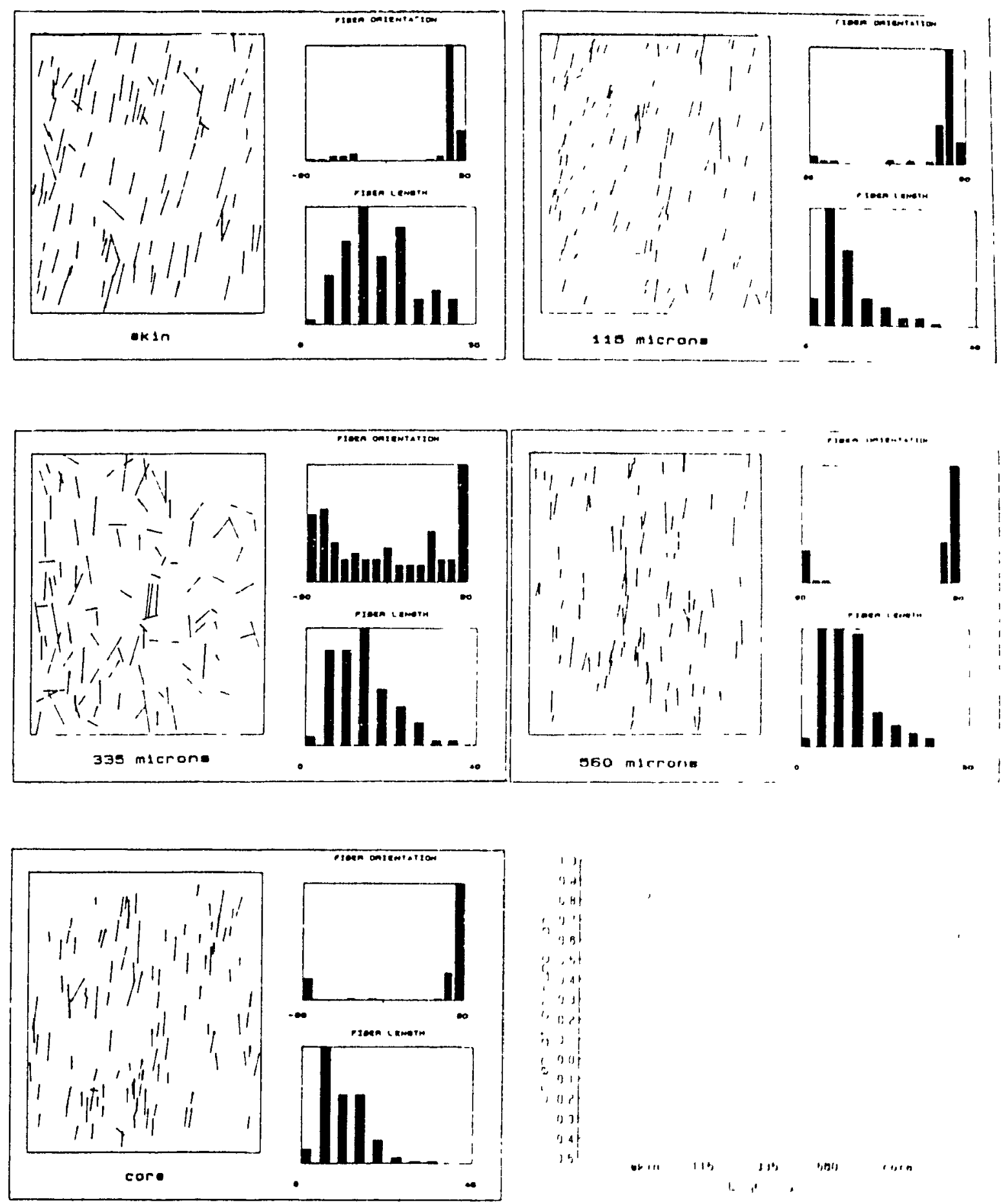

Figure 5.1. Orientation and Length Distributions for Samples Molded with Converging sprurs: at 16\%? (Microtome Location 1). 

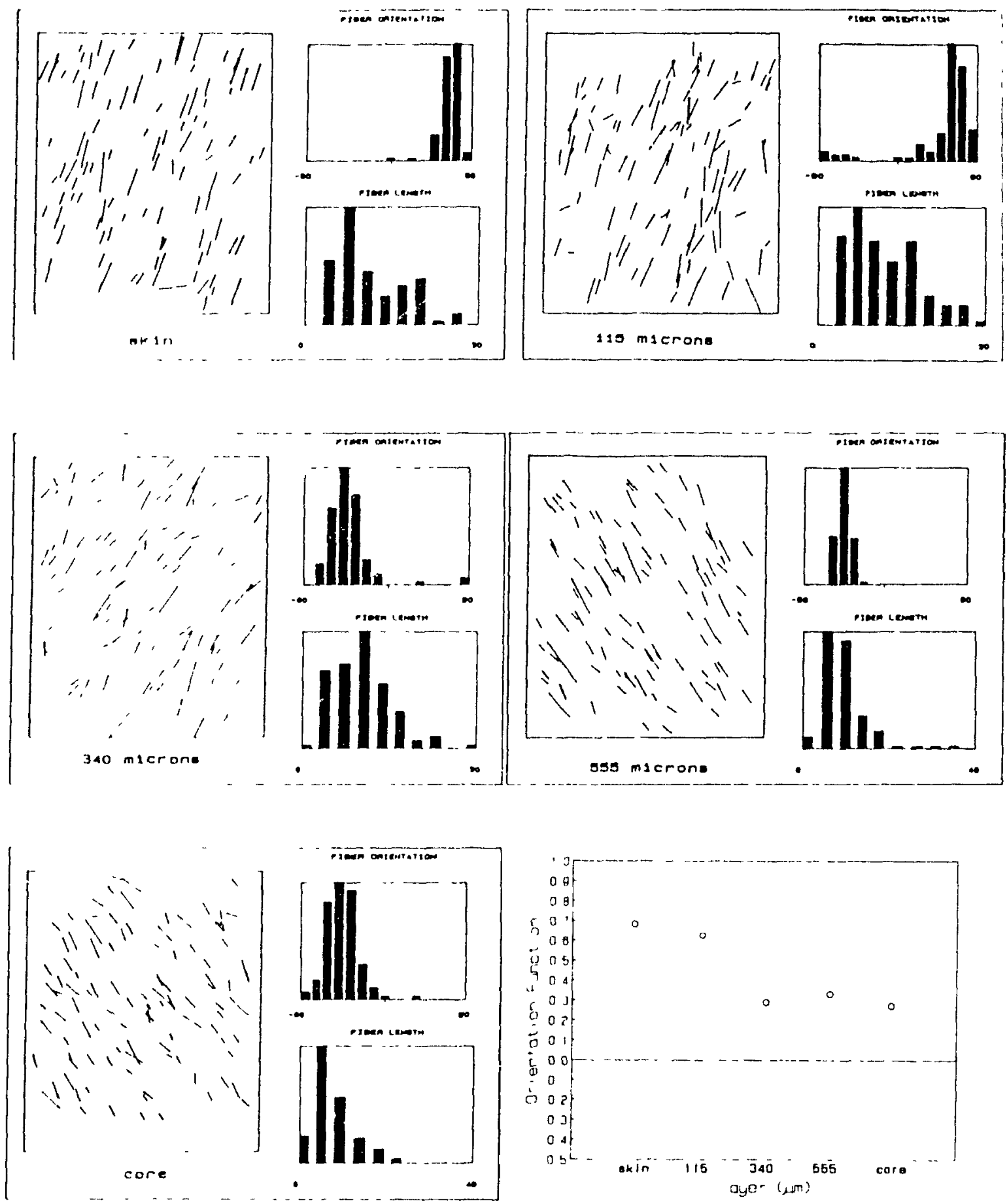

Figure 5.2. Orientation and Length Distributions for Samples Molded with Converging Sprues at $163^{\circ} \mathrm{C}$ (Microtome Location 2). 

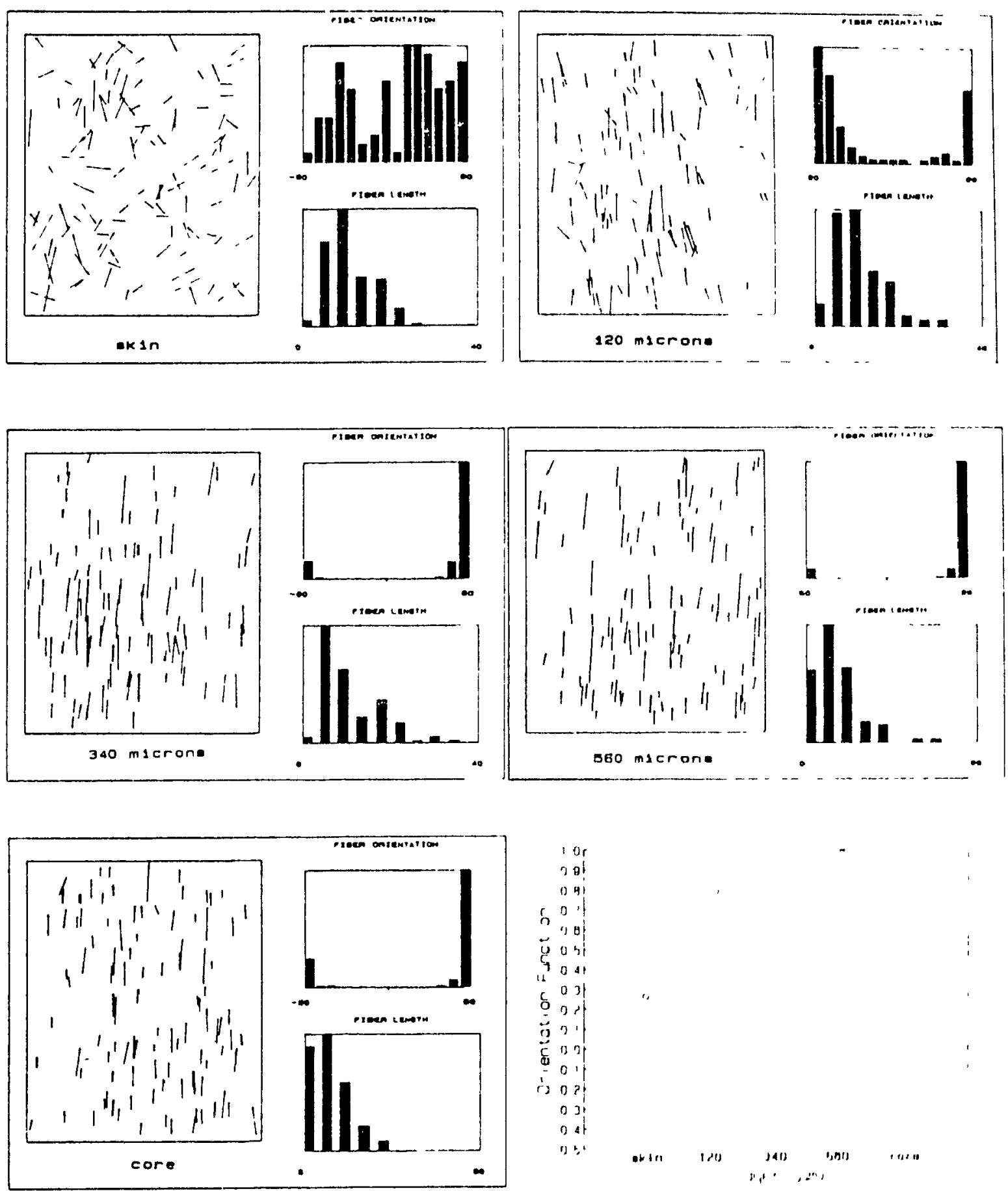

Figure 5.3. Orientation and Length Distributions; for samples Molded with converging iprucs at lo, : (Microtome Location 3). 

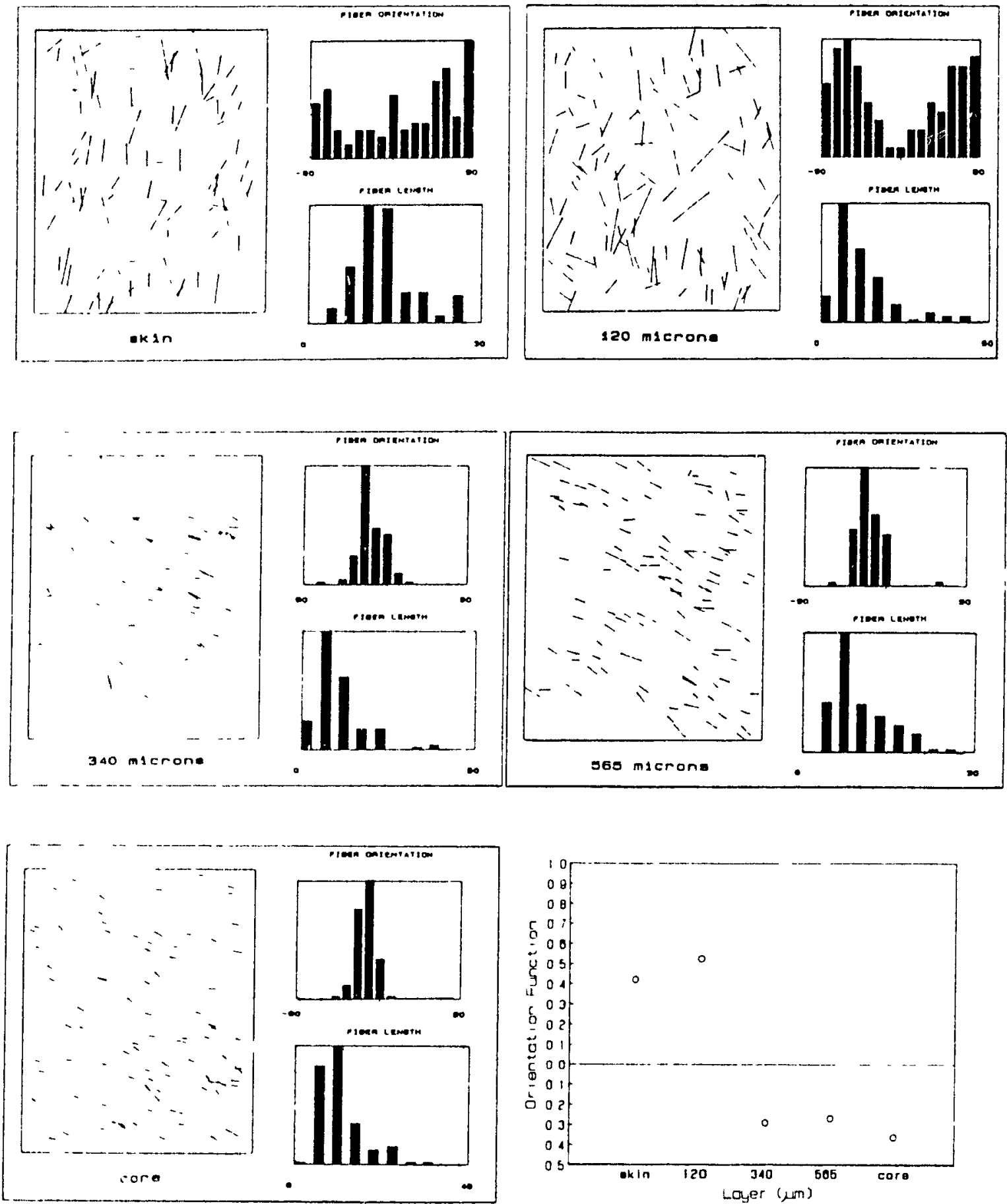

Figure 5.4. Orientation and Length Distributions for Samples Molded with Converging Sprues at $163^{\circ} \mathrm{C}$ (Microtome Location 4). 


\section{Longitude}
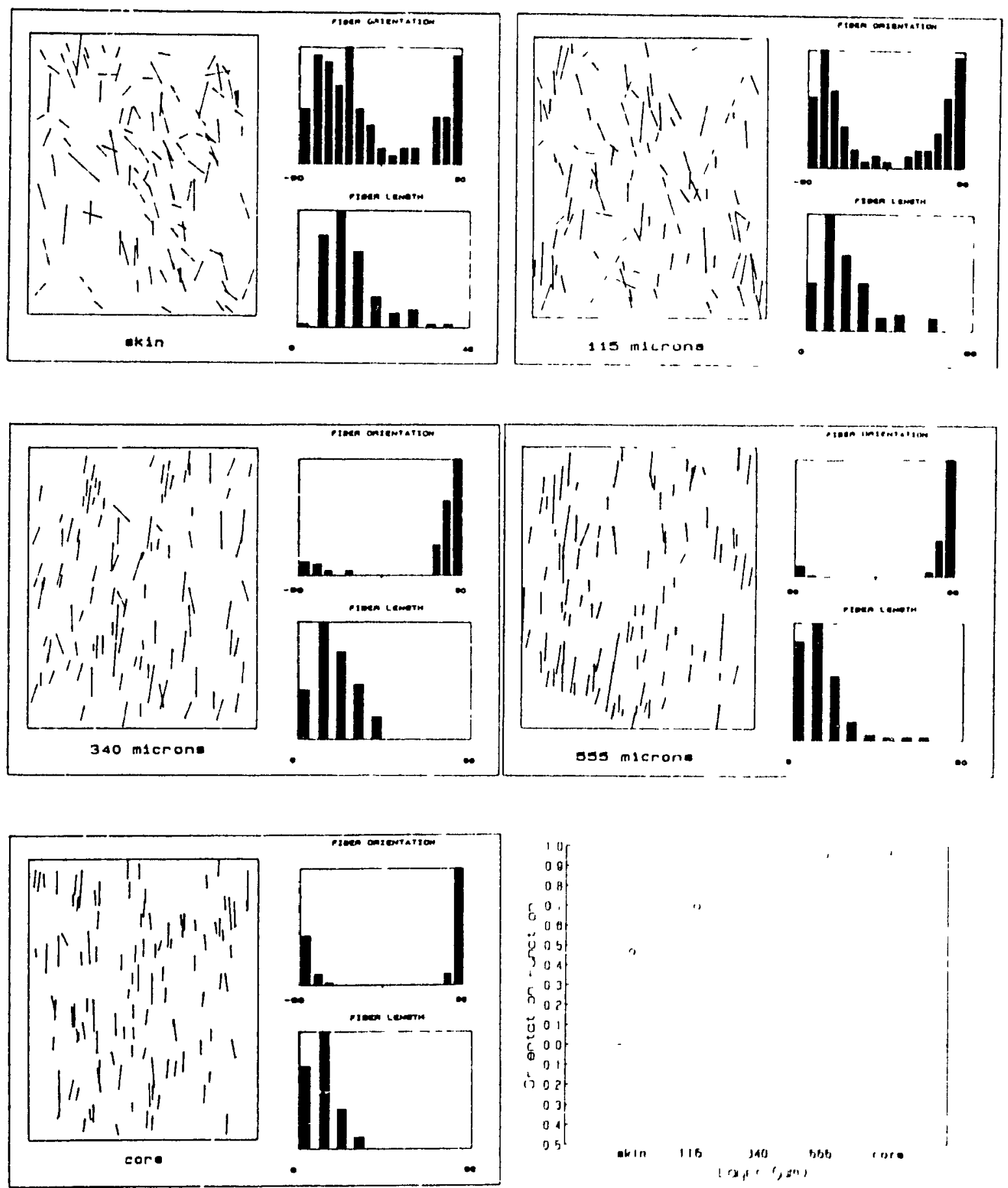

Figure 5.5. Orientation and Length Distributions for Samples Molded with Converging Sprues at $163^{\circ} \mathrm{C}$ (Microtome Location 5). 
1 Longitude

$\longrightarrow$ Transverse

Direction
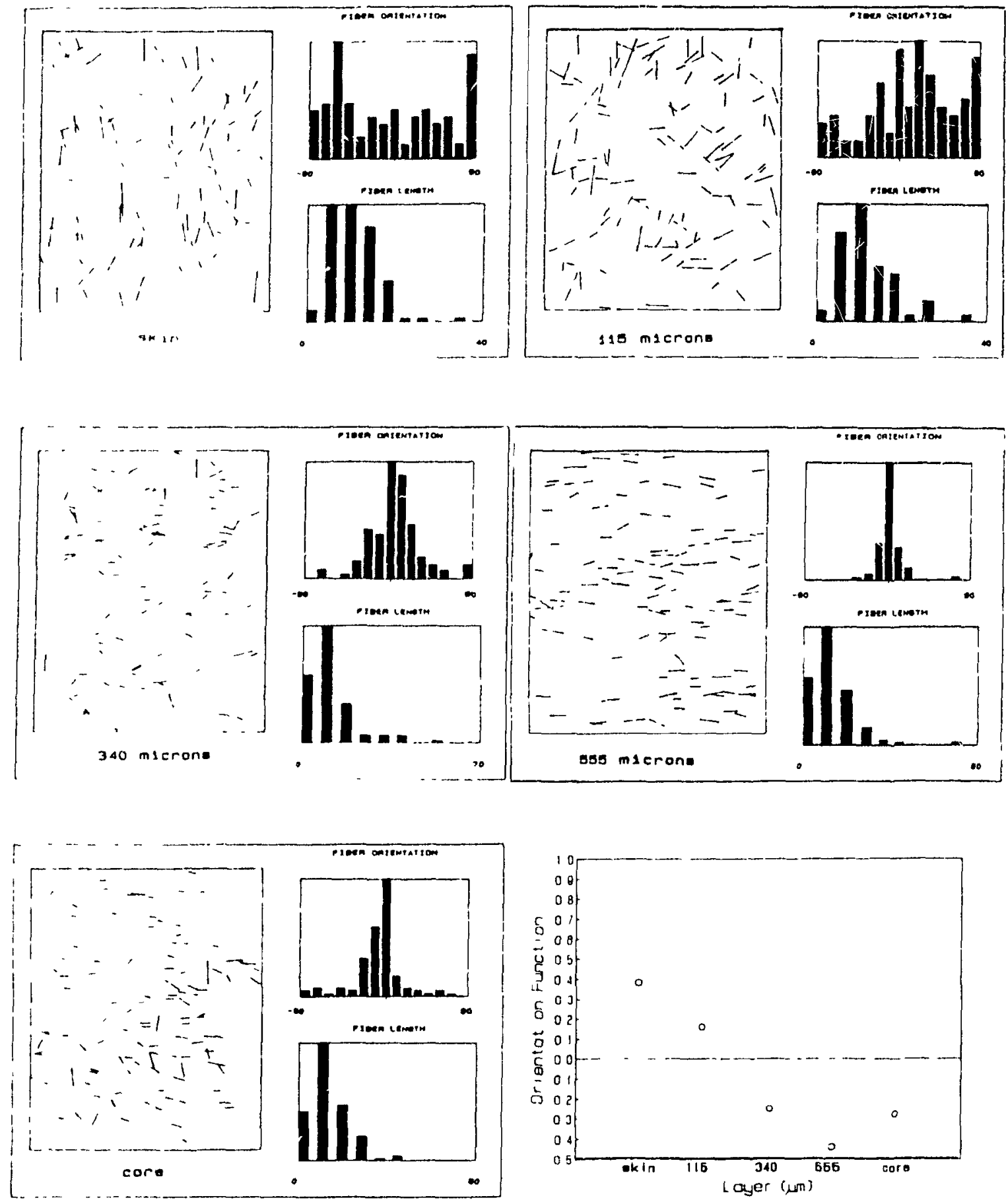

rigure 5.6. Orientation and Length Distributions for Samples Molded with Converging Sprues at $163^{\circ} \mathrm{C}$ (Microtome Location 6). 

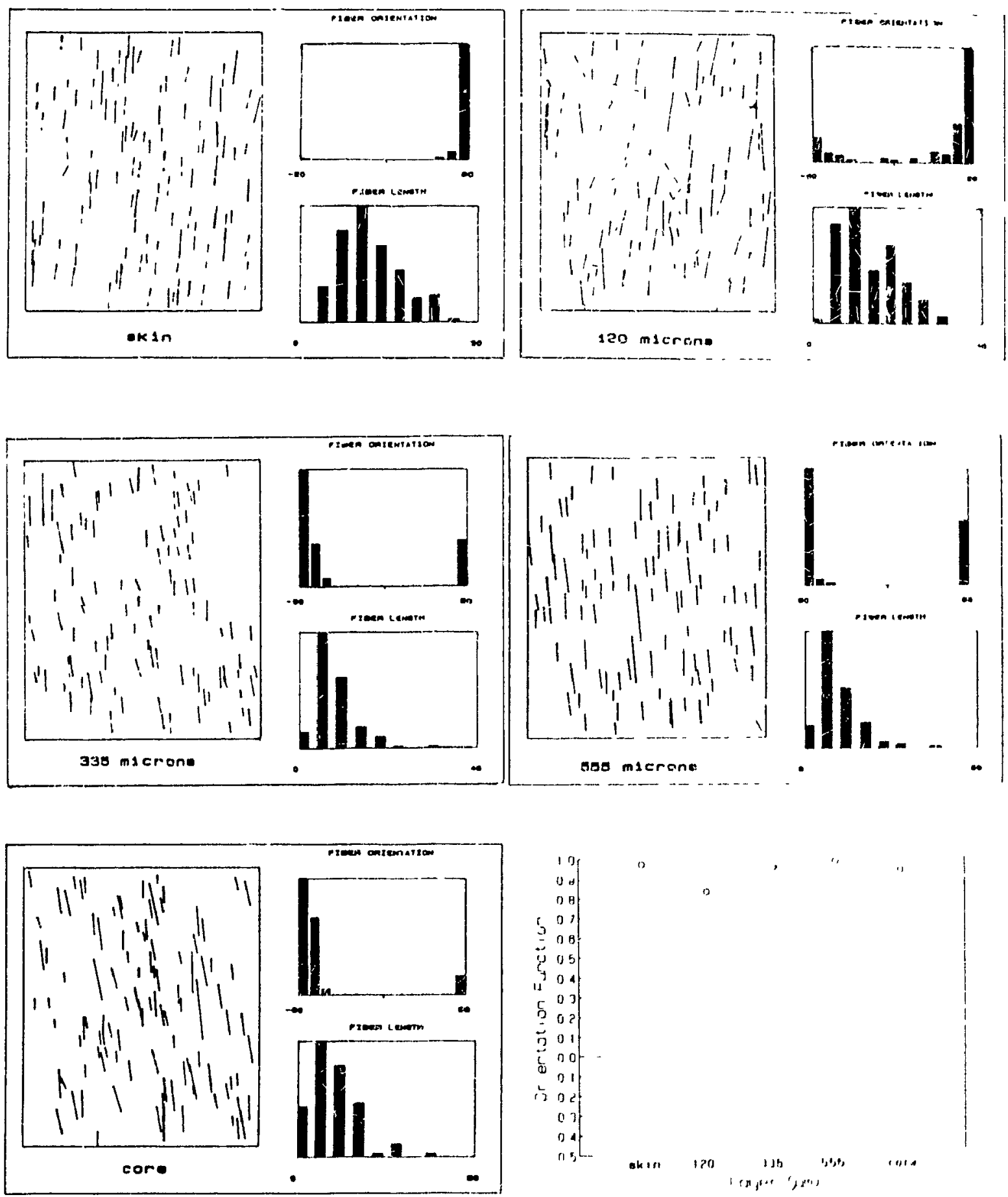

Figure 5.7. ürientation and Length Distributions for Samples Molded with converging sprues at $15 \%$ ' $\mathrm{C}$ (Microtome Location 7). 
ifridicnt causes orientation in the hoop direction (18). As the melt exits the sprue, it has a predominantly random fiber orifnlation, as shown in the orientation functions given in ligures 5.3, 5.4, and 5.5 for the skin layers. These three locations are nearest the sprue. As the melt moves away from the sprucs towards the wall, the fiber oriantation of the skin layer becomes stronger. This is seen in Figures 5.2 and 5.7 lor the locations intermediate between the sprue and the wall. Mlorotome location 7 (Figure 5.7) has very strong longitudinal 1 Her orlentation at each layer, due to the fact that this lintion ls near a weldine where two flow fronts with Ixmitudinal fiber orientation meet. As the fibers approach thw whl, they assume an orientation parallel to the wall, as . wn $1 \mathrm{n}$ Figures 5.1 and 5.6.

$\therefore$ the depth layers approach the core from the skin, the 1Hur; become more oriented, as seen in the orientation lunction distributions. This is due to the fact that these layer:; have more tıme to achieve orientation than the layers nfw the skin, and are less affected by the shearing and Irengling which occur at the mold surface. For virtually all Inations, the orientation was constant from approximately i.il milions to the core.

linures 5.8 to 5.10 show the orientation results for the $\therefore$ mpless molded at $204^{\circ} \mathrm{C}$ with converging sprues. The results Aro similar to those found at $163^{\circ} \mathrm{C}$, except that the skin 

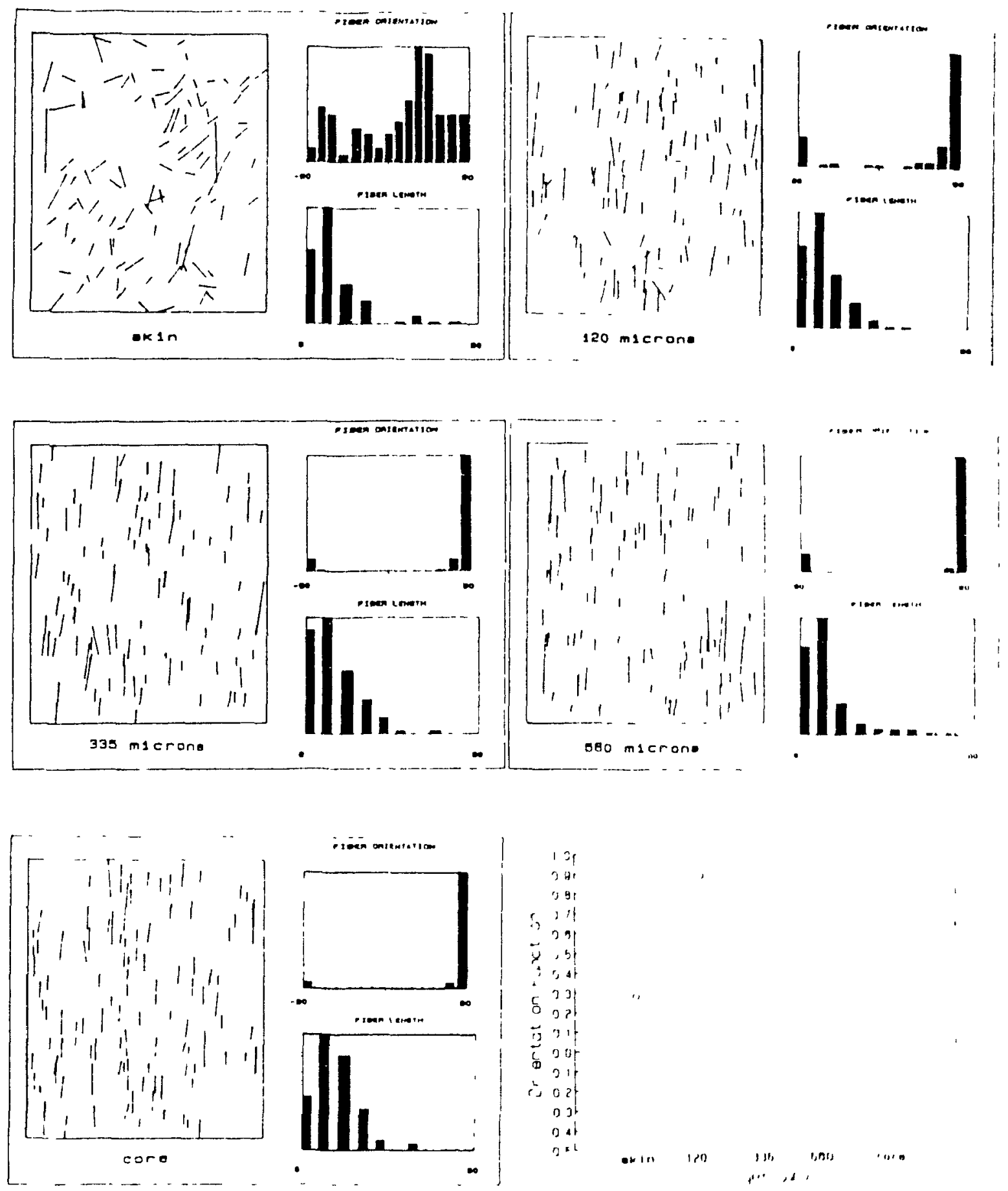

Figure 5.8. Orientation and Length Distributions for Samples Molded with Conserging sprurs it iss: (Microtome Location 3). 

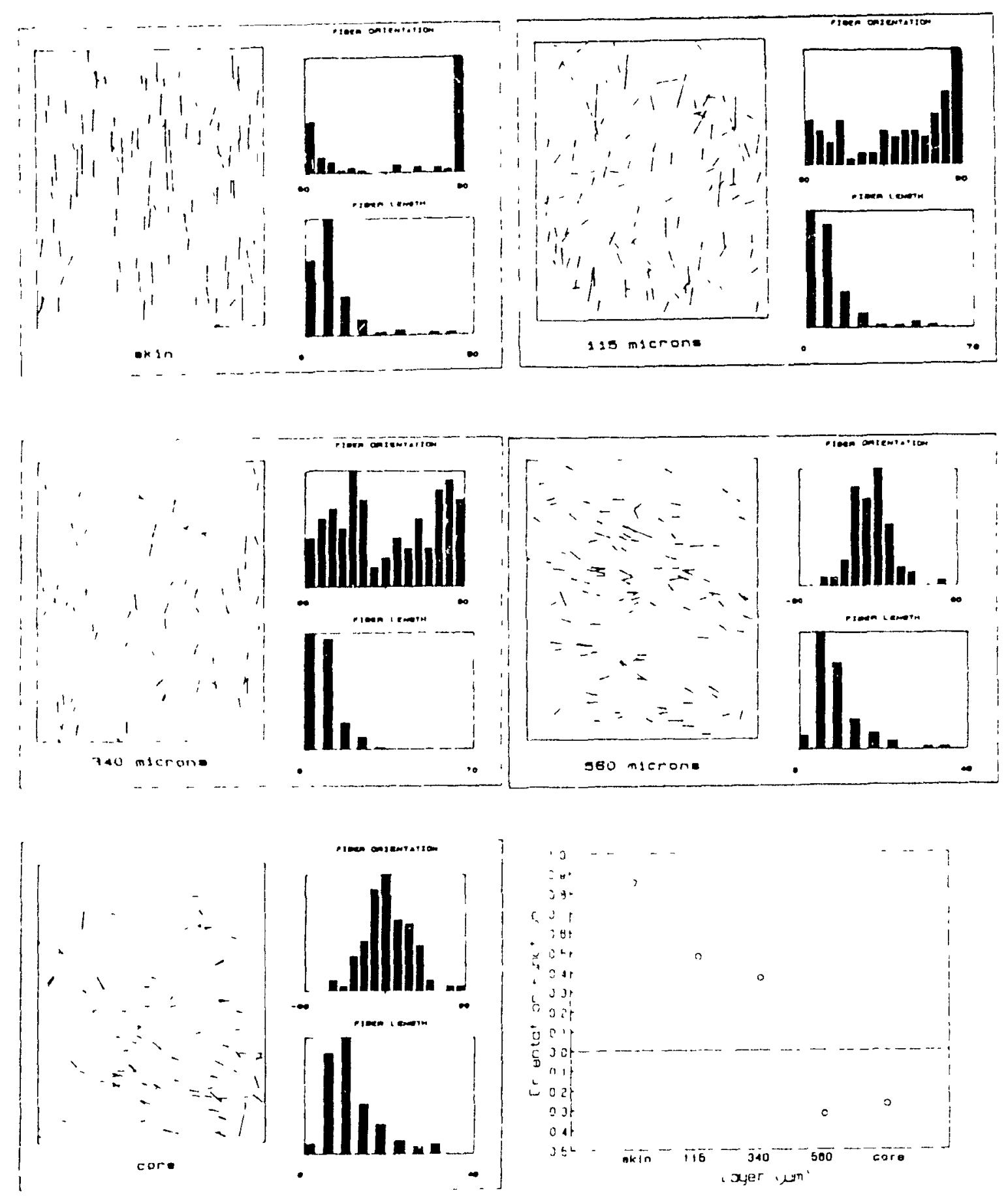

Plgure 5.9. Orlentation and Length Distributions for Samples Molded with Converging Sprues at $204^{\circ} \mathrm{C}$ (Microtome Location 4). 


$$
\text { f Longitude }
$$

$\longrightarrow$ Transverso

Direction
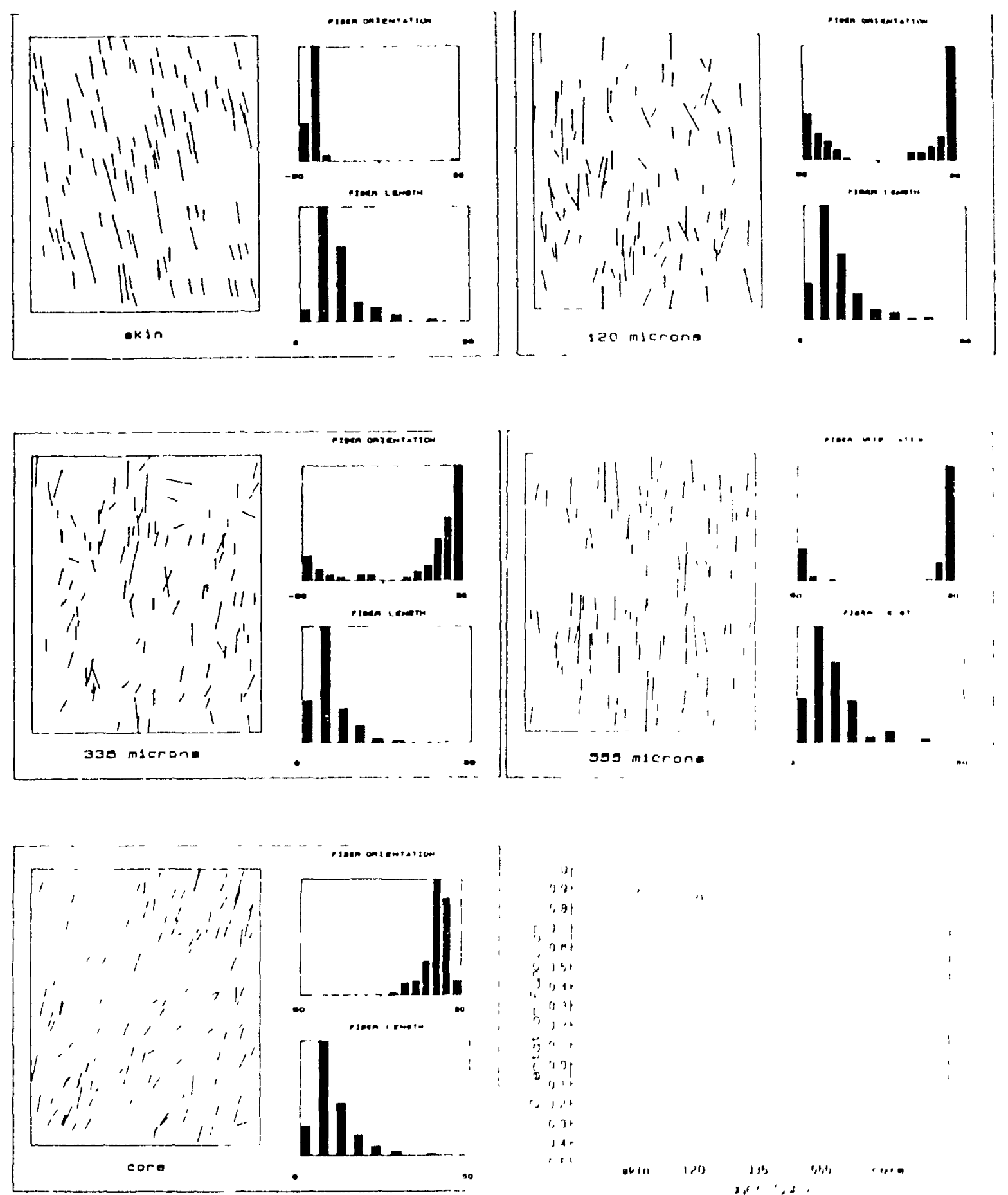

Figure 5.10. Orientation and Length Distribation: for Samples Molded with Conyerging ipruse at zos c (Microtome Location 5). 
liyer has much stronger orientation at the higher temperature. Ihe orientation function at the skin layer is very close to i.) at microtome locations 4 and 5 (Figures 5.9 and 5.10), duc to the fact that the material froze before the orientation 1 nduced in the sprues could change into the random contiguration seen at $163^{\circ} \mathrm{C}$.

'he orlentation and length distributions for the samples molled with straight sprues are given in Figures 5.11 through '. 1: for a molding temperature of $163^{\circ} \mathrm{C}$. The results were imllir to those found with converging sprues. The "rentation Induced in the sprues did not affect the final crientation. This was due to the deformation undergone by the material as it left the sprues and entered the mold cavity, which coused the orlentation to assume a circumferential littern, regardless of sprue design. It was this flow of the m.1t unto the mold cavity that determined the final orlentation in the sample, not the orientation induced during 1 low through the sprue. The fiber orientation for the samples that were molded at $204^{\circ} \mathrm{C}$ with straight sprues is shown in linure!; 5.14 to 5.16. The effect of temperature on the "rluntation was small, except that the skin layer had a it ingre orientation at this temperature.

lhe length distributions for all samples indicated that sukstantial fiber breakage had occurred. The fiber length was generally found to be between 6 and 20 microns, with an 

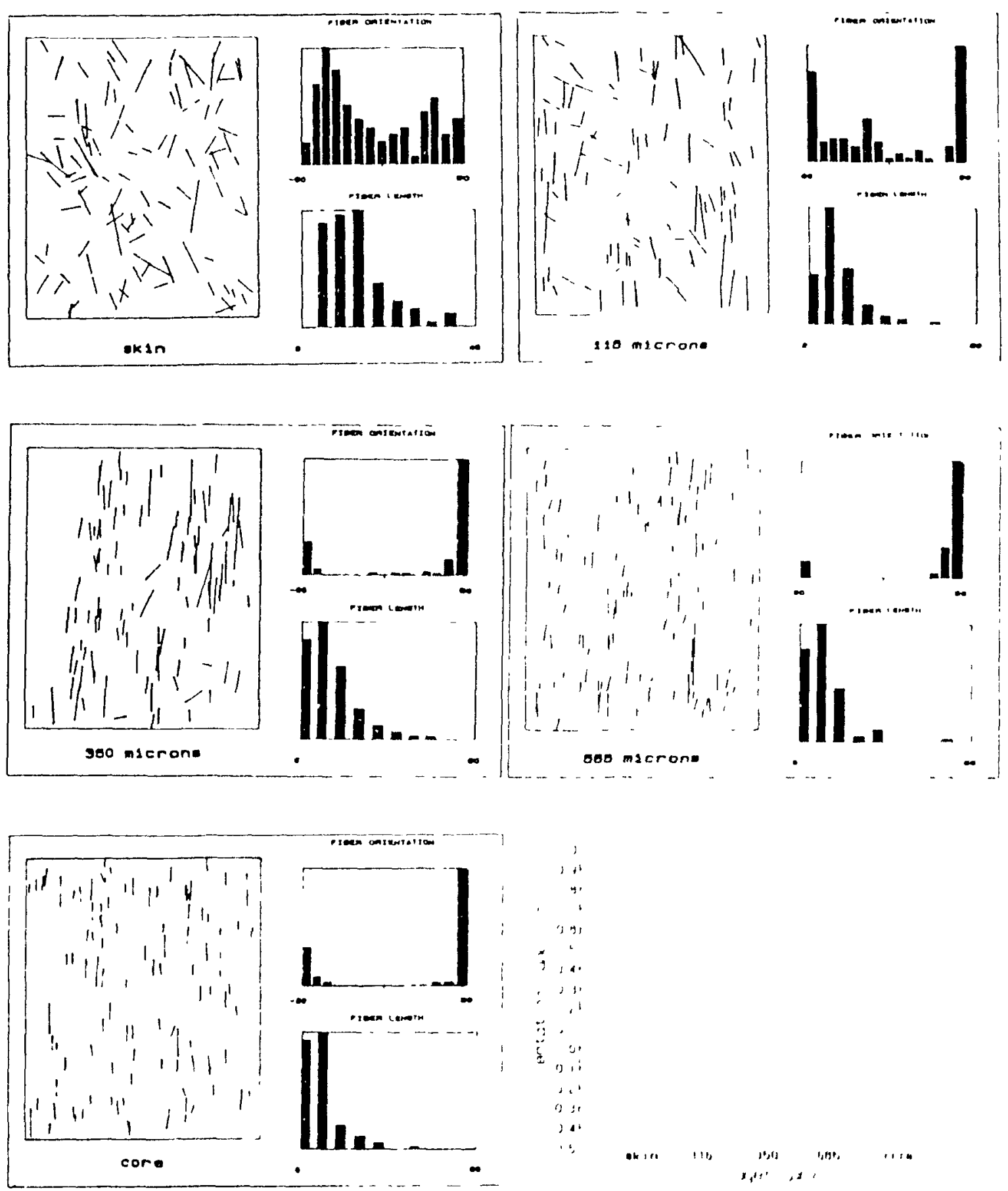

Figure 5.11. Orientation and Length Distrubutions for Samples Molded with strajght ciprurs: at $16: 2$ (Microtome Location 3). 

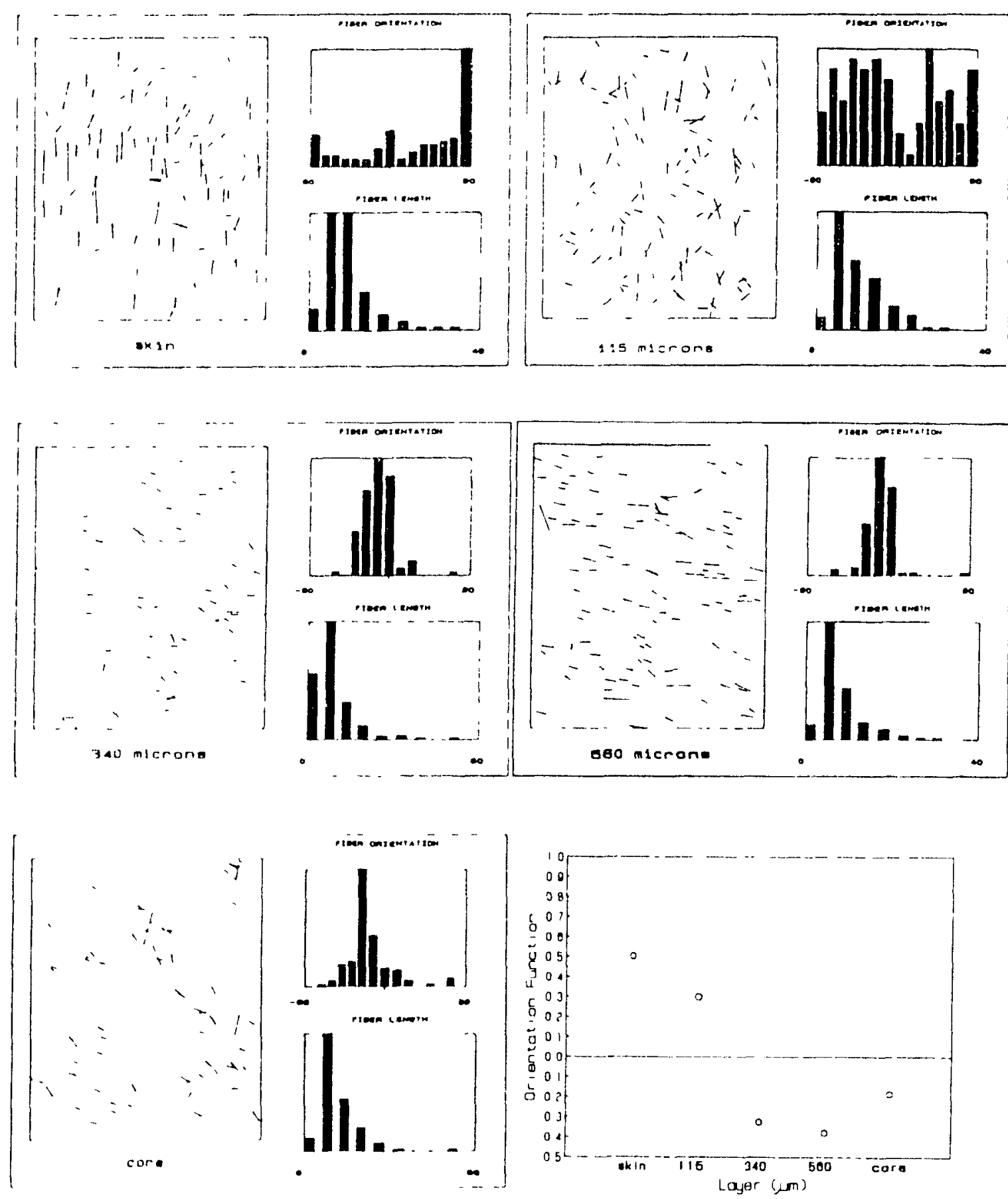

Figure 5.12. Orlentation and Length Distributions for Samples Molded with straight sprues at $163^{\circ} \mathrm{C}$ (Mlcrotome Location 4 ). 


\section{Longitude \\ Direction}

$\longrightarrow$ Transverso

Direction
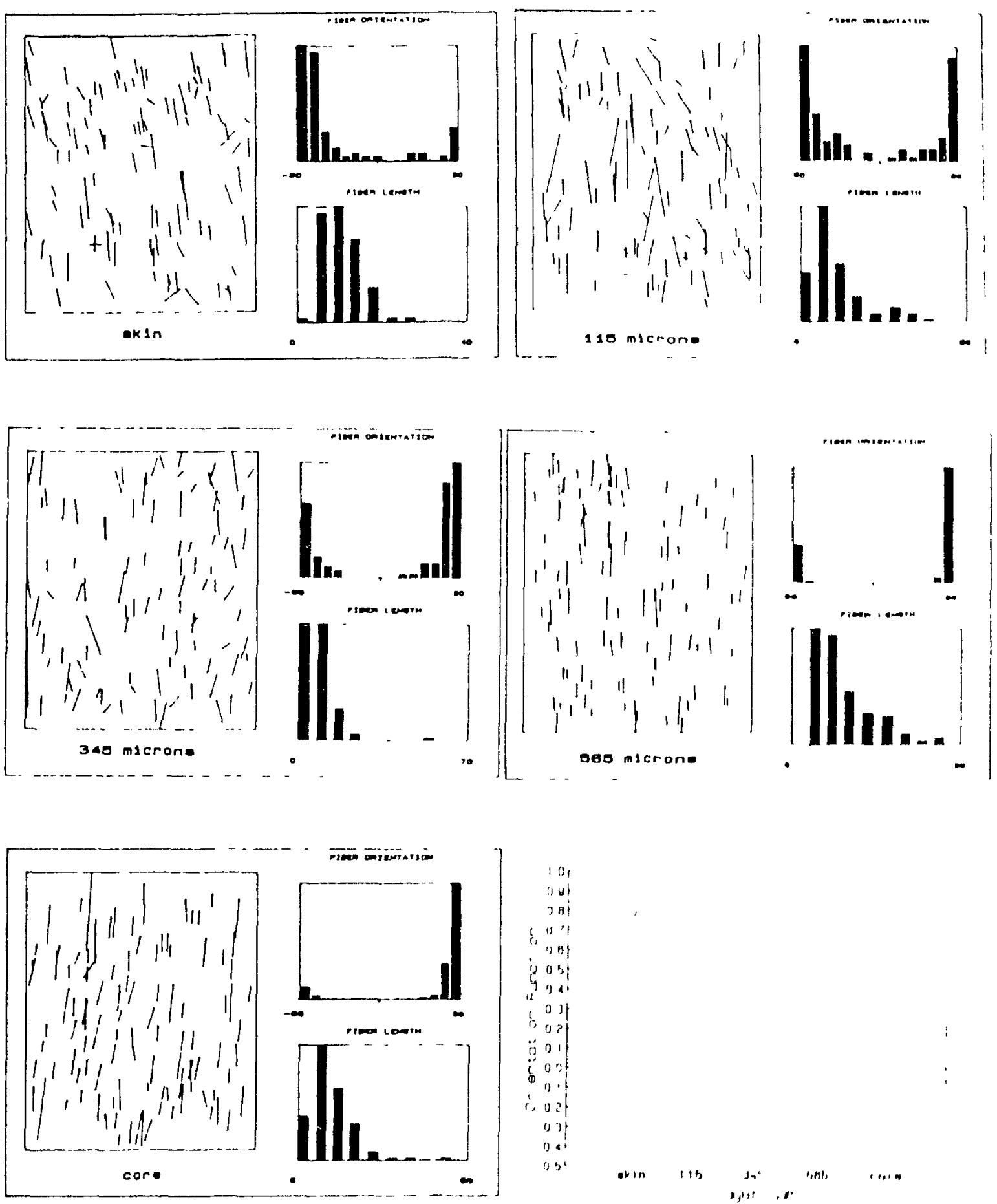

Figure 5.13. Orientation and Length Distribution's is Samples Molded with straight sprure at lf: r: (Microtome Location 5). 

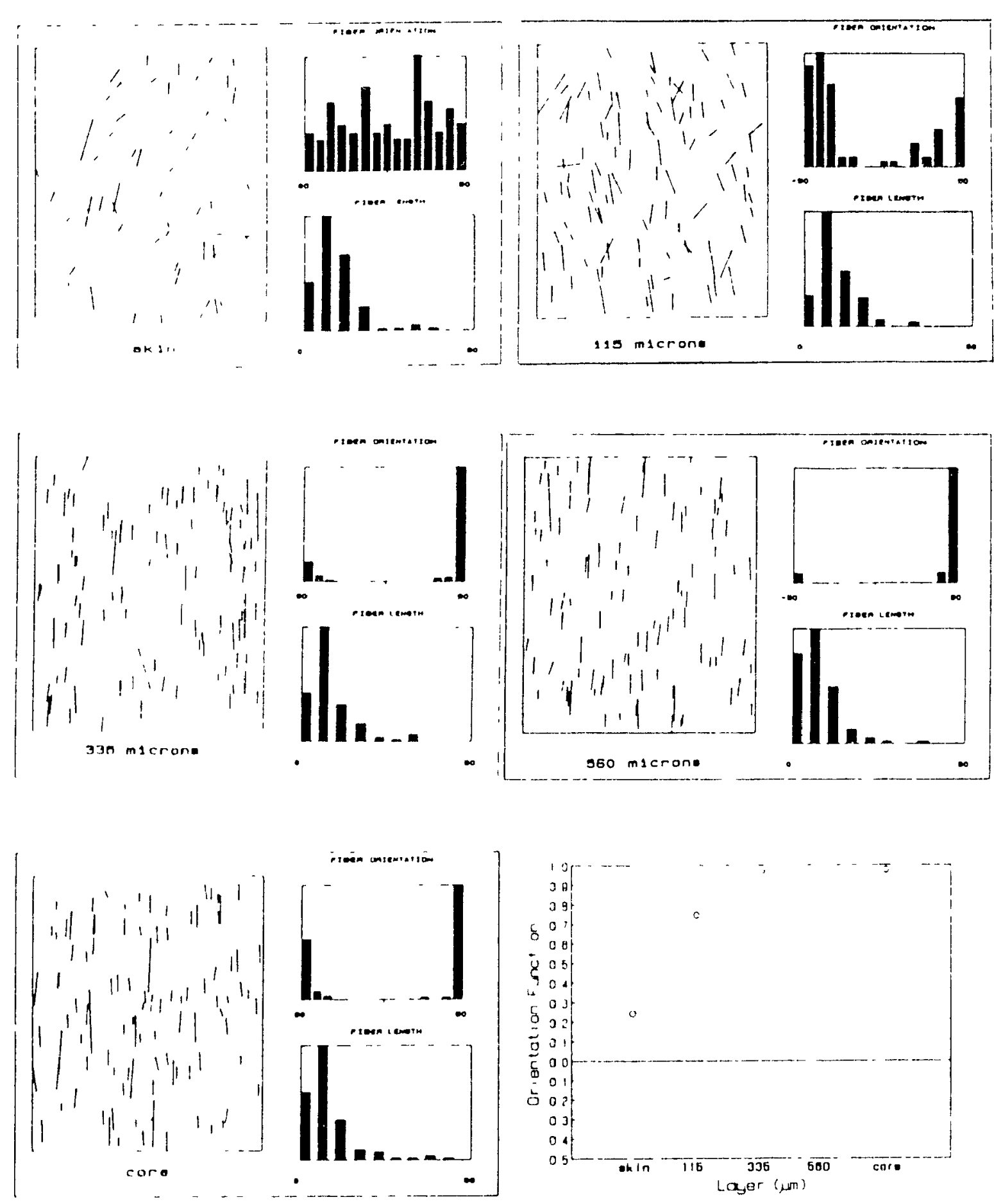

rlgure 5.14. Orientation and Length Distributions for Samples Molded with Straight sprues at $204^{\circ} \mathrm{C}$ (Microtome Location 3). 

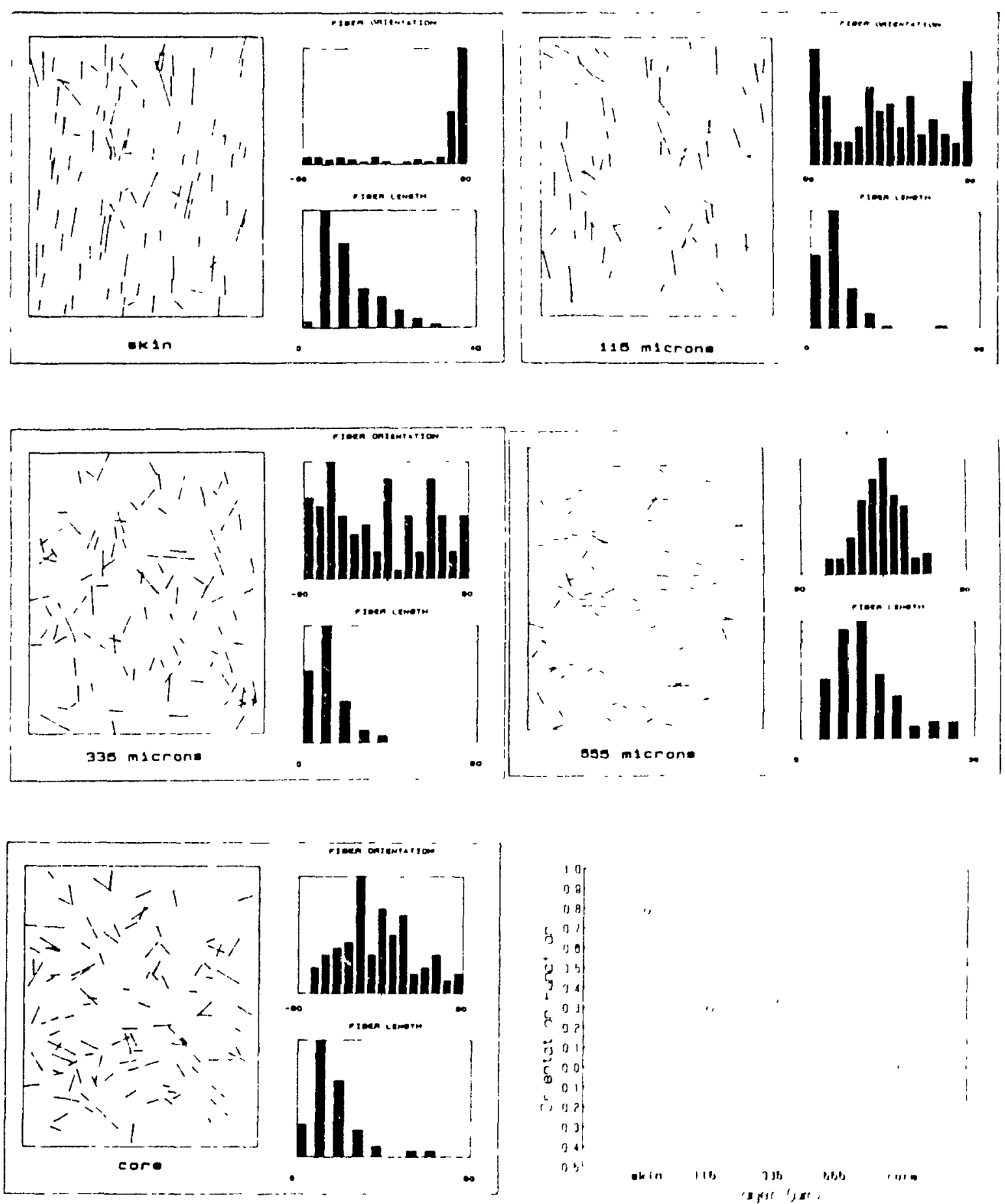

F:gure 5.15. Orientation and Length Distribution: 10, Samples Molded with straight sprues at $71 \%$ : (Microtome Location 4). 

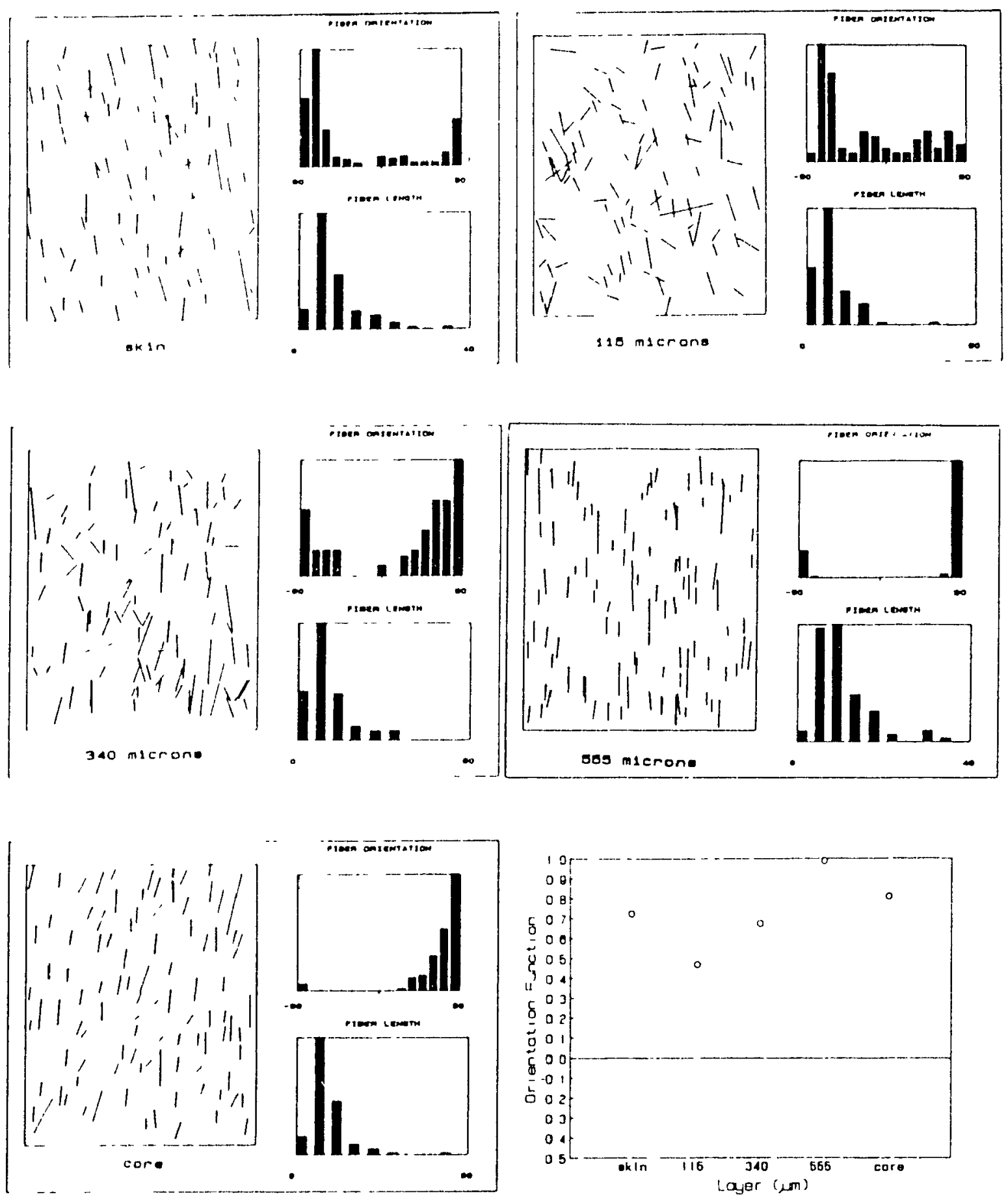

Flgure 5.16. Orientation and Length Distributions for Samples Molded with straight sprues at $204^{\circ} \mathrm{C}$ (Microtome Location 5). 
average of approximately 12 microns. This translates into a fiber aspect ratio of approximately 6 after molding, as compared with a ratio of 30 before molding. Transfer molding causes very strong flow, which contributes to fiber orientation but also causes significant fiber attrition.

\subsubsection{Compression Molded Samples}

Figures 5.17 to 5.23 present the results tor the sumple!, molded at $163^{\circ} \mathrm{C}$ that were prepared with "controlled milling". The orientation of the fibers is generally longitudinal (In the mill direction) for all locations and all dopths. As indicated previously, the "controlled milling" procos:; involves folding the sheet and then passing it buck through the roll mills. This folding increases the thickness of tho feed sheet and subsequently the strain, causing longutudinal fiber orientation (18). The orientation functions demonitrate" that there is little variation from this longltudinal ibrer orientation from skin to core for most layers. Floures, 5.34 and 5.25 show the orientation and length distributions for samples molded at $204^{\circ} \mathrm{C}$. The temperature does not a leor the orientation of the fibers significantly, except at the skin layer where the orientation is very strong. The high molding temperature caused rapid freezing of the orientation at thr. mold surface.

The samples that were milled randomly did not exhibit strong 

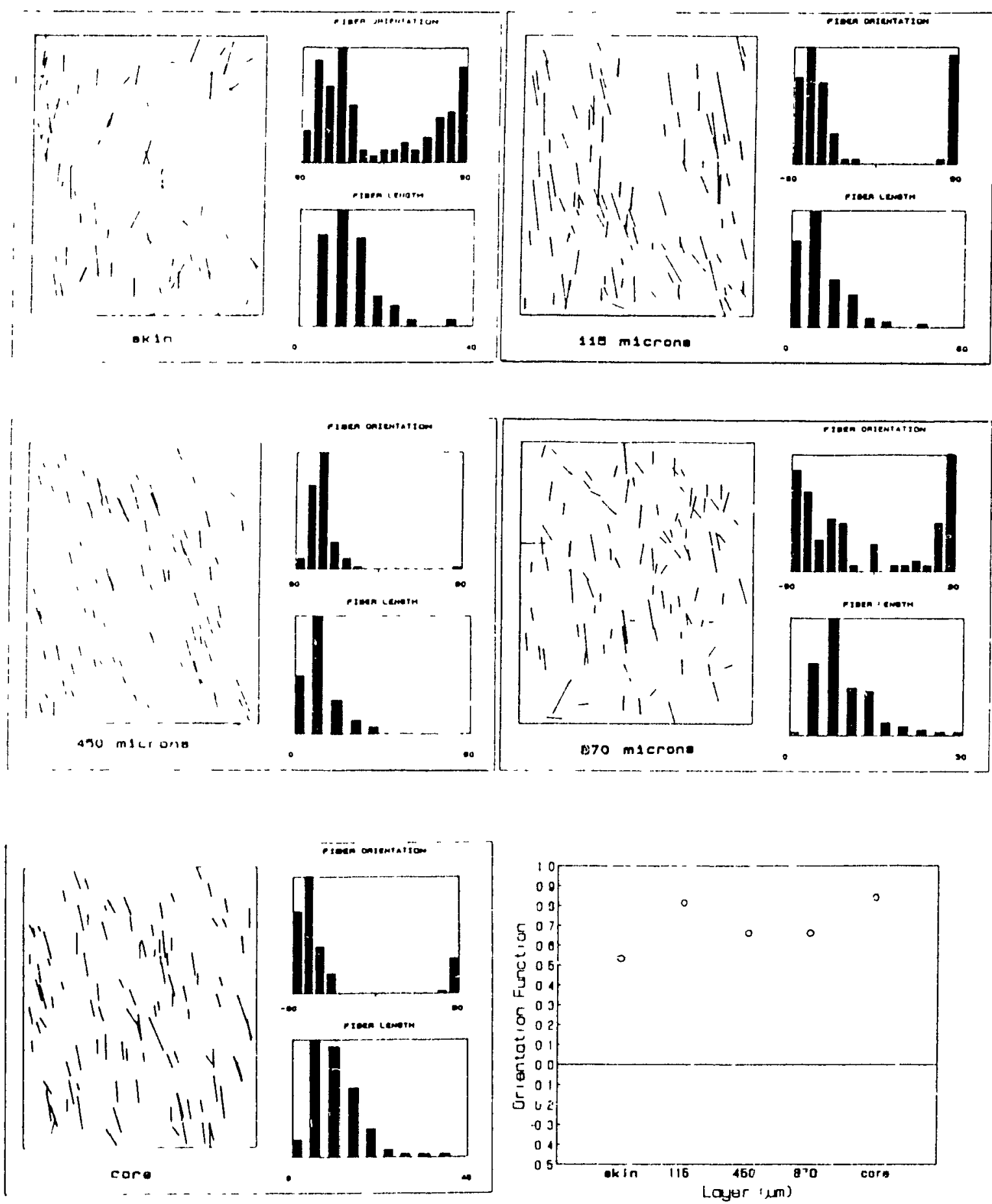

Figure 5.17. Orientation and Length Distributions for Controlied Milling Samples Molcled at $163^{\circ} \mathrm{C}$ (Microtome Location 1 ). 

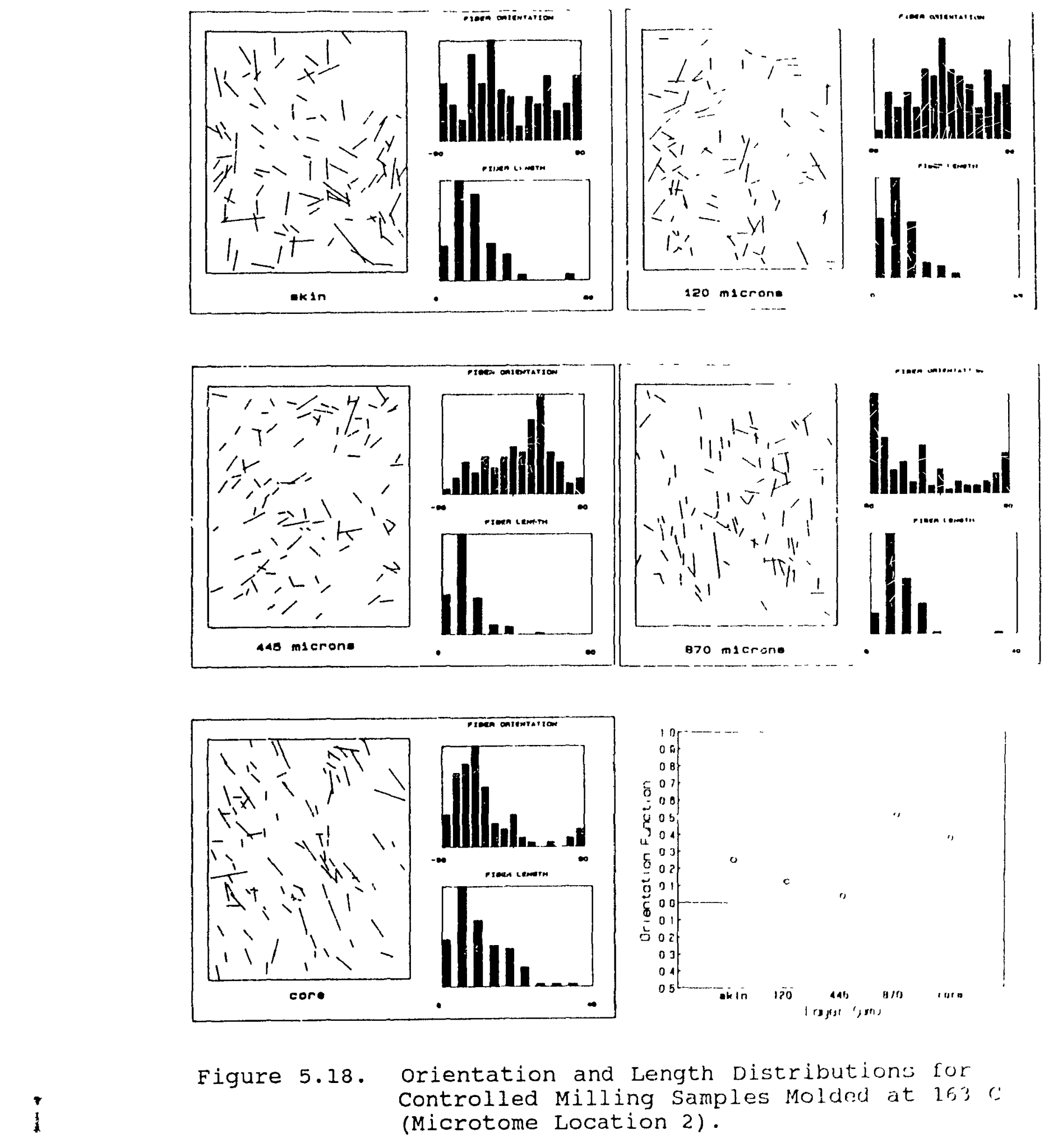

Figure 5.18. Orientation and Length Distributions for
Controlled Miling Samples Molded at 163 (
(Microtome Location 2). 

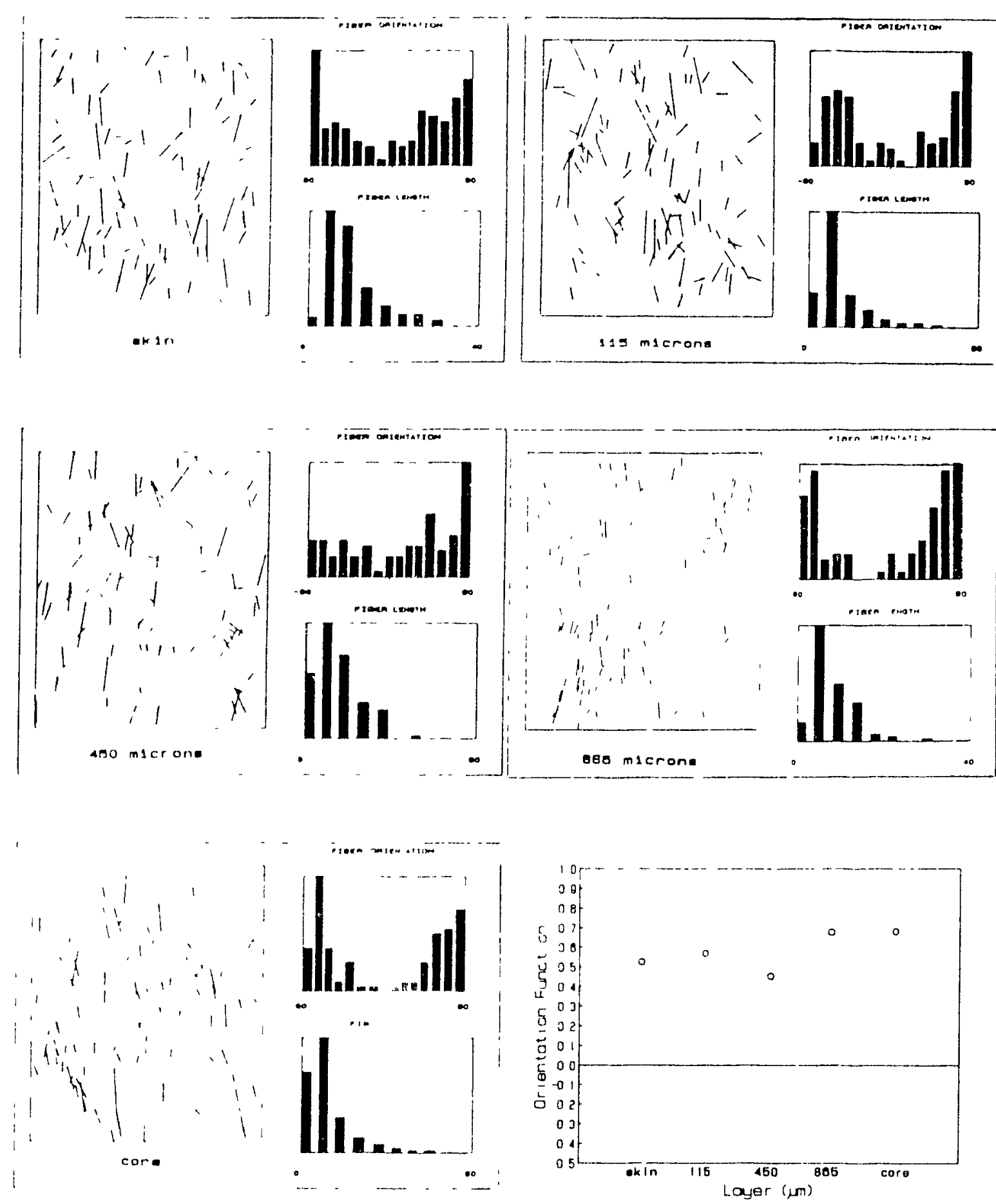

rigure 5.19. Orientation and Length Distributions for Controlled Milling Samples Molded at $163^{\circ} \mathrm{C}$ (Microtome Location 3 ). 

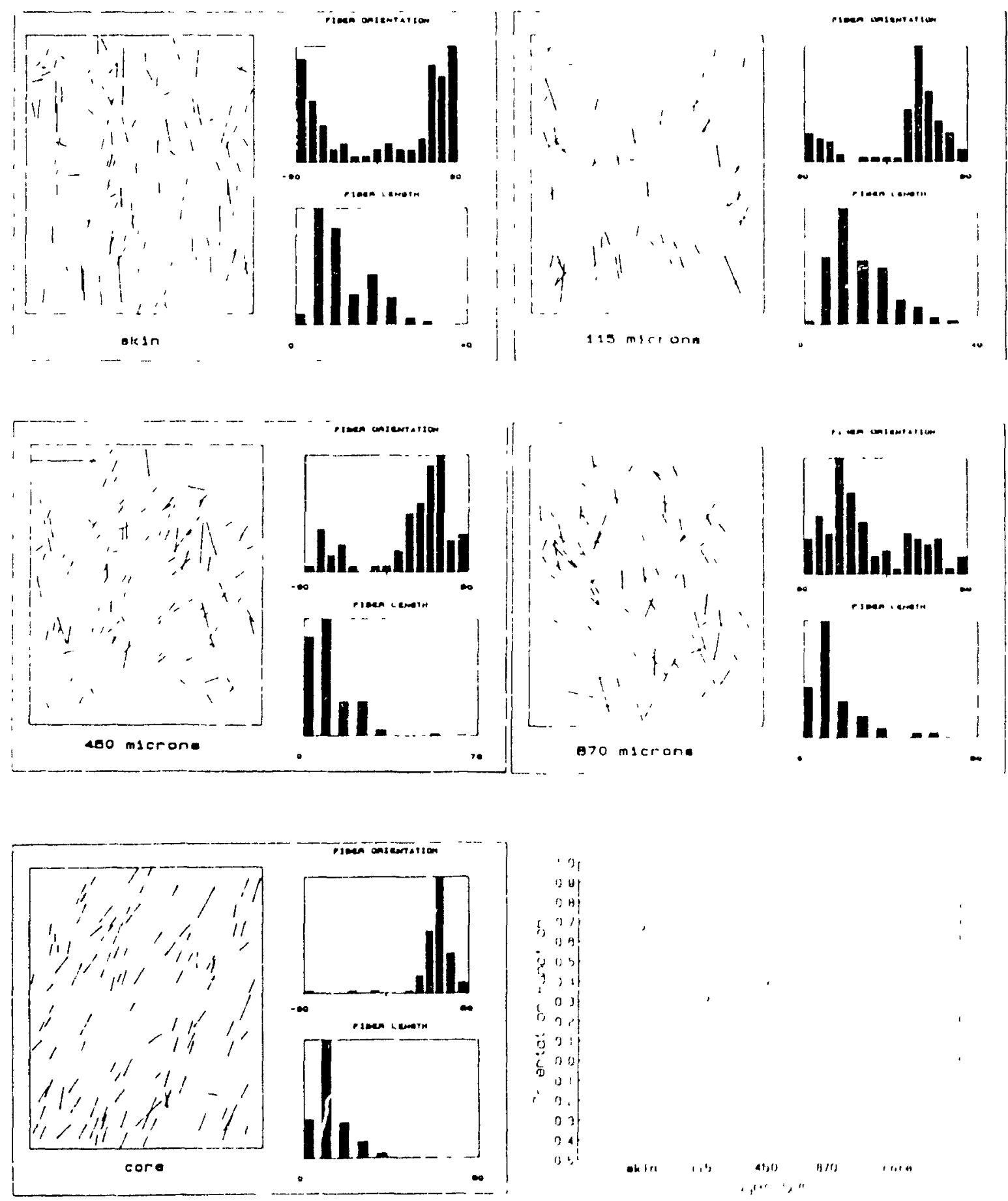

Figure 5.20. Orientation and Length Distributirnr for controlled Milling Sampler Mrslded at $16:$ (Microtome Location 4). 

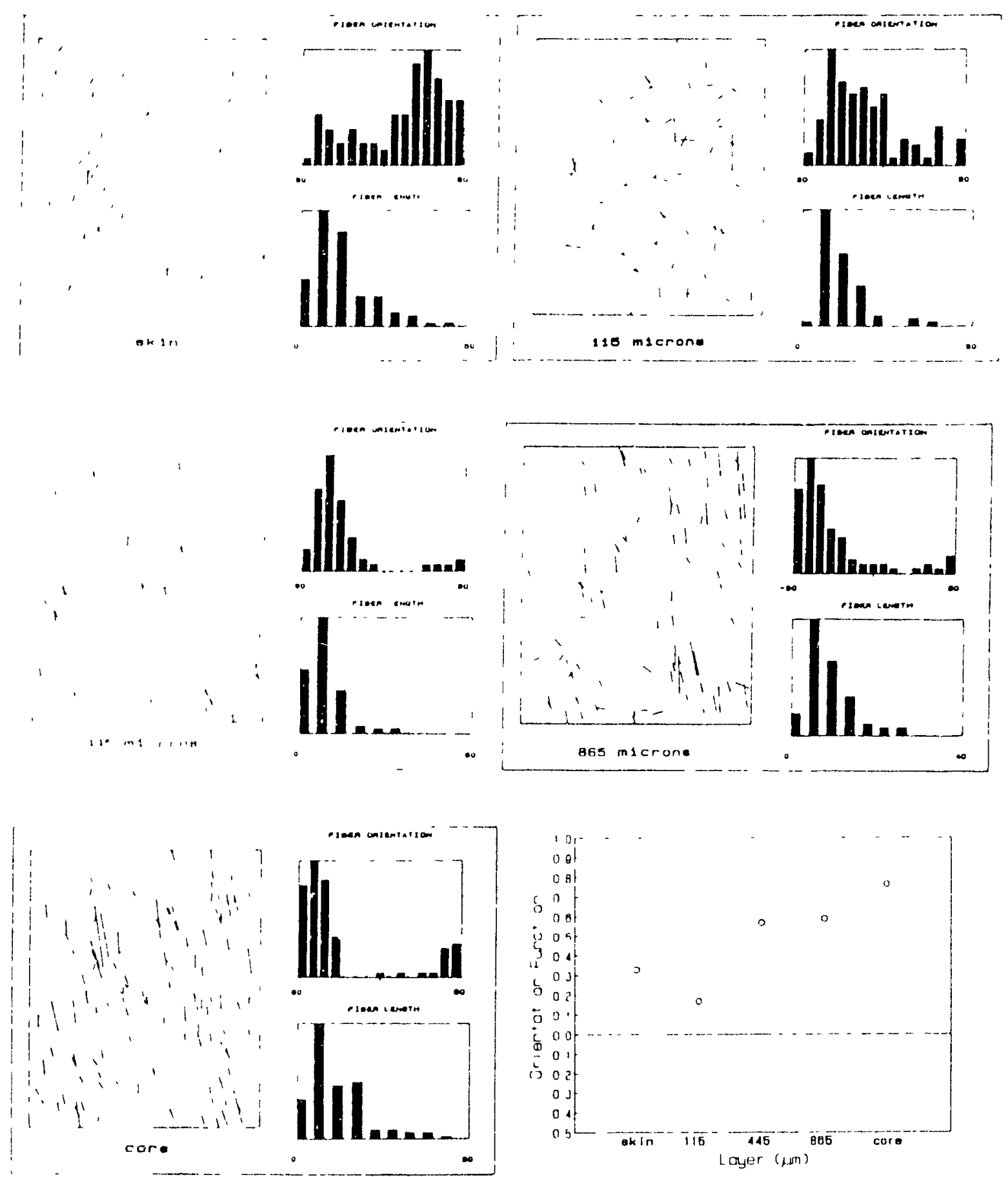

Fiqure 5.21. Orientation and Length Distributions for Controlled Milling Samples Molded at $163^{\circ} \mathrm{C}$ (Microtome Location 5). 

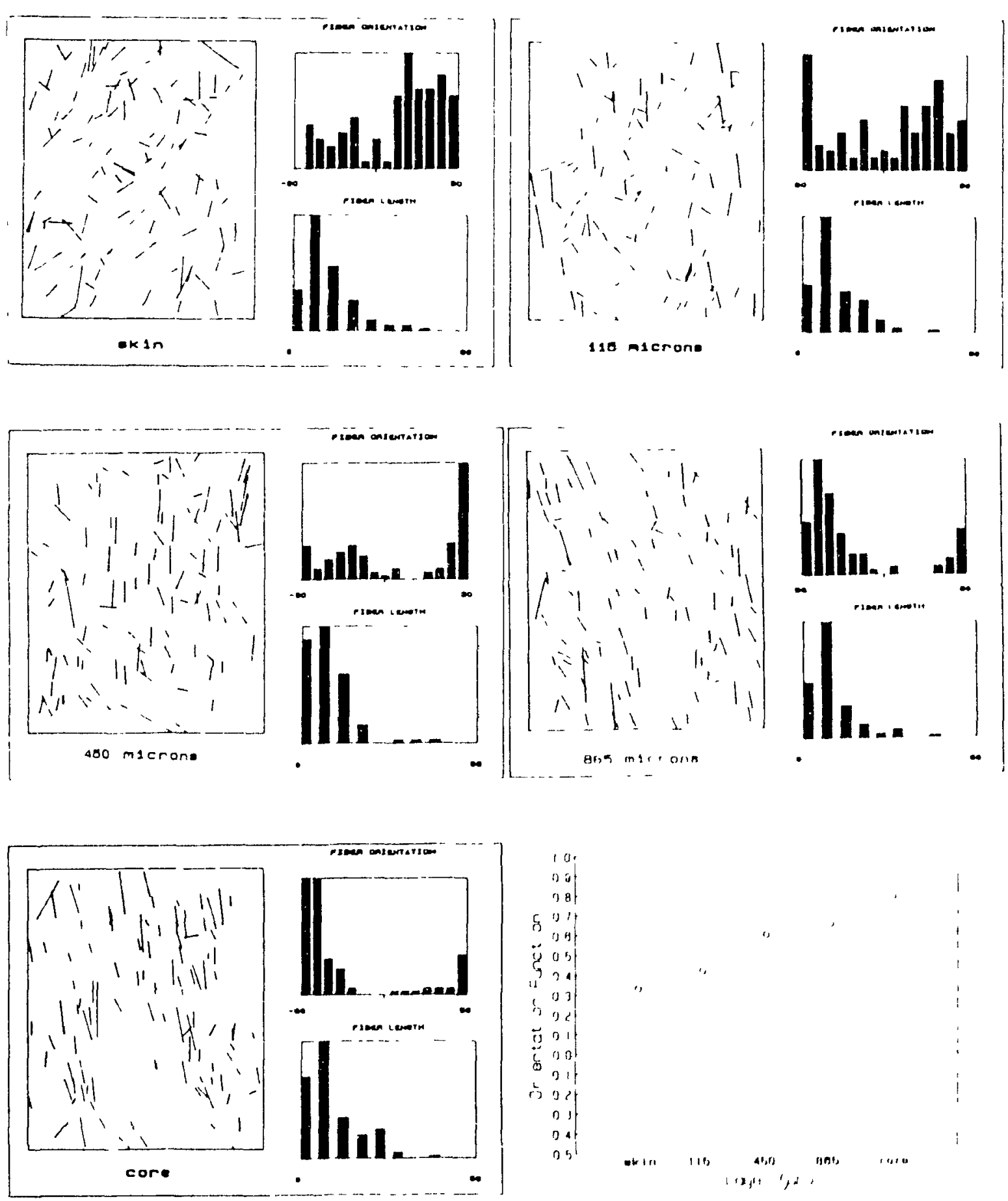

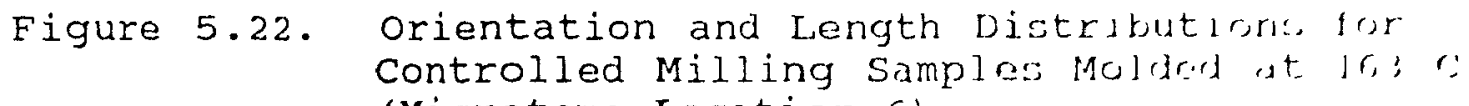
(Microtome Location 6 ). 

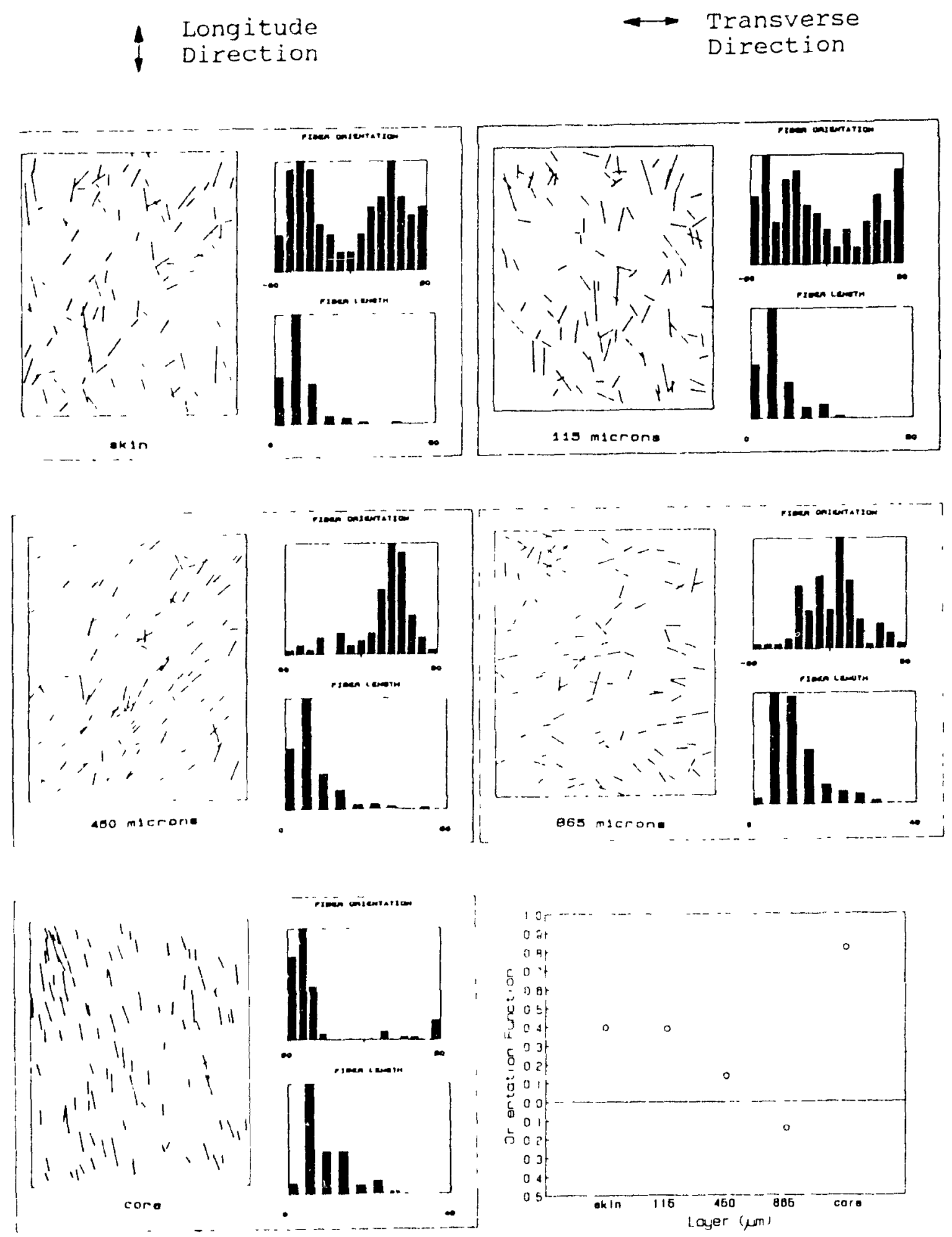

Figure 5.23. Orientation and Length Distributions for
Controlled Milling Samples Molded at $163^{\circ} \mathrm{C}$ (Microtome Location 7 ). 

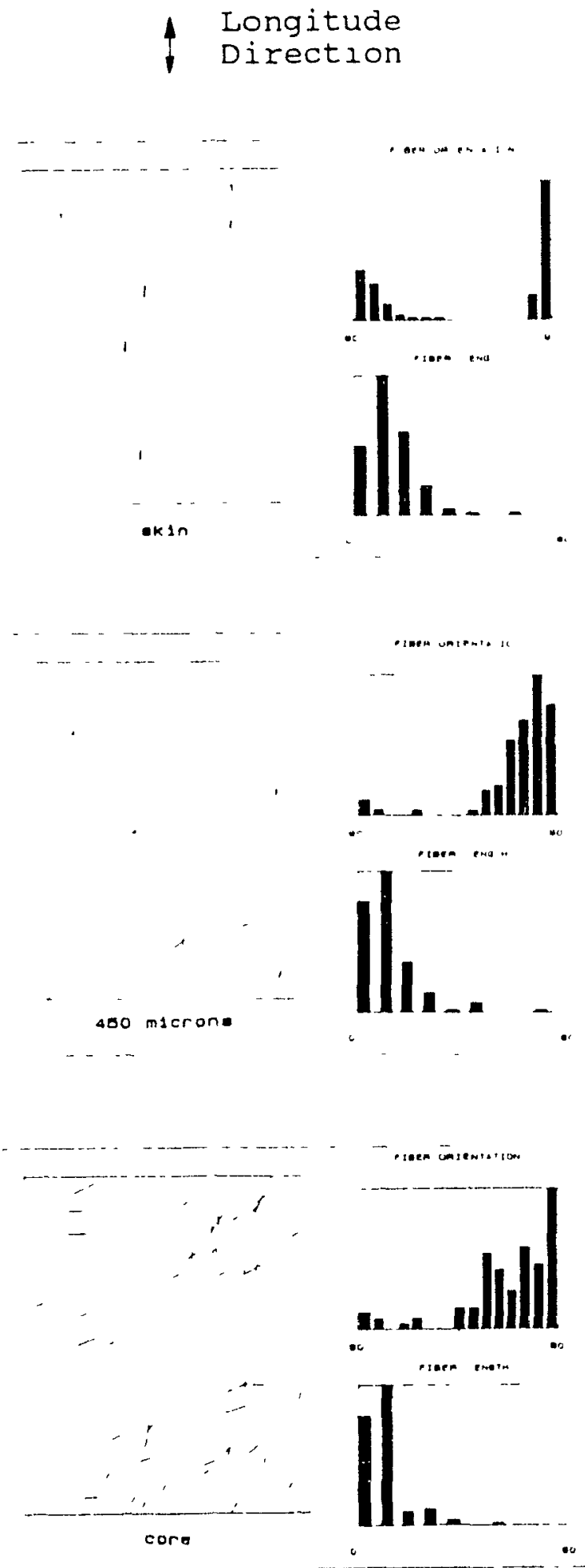

- Tranivorso

lirotion

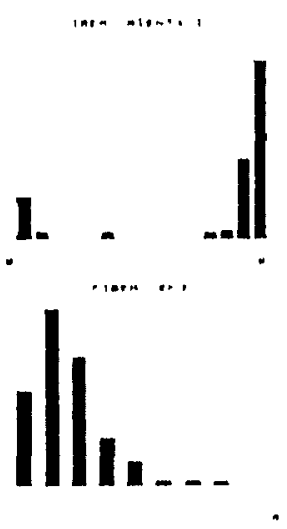

120 microne
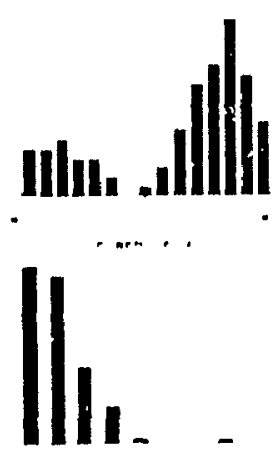

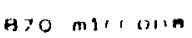

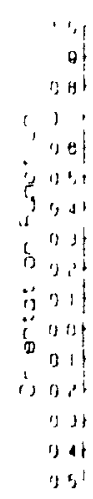

Figure 5.24. Orientation and Length Dijtributirn"; fir Controlled Milling Samplos Molidrit at as: (Microtome Location 2). 

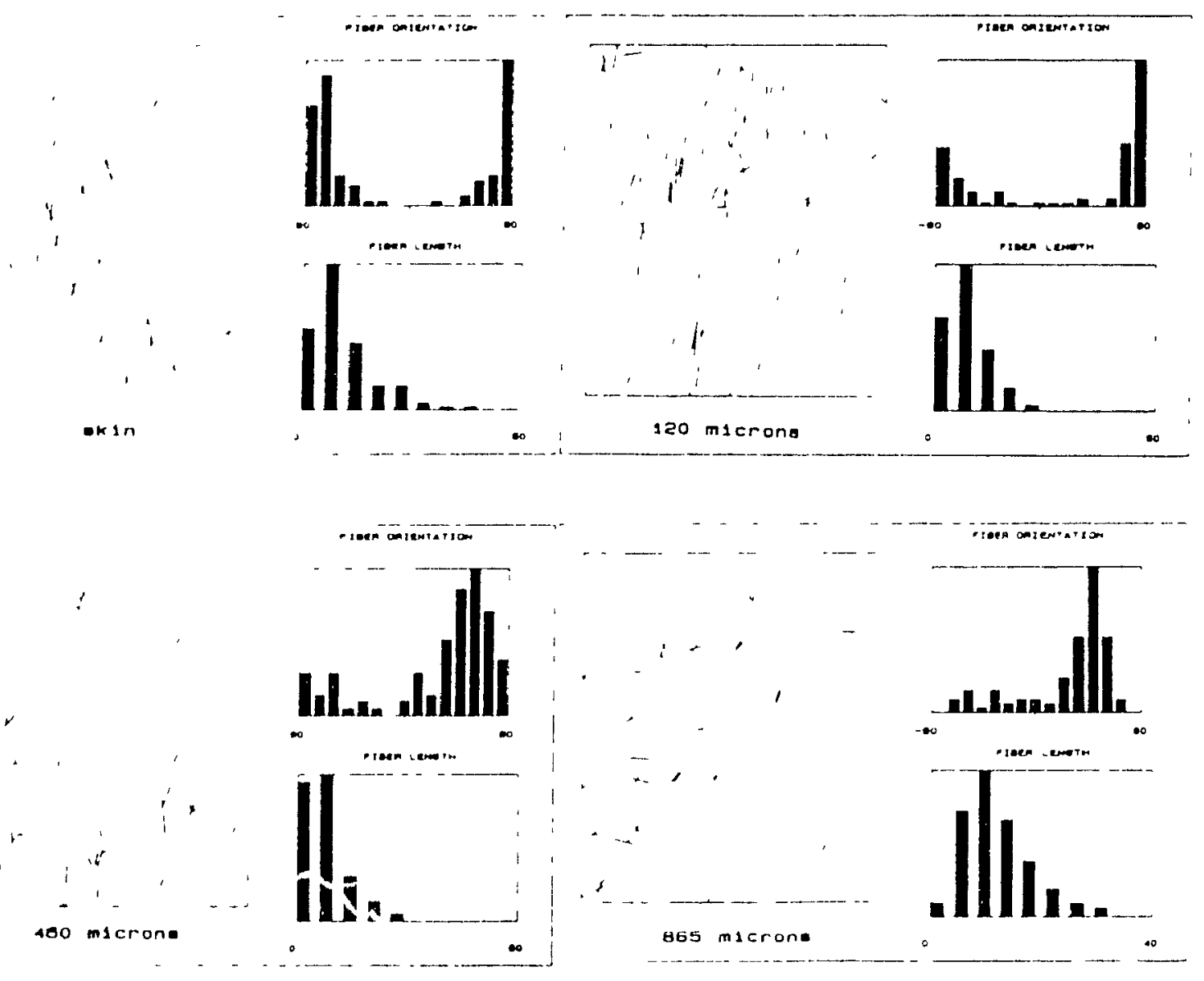

luyro 3.25 . Orientation and Length Distributions for controlled Milling Samples Molded at $204^{\circ} \mathrm{C}$ (Microtome Location 3). 
fiber orientation. This is shown in Figures 5.20 to 5.32101 the samples molded at $163^{\circ} \mathrm{C}$. Since the shoct was taken oft the mill and then placed back through the rolls without folding the sheet or reducing the gap space in thi:; procolube, all fiber orientation was achieved at ter the $t$ lat prat. through the mill (13), and no increase in the struin wa: achieved. Therefore, the orientation :ihould b l.... pronounced than that found in the samplos thit lumbrivent "controlled milling". The orientation funct 1 m l willt:; show that the fiber orientation was nearly random tor mo.t l. $y^{\prime} \cdot \mathrm{r}^{\prime}$,

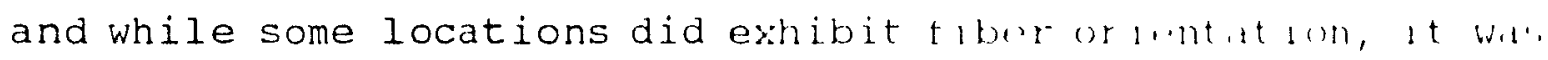
much less substantial than that tound in the ihmel: whth "controlled milling".

The fibers suffered extensive breakagr, as ahw:.h in thr 1 ib 1 length distributions for all samplos. The 1 llul lumth wa, reduced to an average of approximatoly l' mic Im,. 'Ihl', decreased the aspect ratio of the flburs til 1. Frint:llll

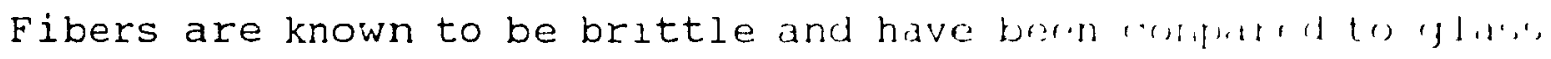
fibers (12), which suffer severe brontarge when m111!1 (14). However, the fiber lengths after molding wrir thr "inm lor

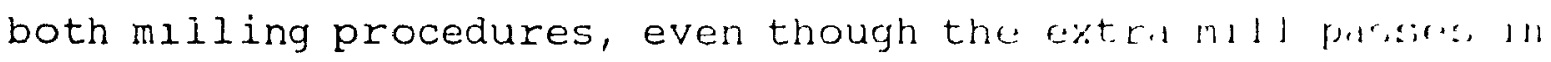
the randomly milled composite have no effoct on thr tirme.. This suggests that the initial mlxing and milling of thr composites caused the majority of the breakngrs, not thr. milling techniques used in this study. 


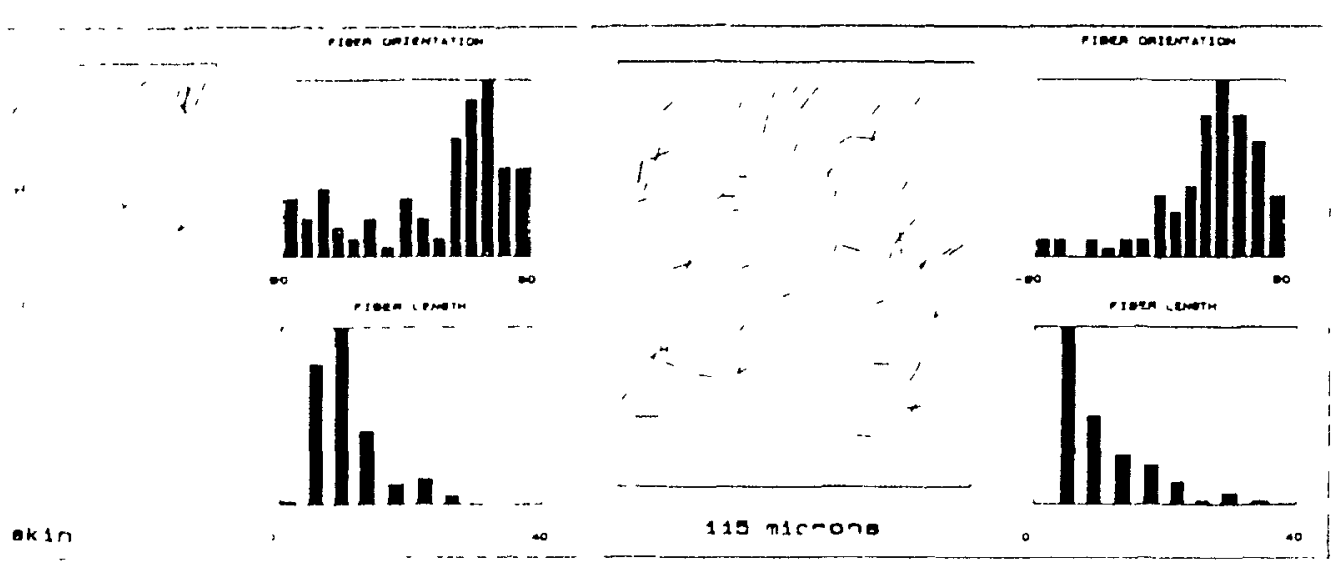

450 microne
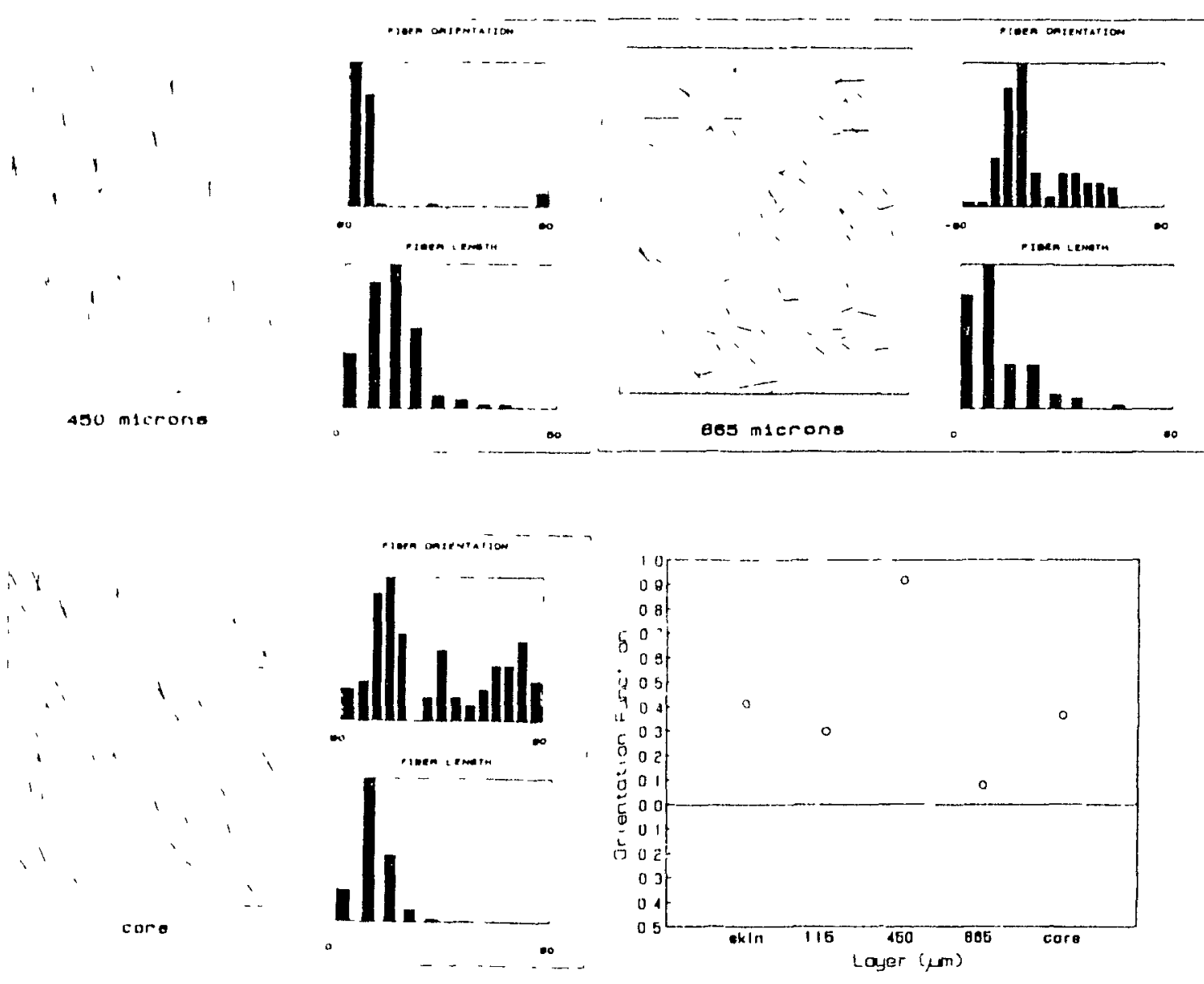

l'uml 5.26. Orientation and Length Distributions for Random Milling Samples Molded at $163^{\circ} \mathrm{C}$ (Microtome Location 1 ). 

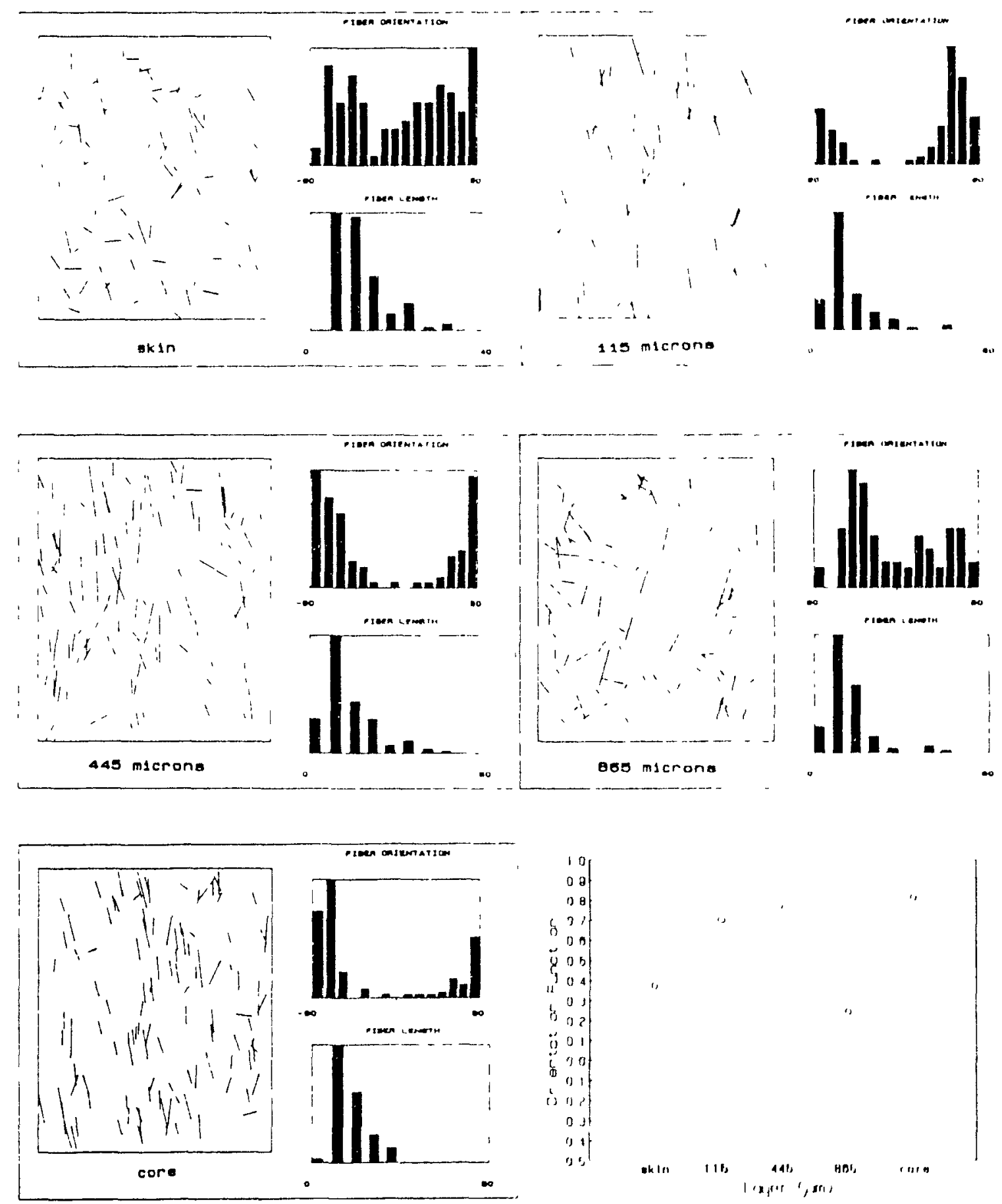

Figure 5.27. Orientation and Length Distributions for Random Milling Samples Molderd at $16:$ ' $C$ (Microtome Location 2). 
14 Direction

$\longrightarrow$ Transverse

Direction

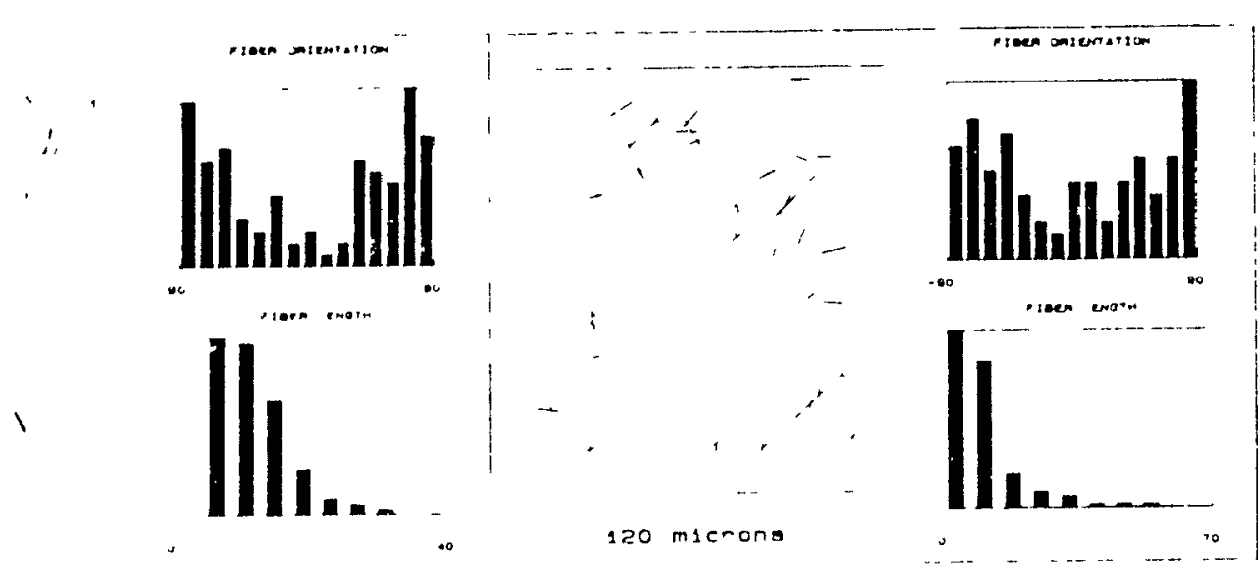

akin

440 mireuns
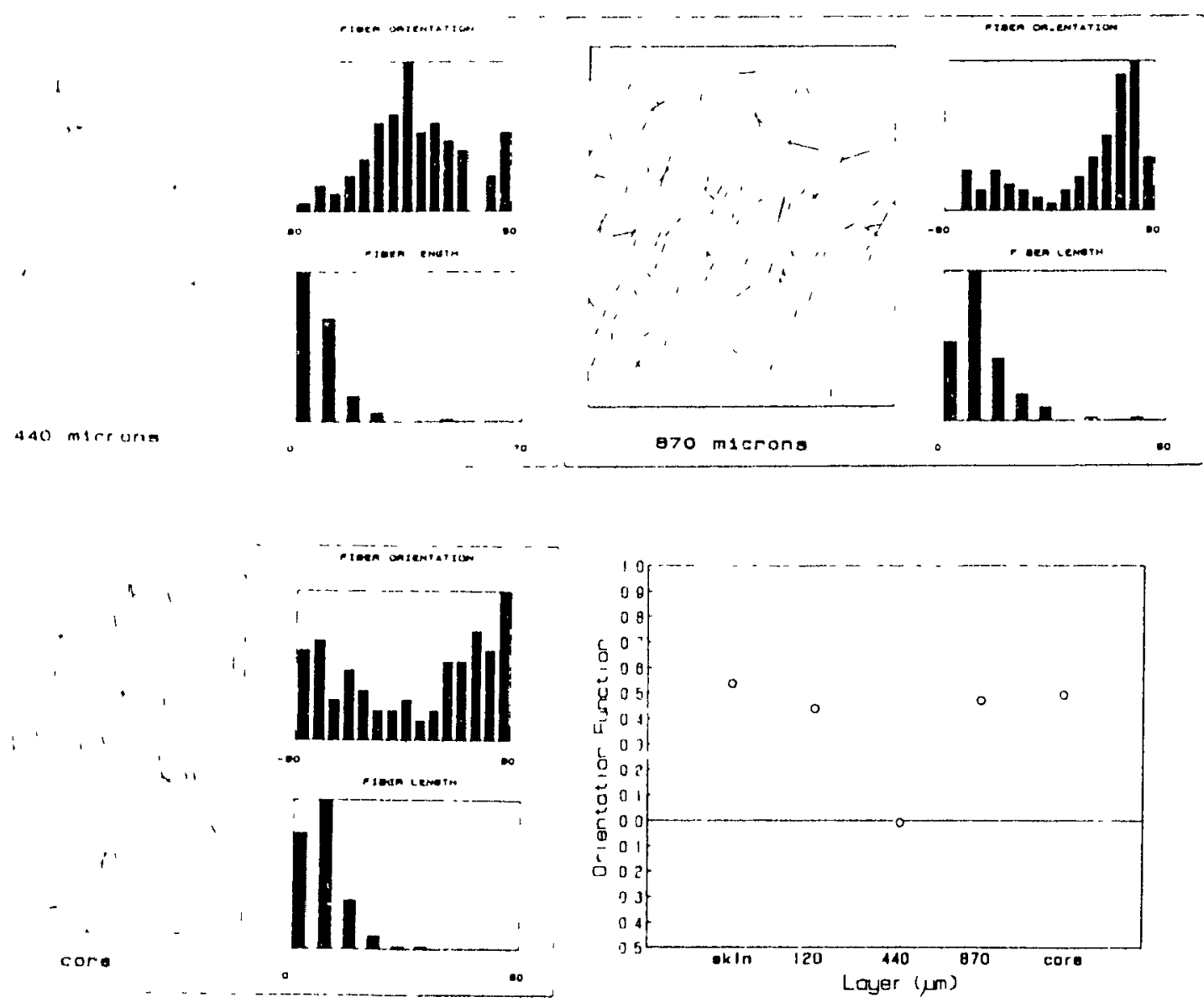

Floure 5.28 .

Orientation and Length Distributions for Random Milling Samples Molded at $263^{\circ} \mathrm{C}$ (Microtome Location 3). 

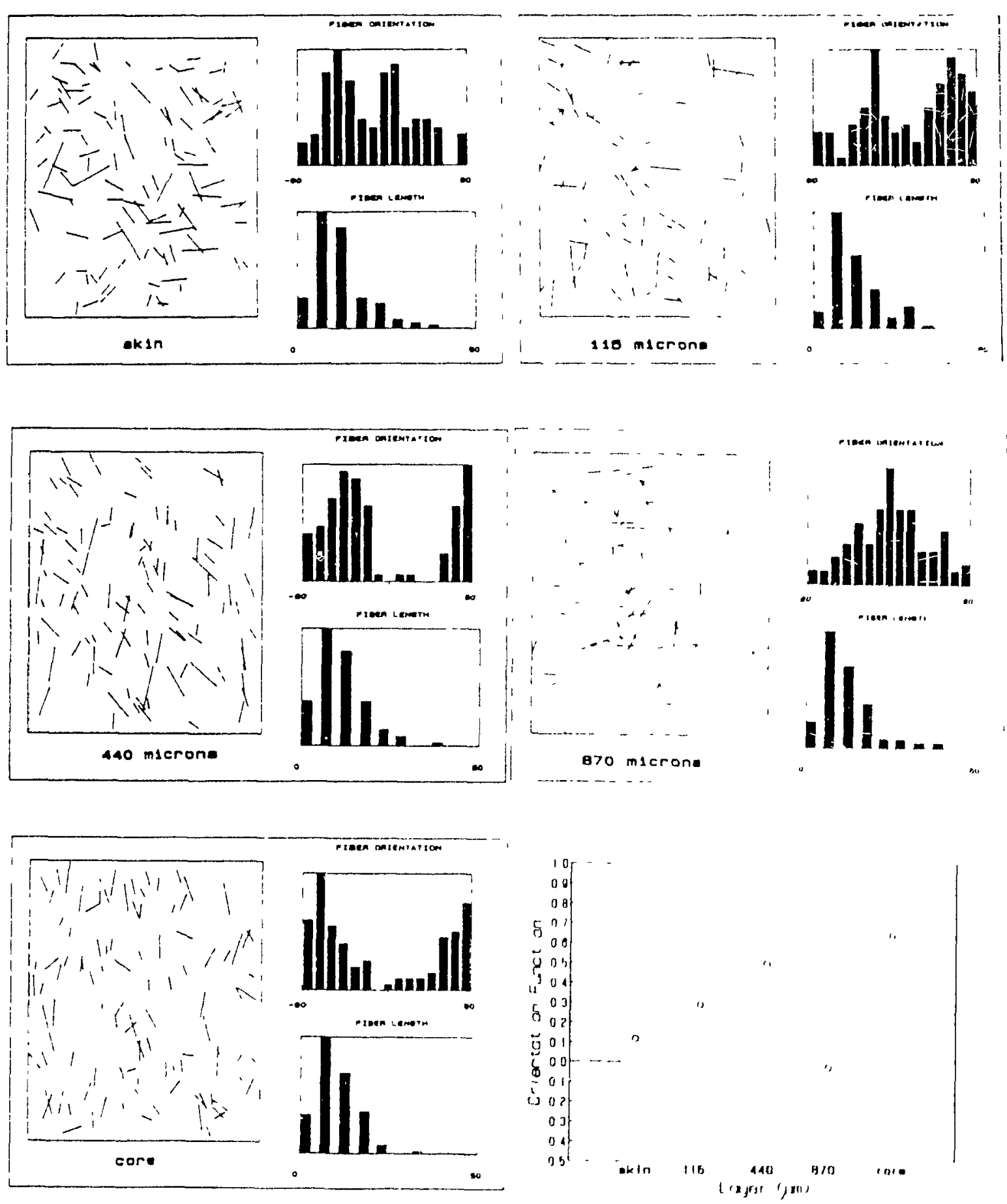

Figure 5.29. Orientation and Length Distributirns; for Random Milling Samples Molded at $153^{\prime} \mathrm{C}$ (Microtome Location 4). 

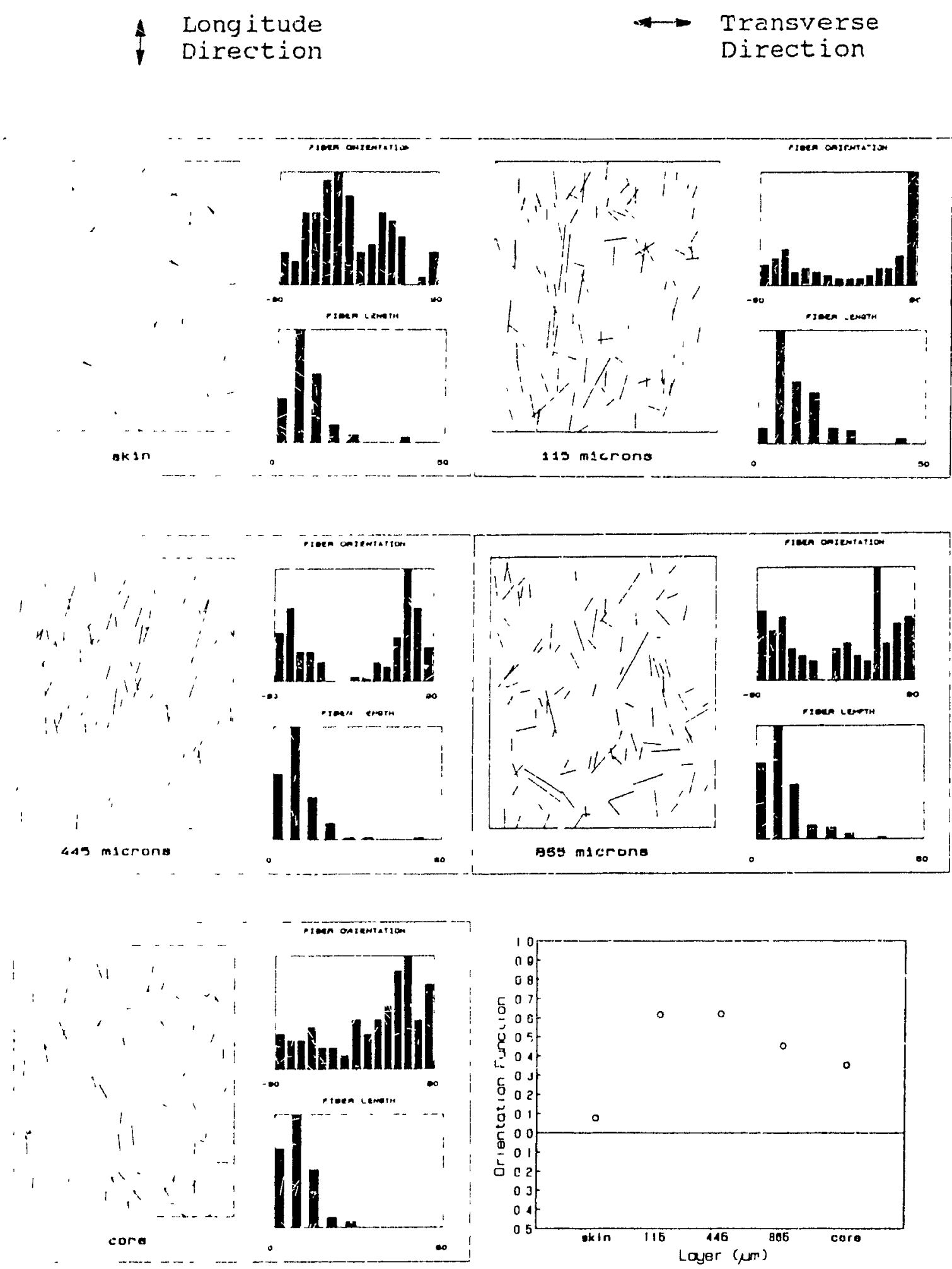

1 iqurs 5.30. Orlentation and Length Distributions for Random Milling Samples Molded at $163^{\circ} \mathrm{C}$ (Microtome Location 5). 


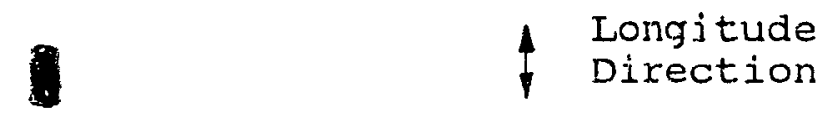

$\begin{aligned}- & \text { Transverse } \\ & \text { Direction }\end{aligned}$
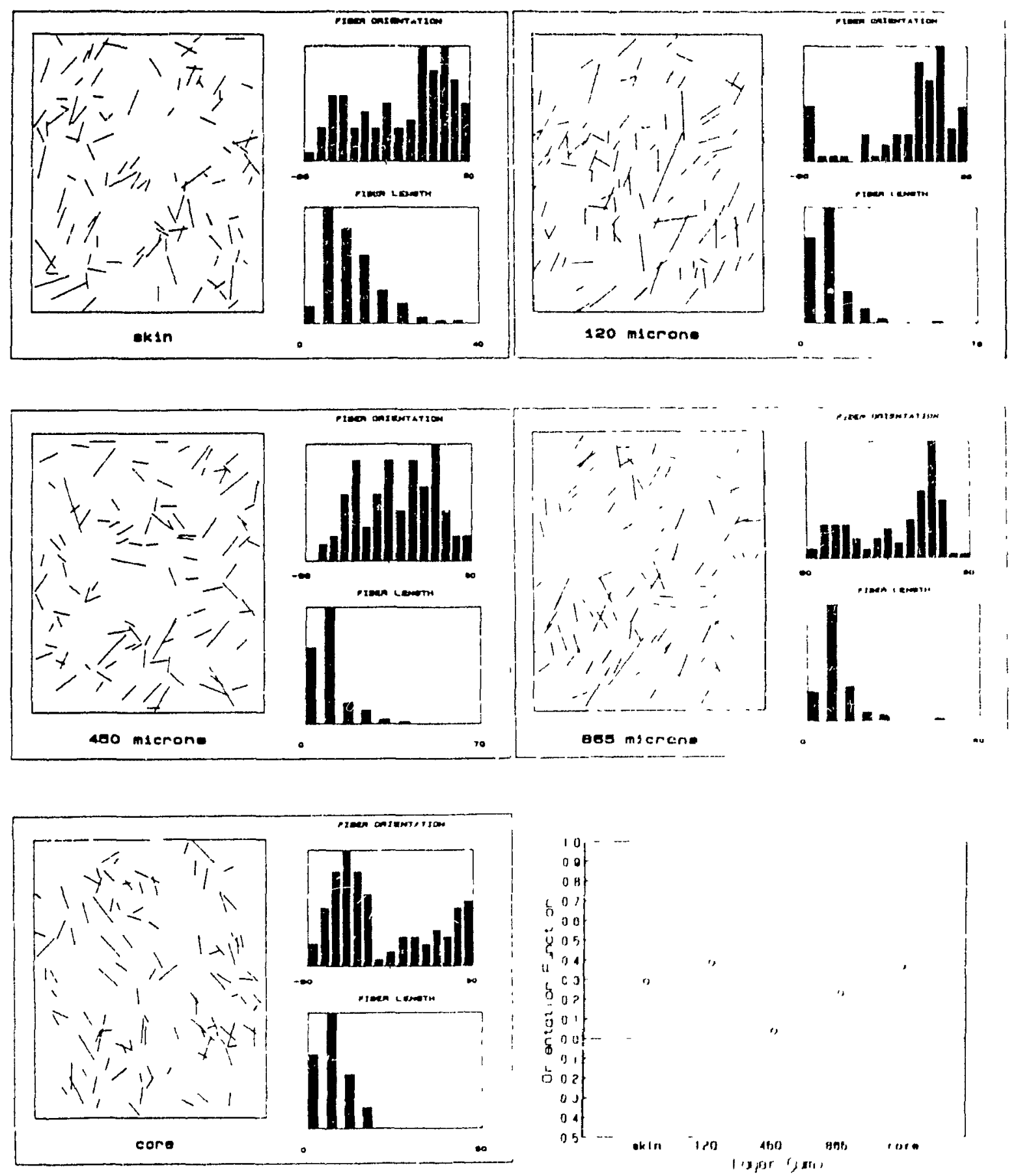

Figure 5.31. Orientation and Length Distributirna, irs Random M1ling samples Molded at $16 \%$ " (Microtome Location 6). 

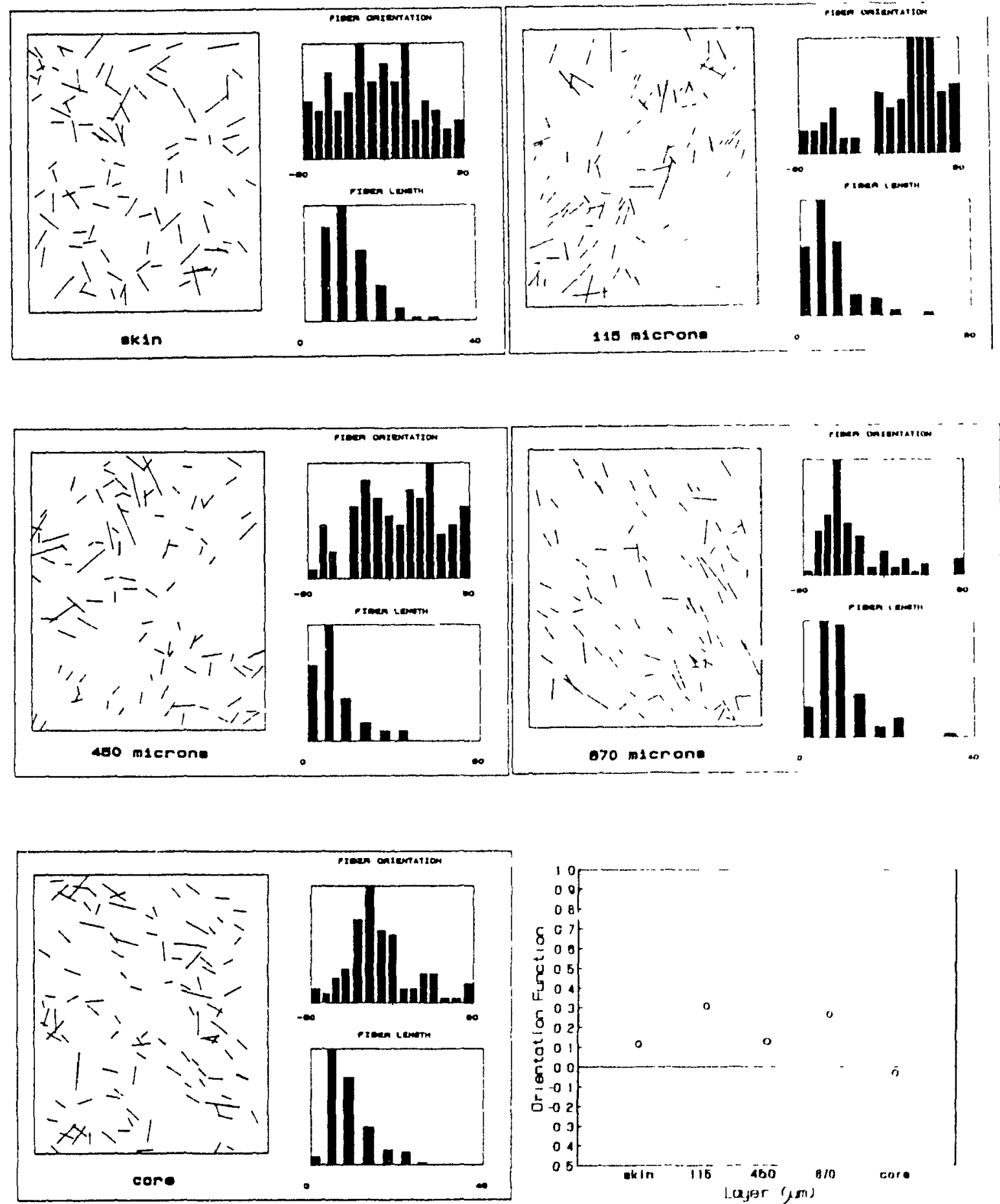
Figure 5.32. Orientation and Length Distributions for
Random Milling Samples lolded at $153 \mathrm{C}$ (Microtome Location 7). 


\subsubsection{Comparison Between Transfer and Compression Molding}

The transfer molded samples exhibited strong anisotropic and non-homogeneous fiber orientation for all sprue designs. The orientation of the fibers in the compression molded samples was dependent on the milling procedure. For samples with "controlled milling", the fiber orientation was longitudinal, anisotropic, but homogeneous. The samples that were randomly milled generally exhibited random, isotropic, and homogeneous flber orientation. The orientation found in the compression molded samples was more consistent from skin to core and from location to location than the orientation in the transfer molded samples. For both molding procedures, an increase in tomperature had little effect on fiber orientation, except at the skin layer. Fiber breakage was substantial for both transfer and compresion molding.

\subsection{Tensile Test Results}

'The results from the tensile testing, which measured tensile strongth, elongation at break, and Young's modulus, are presented in this section. Bartlett's test was used to find a pooled variance for each type of sample, so a single standard deviation is given for each sample and each type of test. 


\subsubsection{Transfer Molded Samples}

The results for the samples molded with converging sprues at a temperature of $163^{\circ} \mathrm{C}$ are presented in Figure 5.33. The observed behavior at $163^{\circ} \mathrm{C}$ indicated that, statistically, there was no difference between tensile strongths: and elongations at break at virtually every location. 'lhe orientation results indicated substantial variation in $\mathrm{t}$ iber orientation from location to location, but this did not result in differences in tensile strength or elongation at brak. This could be due to the very small size of the fibers, specifically after processing, which was shown in the fiber length distributions in the previous section. As woll, the fiber concentration was only $2 \%$ by volume, and may have been too low to cause an appreciable difference between lovation: with different fiber orientations.

The Young's modulus is more sensitive to fiber orientition than tensile strength or elongation at break (18) and did show a statistical variation with test location. The grentest modulus value was seen at tensile location 4 , where the 11 bers are oriented in the test direction (longitudinal 1 iber orientation), and the lowest values occured at locations;, 5, and 6 where the orientation was perpendicular to the direction of test (transverse fiber orientation).

The results for the samples molded with converging sprues at 


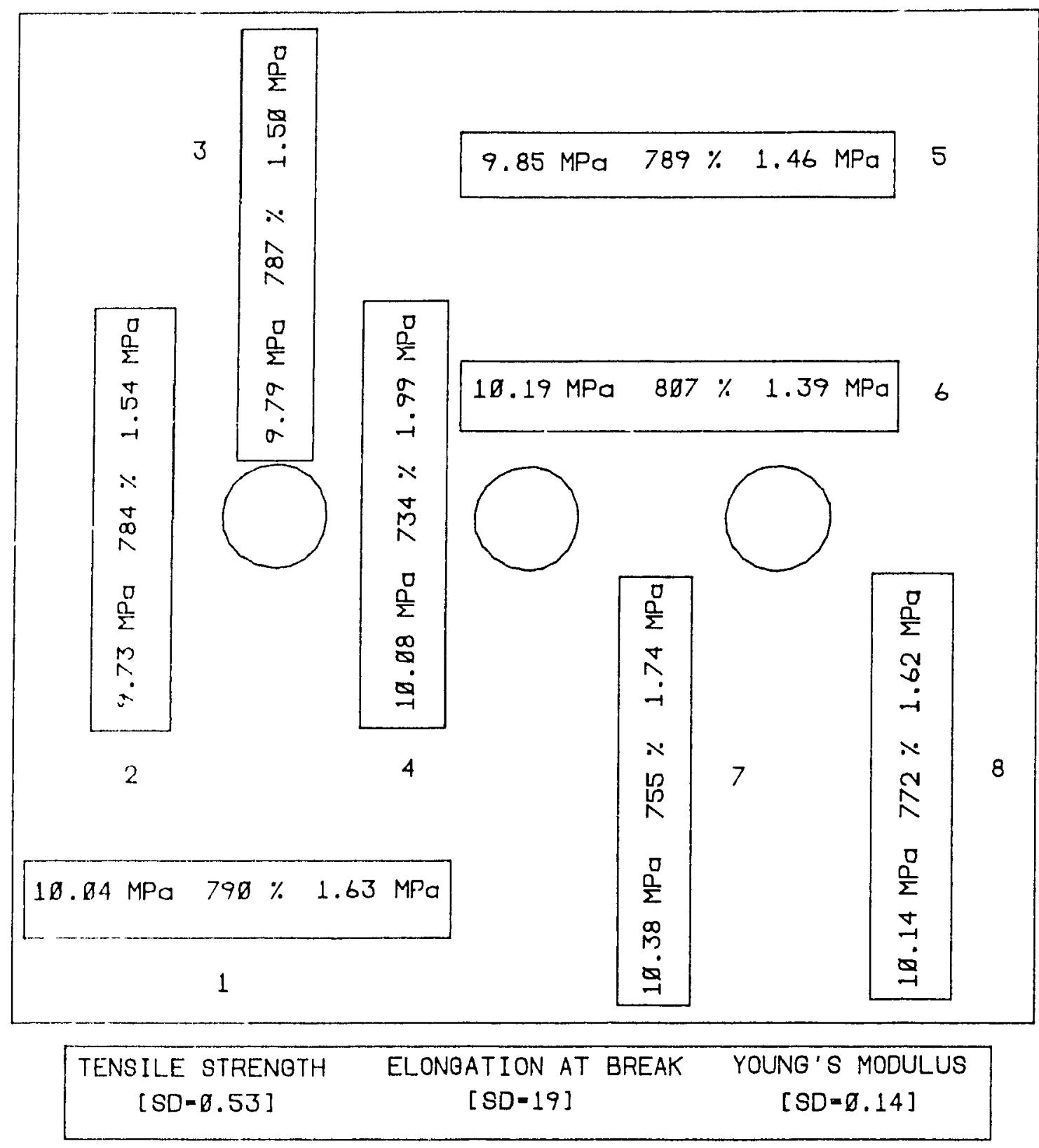

Figure 5.33. Tensile Test Results for samples Molded with Converging Sprues at $163^{\circ} \mathrm{C}$. 
$204^{\circ} \mathrm{C}$ are shown in Figure 5.34. The strength and elongation at break were generally lower than the values at $163^{\prime \prime} \mathrm{C}$. Thi:; was expected since an increase in temperature usually results in a reduction in cross-linking efficiency and a decroase in properties $(17,23)$. The Young's modulus did not chmye significantly and, at some locations, increased slight ly. An increase in anisotropy in the tensile strength and elongatuon at break was found at this temperature.

Figure 5.35 gives the tensile test results for samplos moldoul with straight sprues at $163^{\circ} \mathrm{C}$. The results wero $=1 \mathrm{~m} 1 \mathrm{lu}$ to those found for the samples that were transfor moldud with converging sprues at this temperature. The tensilo strmuth and elongation at break did not vary with lo(mition, (i) the straight sprue had no effect on these tensile propert in... 'Th" Young's modulus did show anisotropy.

An increase in molding temperature to $204^{\text {"C }} \mathrm{did}$ cims." " variation in properties, as shown in Figure 5.36. "There wa'; significant anisotropy in tensile strength, clongation at break, and Young's modulus. The Young's modulus at location 3 was higher than at location 4 , even thourgh the or contution results indicated that the fiber orlentation at locition:; and 4 were transverse and longitudinal, respectively. 'IhI, did not correspond with theory or with the previous results, and this abnormality was not due to a change in firsur orientation. 


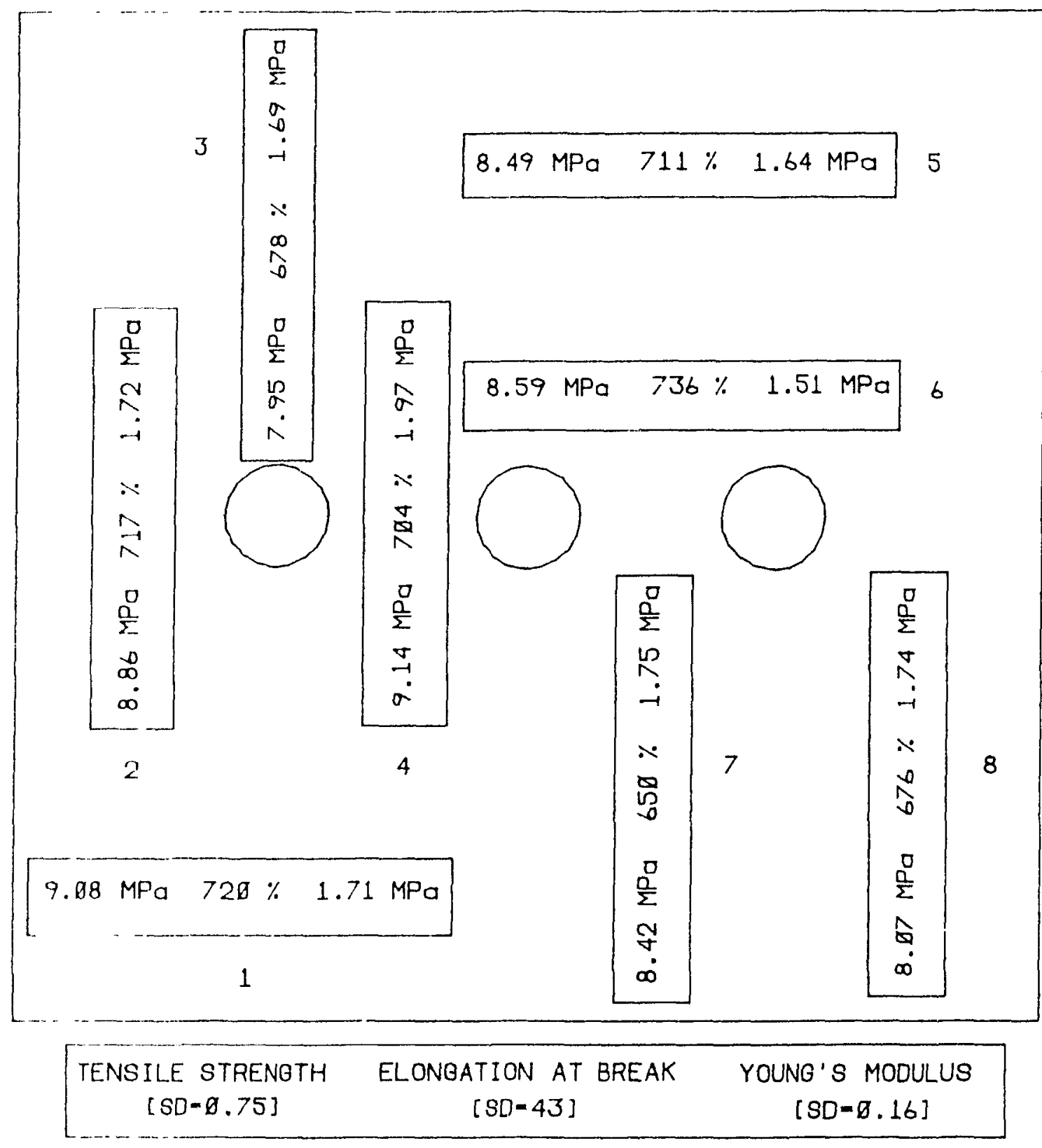

Flgure 5.34. Tensile Test Results for Samples Molded with Converging sprues at $204^{\circ} \mathrm{C}$. 


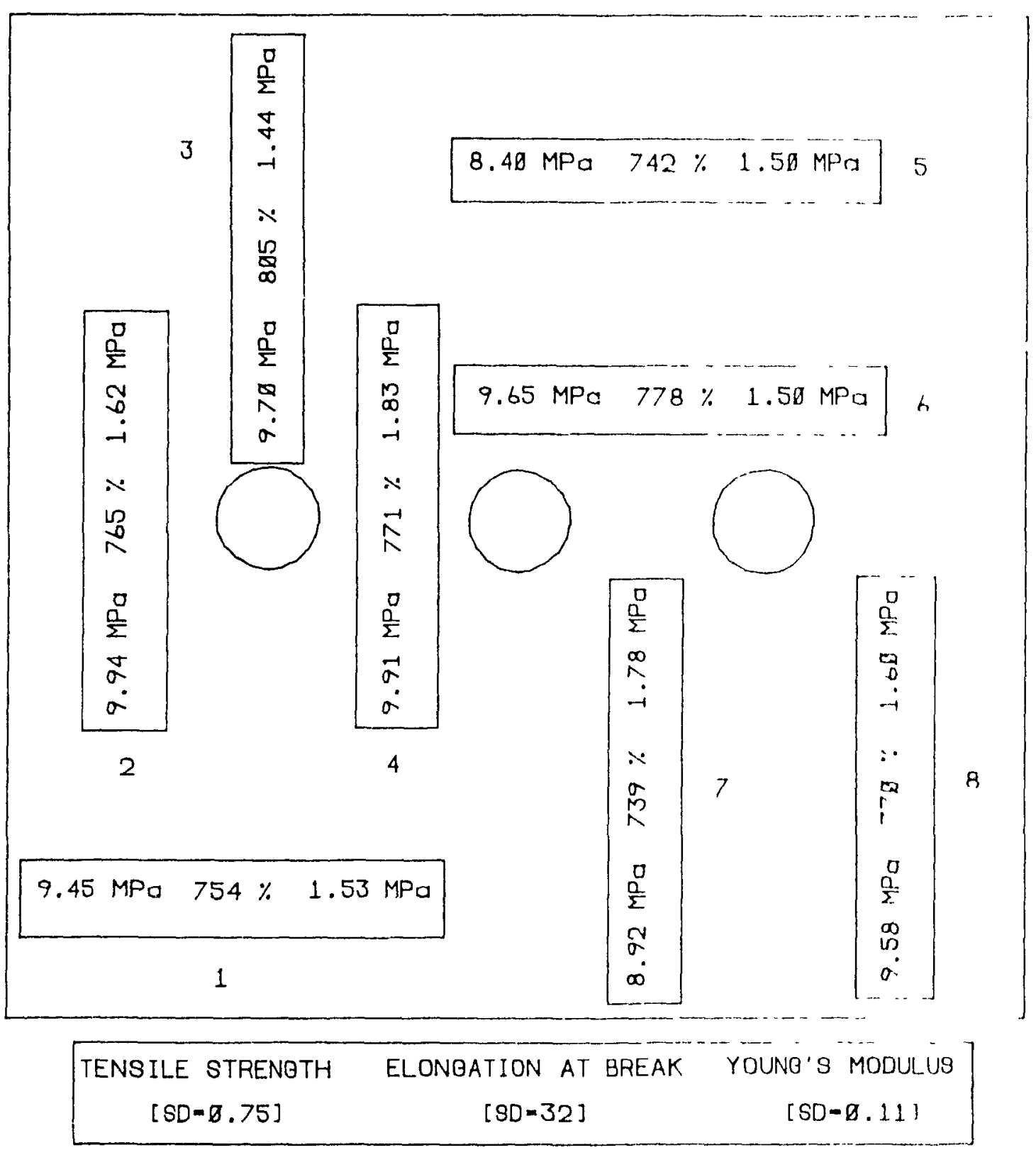

Figure 5.35. Tensile Test Results for Samples l1oldred with straight sprues at $163^{\circ} \mathrm{C}$. 


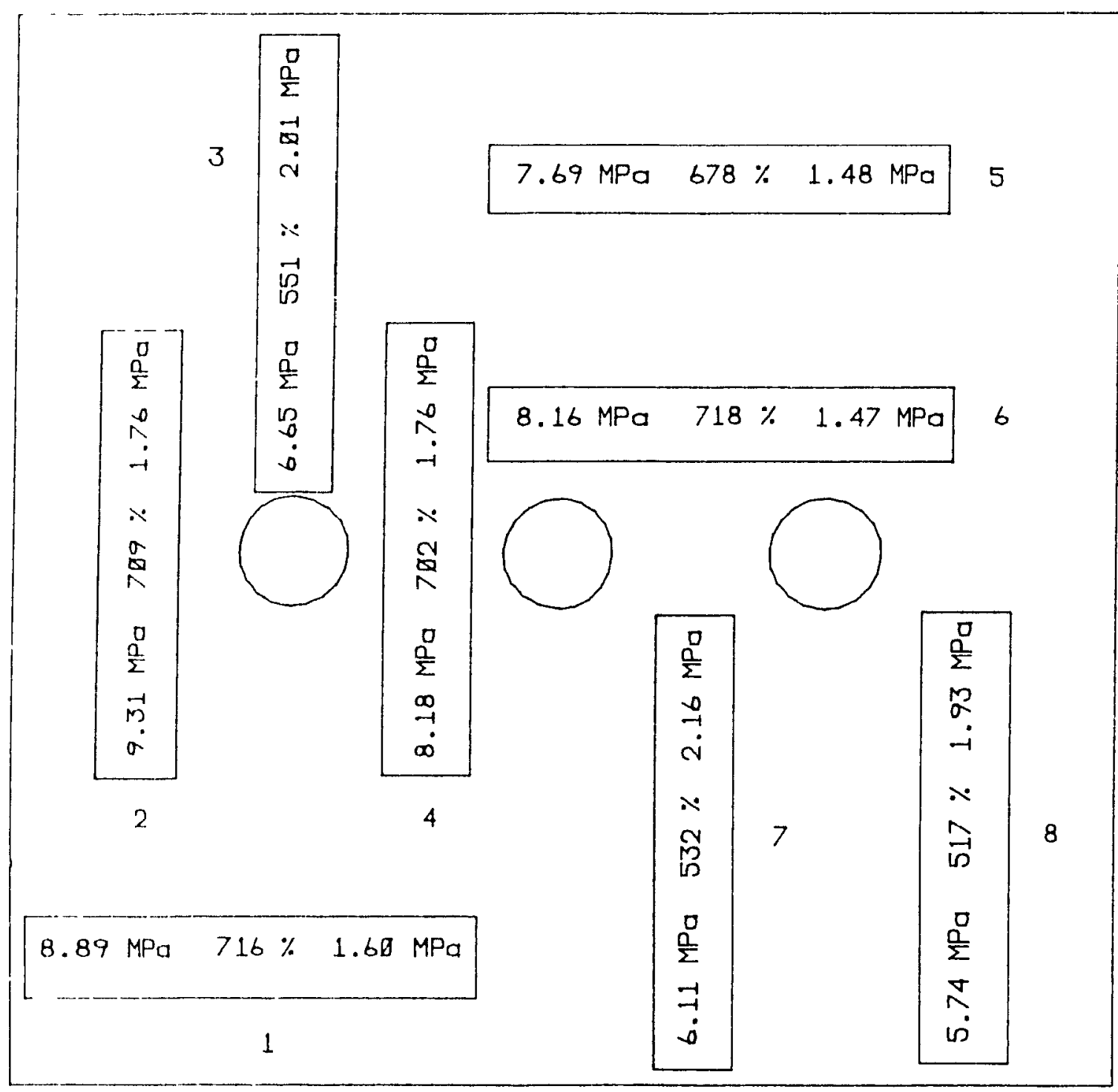

TENSILE STRENOTH ELONGATION AT BREAK YOUNO'S MODULUS $[S D=0.59]$ $[S D-34]$ $[S D=0.10]$

Figure 5.36. Tensile Test Results for Samples Molded with Straight sprues at $204^{\circ} \mathrm{C}$. 
A dynamic mechanical analysis was performed to dotermine whether a difference in curing may have causod the observel behavior in the Young's modulus. Two rectangular sections, one taken from tensile location 3 for a sample molwed at l1.3 and the other from a similar location at $20.4 \mathrm{C}$, wele m.mly.ul. The dynamic mechanical analysis was performod usim thxum of the samples at a strain of 64 microns, puth to mith, frequencies of 1,10 , and $30 \mathrm{~Hz}$, and a houting rite of 1 ${ }^{\circ} \mathrm{C} / \mathrm{min}$. The mechanical loss angle (tan $\delta$ ), itorum molulu: $\left(E^{\prime}\right)$, and loss modulus (E") are shown in Floure: $1,3,1, \ldots 3$, and 5.39, respectively, for the sample molind it $11 ; 1$. Il

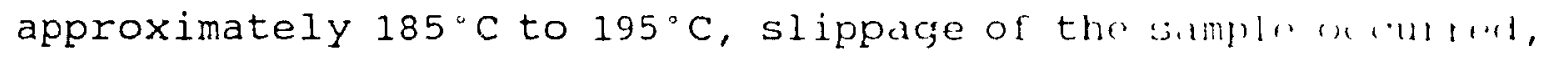
and the data points in this range were omitted. How.vi, 111. Figures indicate that a smooth continuation ot the .ull. appears likely in this area. Figures $5,40,1, \ldots 1$, , ml '...' show these properties for the sample moldred it illi i. Ifl. curves at this temperature are continuous and imoth tim $185^{\circ} \mathrm{C}$ to $195^{\circ} \mathrm{C}$, so it may be presumrel that thl', wa, $11 \cdots+1 h^{\prime}$ case for the sample molded at $163^{\circ} \mathrm{C}$.

The increase in $E^{\prime}$ for both samples at appro\%imitrly :(1)" indicates that neither sample was fully cured it thl. prinl. However, the very large increase in $\tan \delta$ at 200 ' 6 for thu. sample molded at $204^{\circ} \mathrm{C}$ shows that a variation in thr i,t,1, i, cure between the two samples had occurred. T'sn is $1:$ thr. rit. in, of $E^{\prime \prime}$ to $E^{\prime}$, so an increase in tan $\delta$ means athor an in.r..... in $E^{\prime \prime}$ or a decrease in $E^{\prime}$. Since $E^{\prime \prime}$ is the vlocous "usmponrut 
I

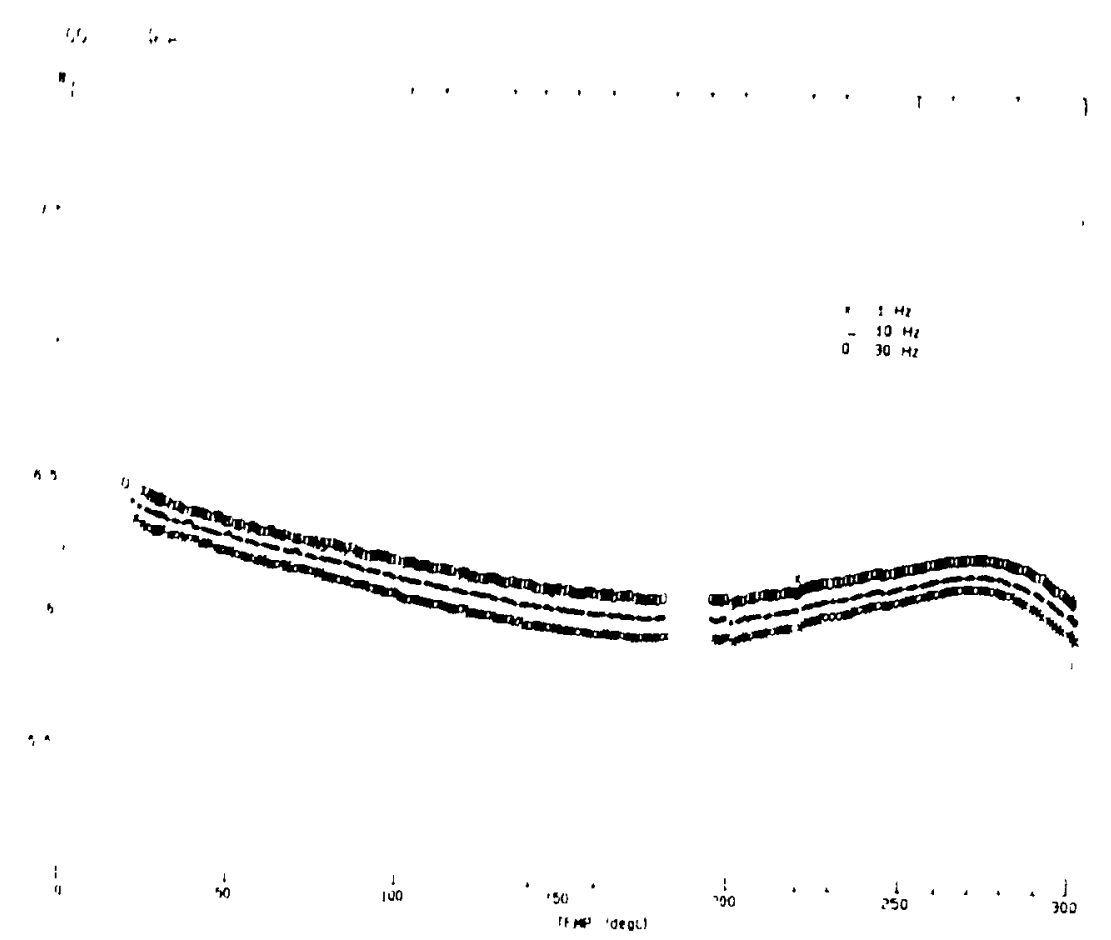

Figure 5.37. E' for Sample Molded at $163^{\circ} \mathrm{C}$.

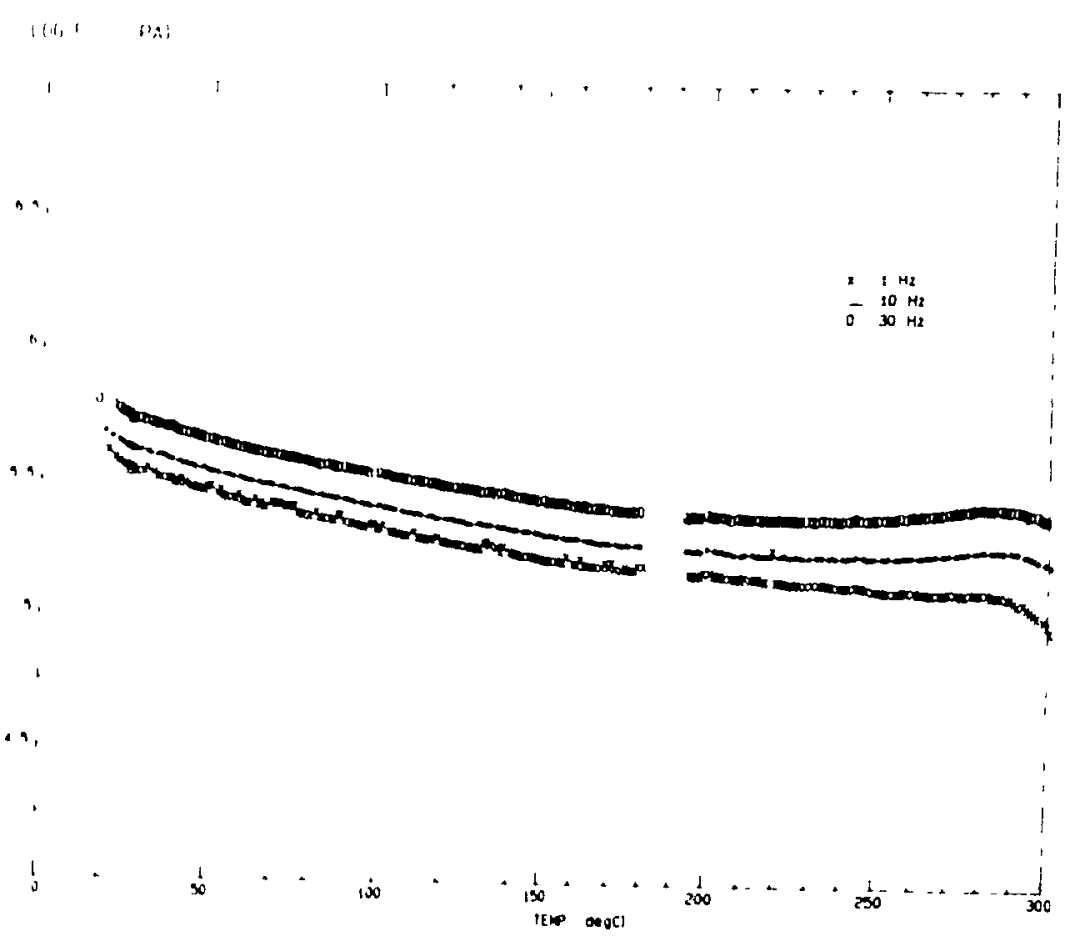

Figure 5.38. E" for Sample Molded at $163^{\circ} \mathrm{C}$. 


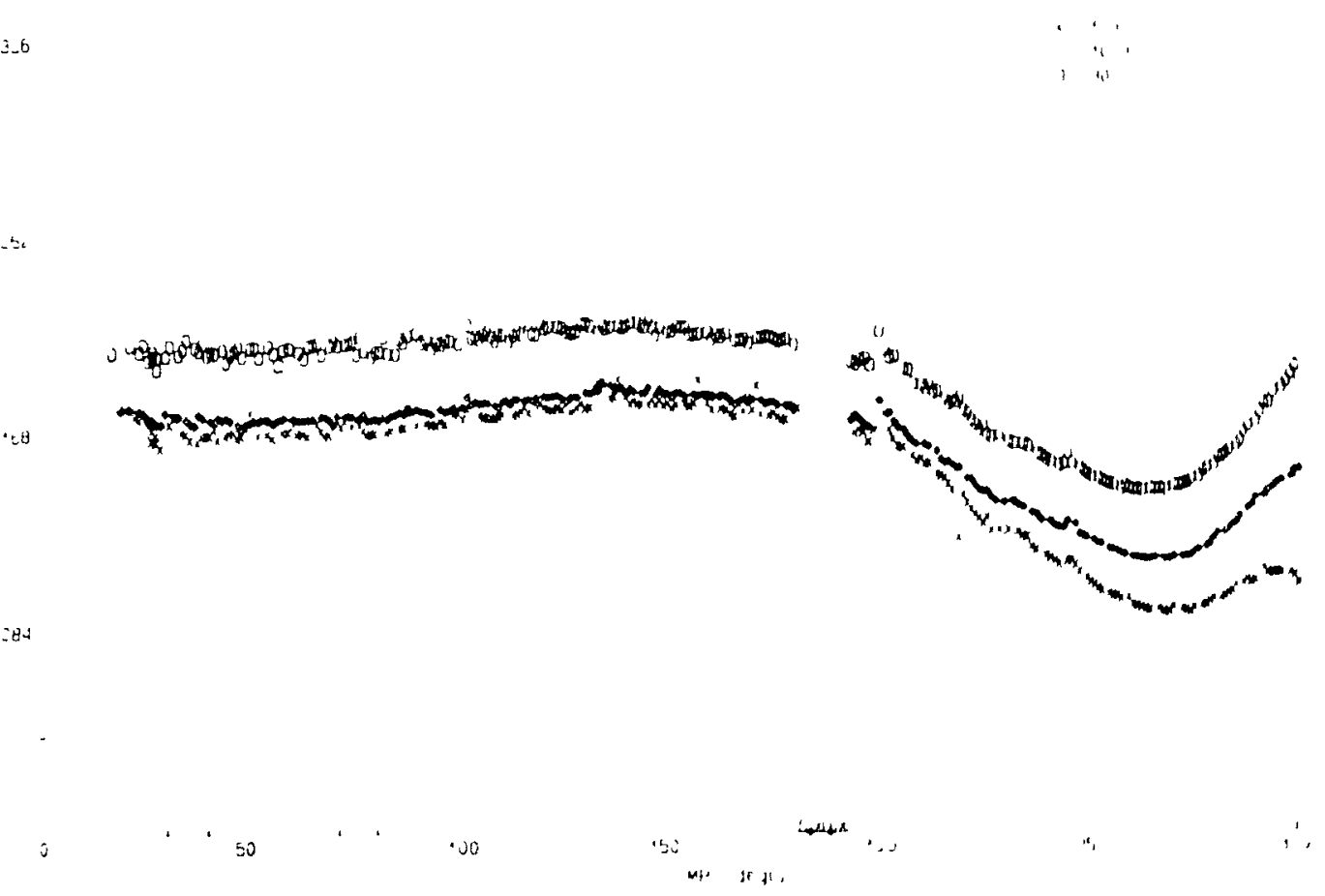

Figure 5.39. Tan $\delta$ for Sample Molded at $163^{\circ} \mathrm{C}$. 


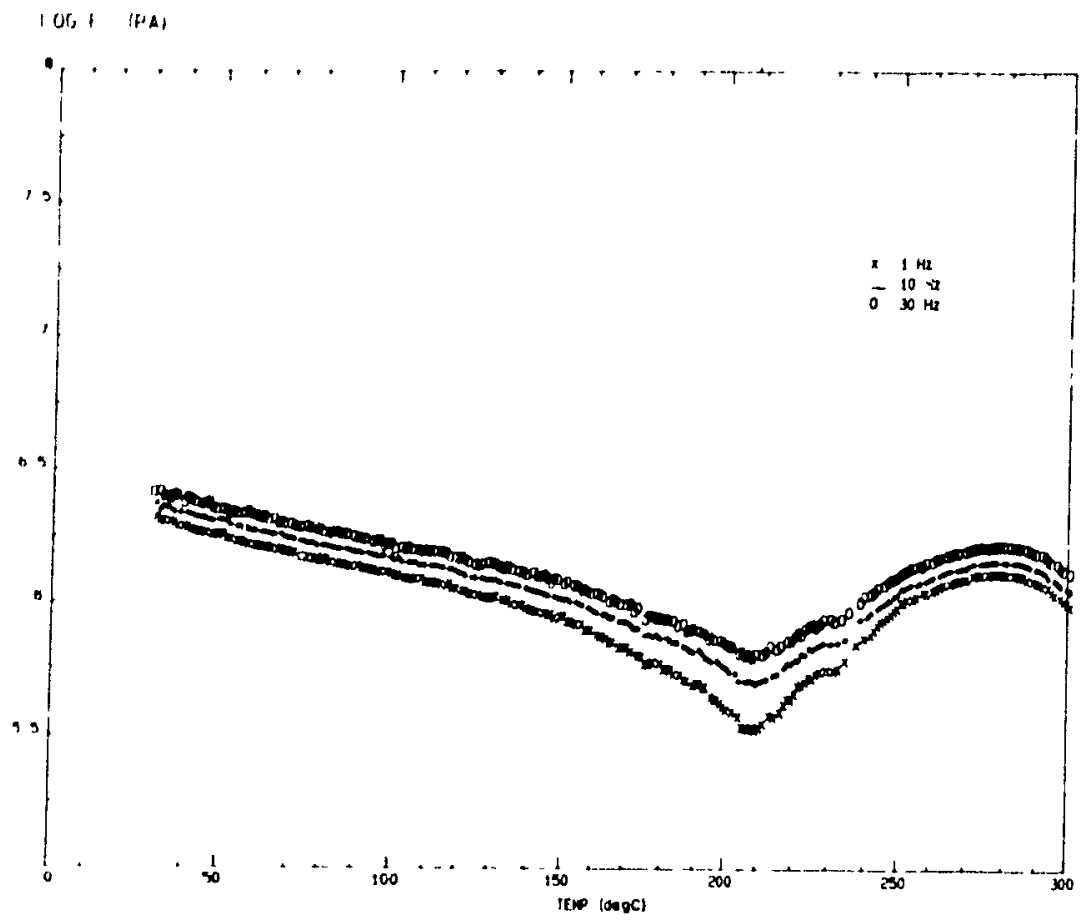

Elqure 5.40. E' for Sample Molded at $204^{\circ} \mathrm{C}$.

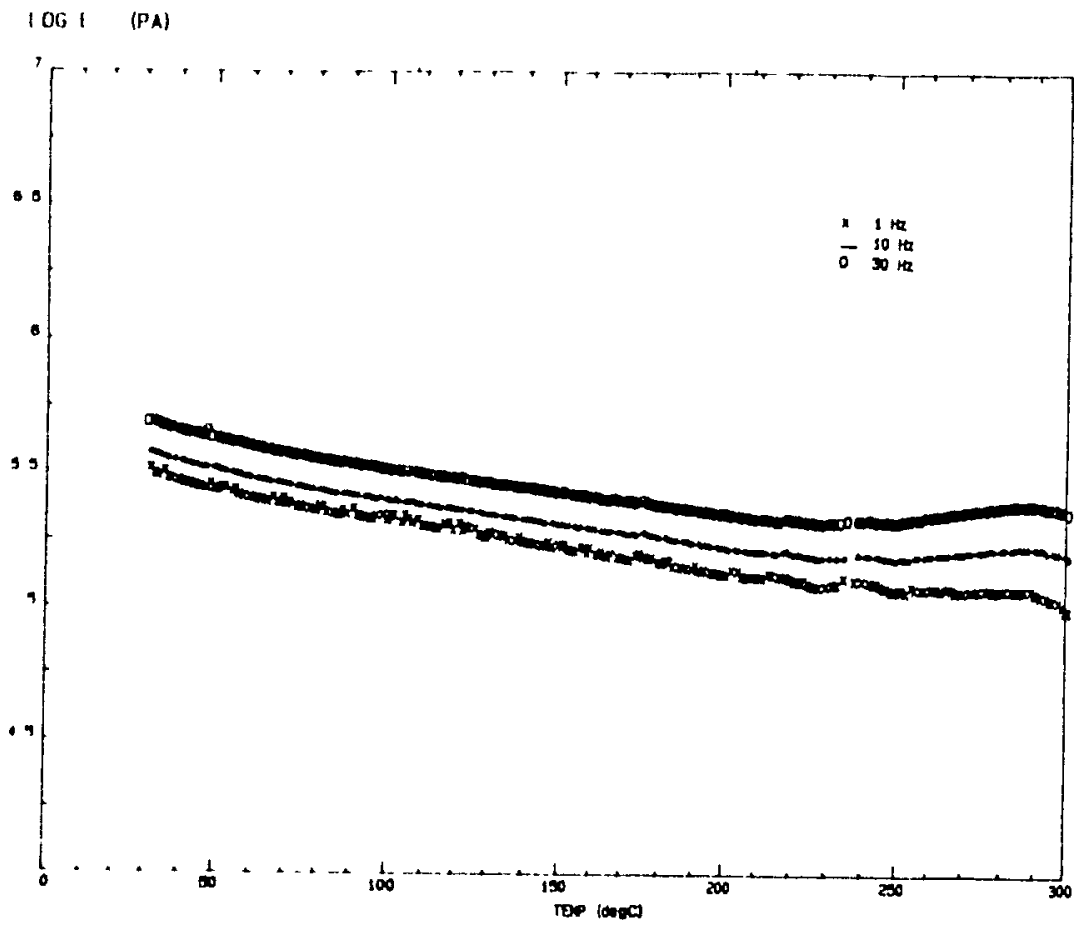

Figure 5.41. E" for Sample Molded at $204^{\circ} \mathrm{C}$. 


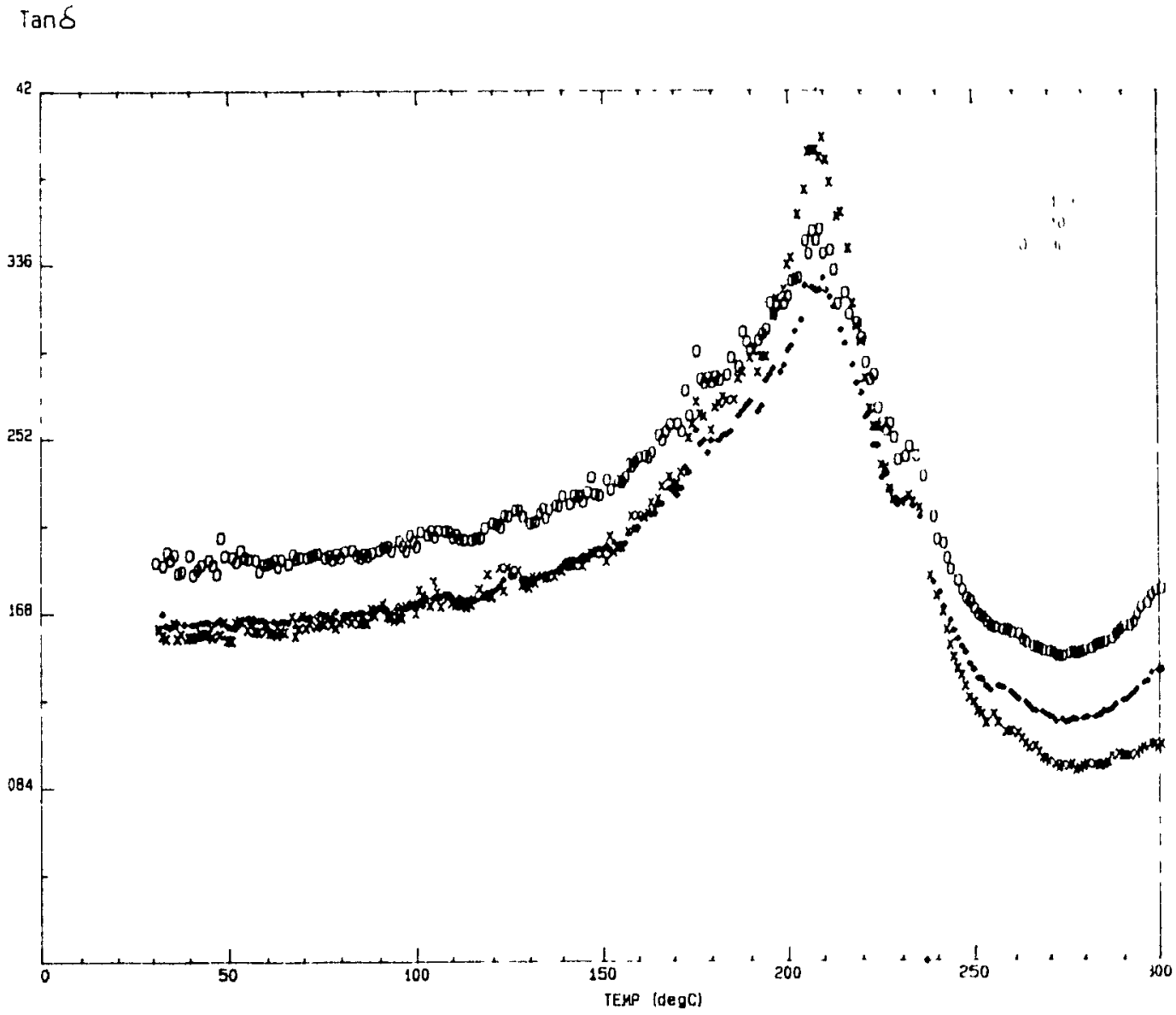

Figure 5.42. Tan $\delta$ for Sample Molded at $204 \mathrm{C}$. 
and $E^{\prime}$ is the elastic component, the increase in $\tan \delta$ at $204^{\circ} \mathrm{C}$ indicates that the composite is less elastic. Premature vulcanization, or scorch, is a likely possibility since a scorched sample exhibits poor elasticity, decreased elongation and strength, and increased stiffness. These are all seen for the sample moided at $204^{\circ} \mathrm{C}$ at location 3 , as well as locations 7 and 8 . This suggests that the temperature was not constant throughout the mold.

\subsubsection{Compression Molded Samples}

I'he samples that underwent "controlled milling" exhibited homgeneous tensile properties. This is shown in Figure 5.43 for a molding temperature of $163^{\circ} \mathrm{C}$. There was no statistical variation from location to location for strength, elongation at break, or Young's modulus. This isotropy was also seen at $204^{\circ} \mathrm{C}$, as shown in Figure 5.44. An increase in mold tomperature caused a decrease in tensile strength and elongation at break, but did not significantly effect the Young's modulus.

Figure 5.45 presents the tensile results for samples that underwent "random milling" and were molded at $163^{\circ} \mathrm{C}$. No statistical variation of properties occurred between locations.

The sanples that were milled using the "controlled milling" 


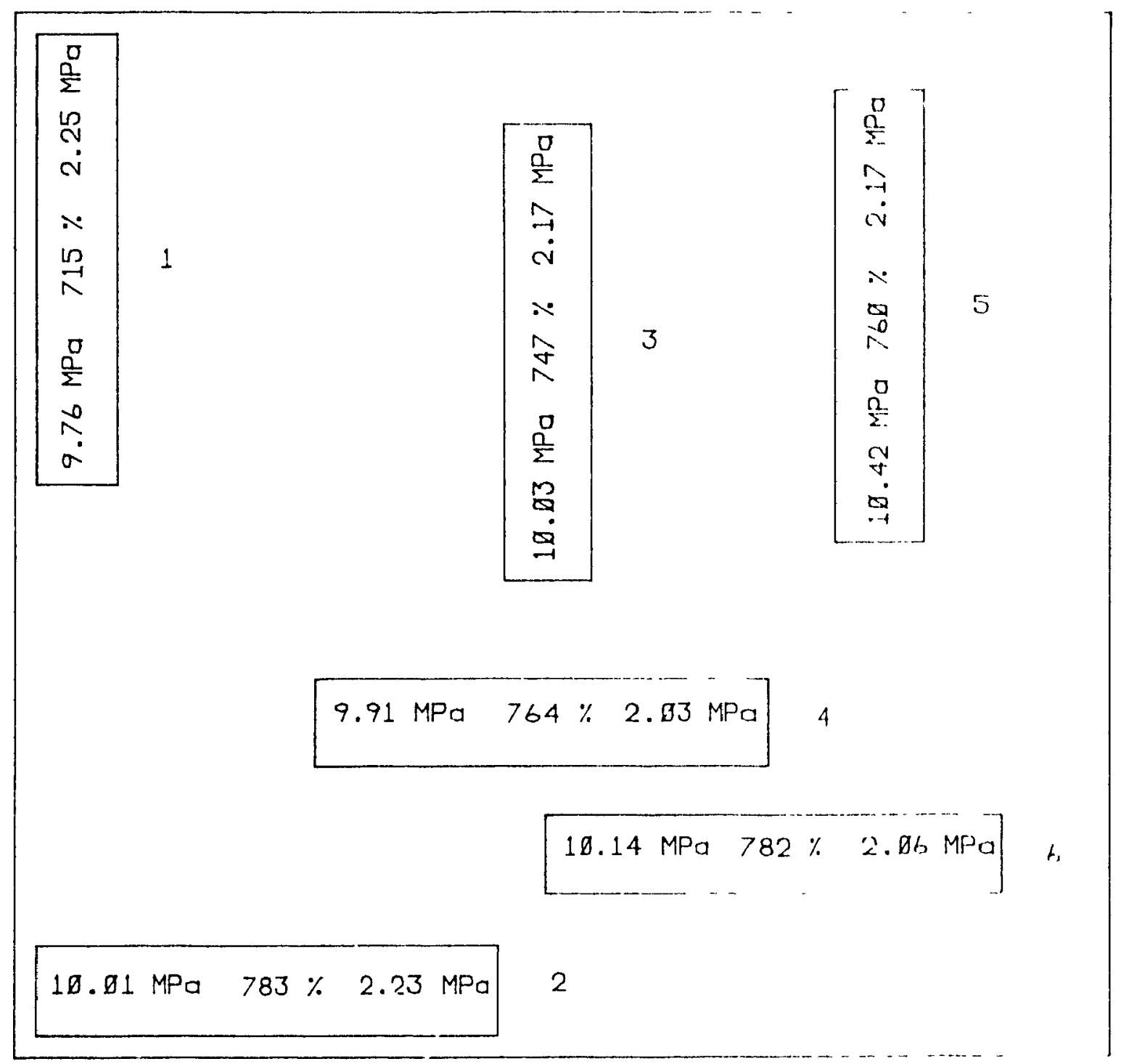

$\left.\begin{array}{ccc}\begin{array}{c}\text { TENSILE STRENGTH } \\ {[S D=0.47]}\end{array} & \begin{array}{c}\text { ELONGATION AT BREAK } \\ {[S D=30]}\end{array} & \text { YOUNG'S MDDULU: } \\ {[S D-0.15]}\end{array}\right]$

Figure 5.43. Tensile Test Results for Controlled Millinr Samples Molded at $163^{\circ} \mathrm{C}$. 


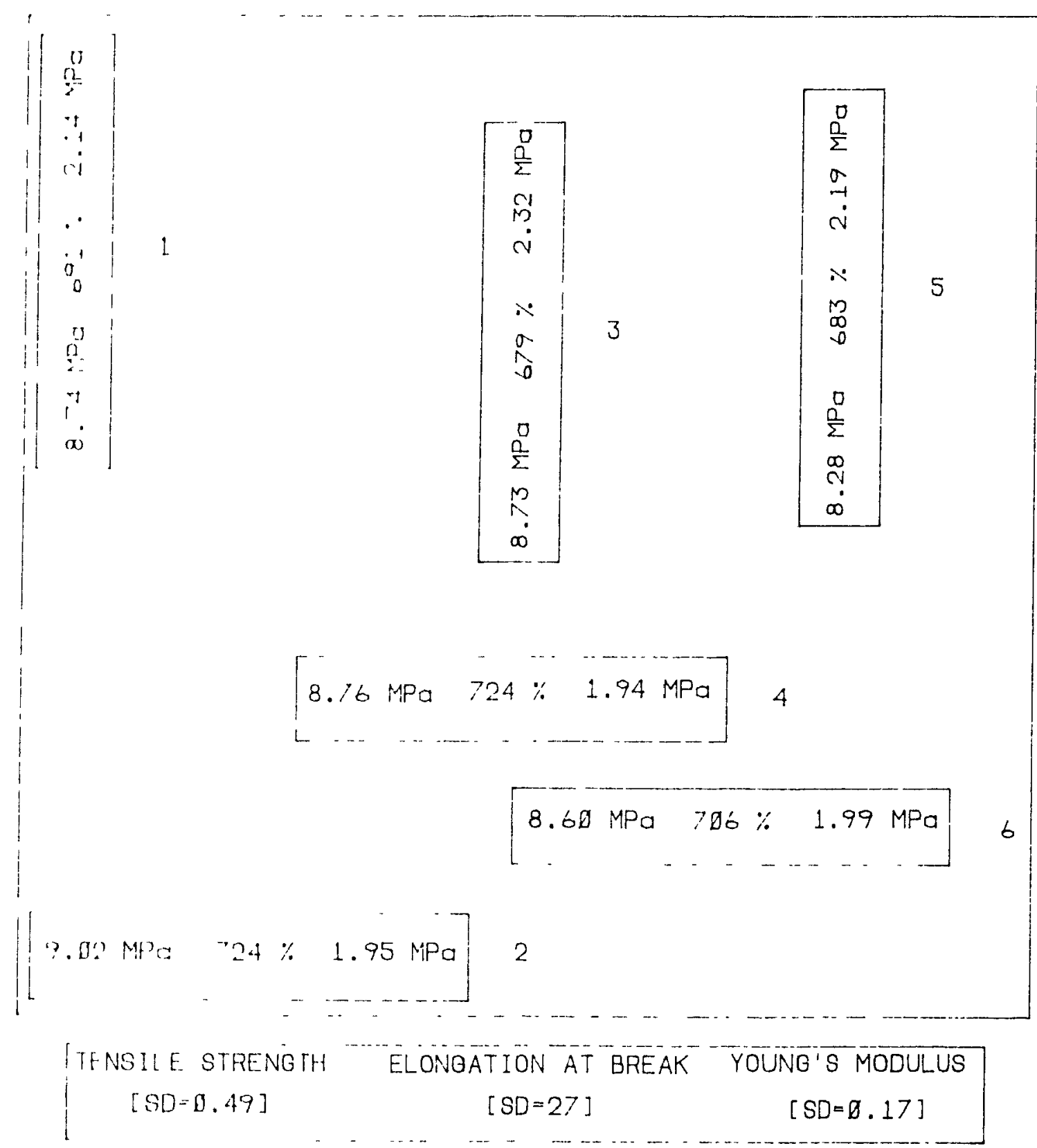

Figure 5.44. Tensile Test Results for Controlled Milling Samples Molded at $204^{\circ} \mathrm{C}$. 


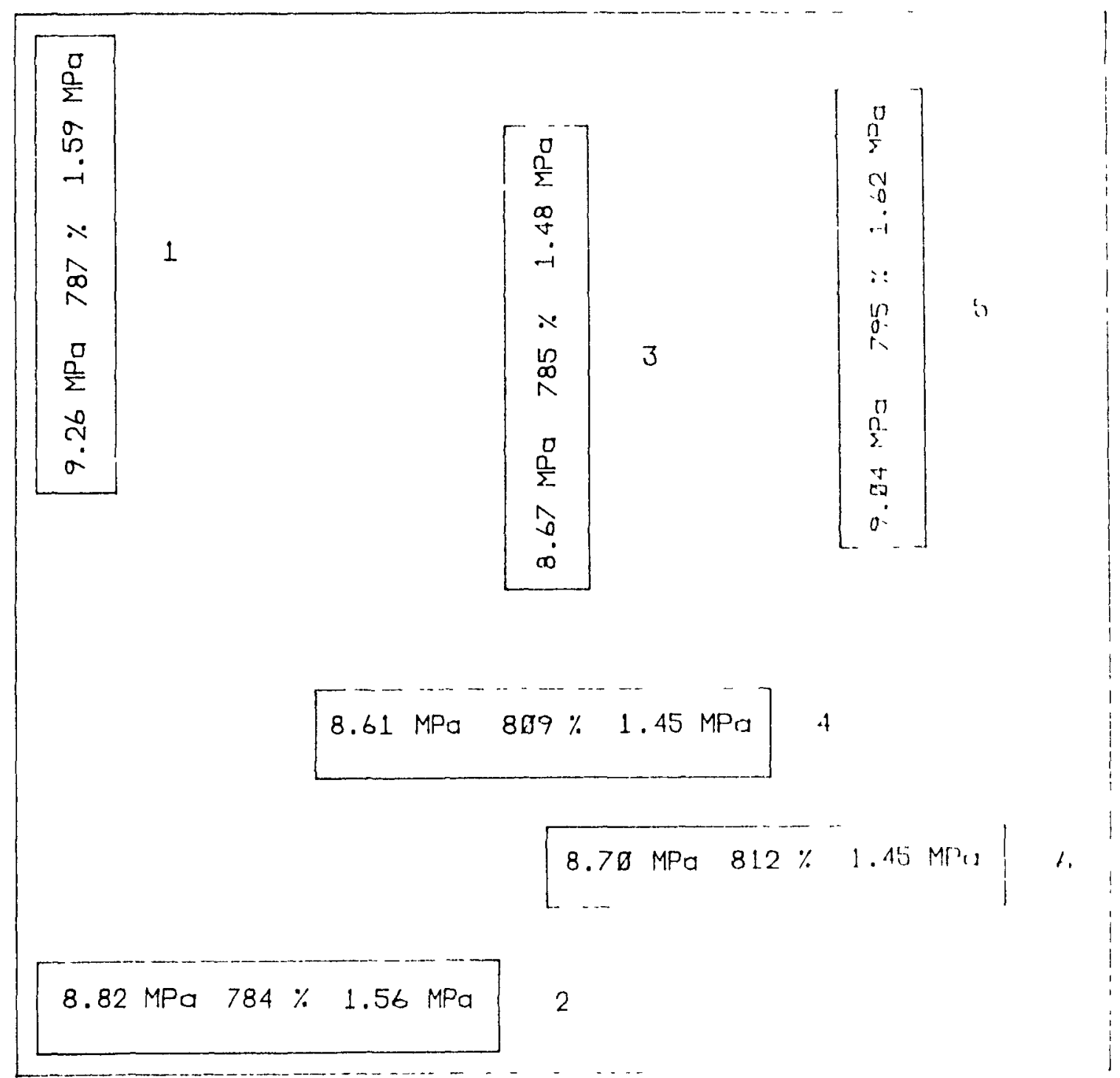

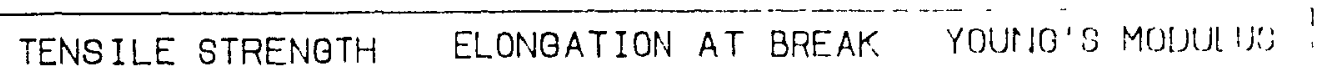
$[S D=0.66] \quad[S D=21]$

$[S 0=0.07]$

Figure 5.45. Tensile Test Results for Random Milling Samples Molded at $163^{\circ} \mathrm{C}$. 
technique had greater tensile strength and Young's modulus than those that were randomly milled. The tensile strength and Young's modulus attain their highest values when the libers are oriented longitudinally, and the "controlled milling" process caused longitudinal fiber orientation. The elongation at break was not strongly affected by the milling procedure. These observations were seen at both molding temperatures.

\subsubsection{Comparison Between Transfer and Compression Molding}

'Ihe tensile strength and elongation at break were generally slmilar for all transfer molded samples and the compression molded samples with "controlled milling", at a molding temperature of $163^{\circ} \mathrm{C}$. The Young's modulus was greater for the compression molded samples with "controlled milling", even when compared to the transfer molded locations with strong longltudinal orientation. The orientation results showed that the compression molded samples had a more uniform orientation from skin to core than the transfer molded samples. As well, the orientation in the compression molded samples with "controlled milling" was more homogeneous over the entire sample, whereas the orientation in the transfer molded plaques varied considerably throughout the sample. Therefore, the orlentation was much more likely to be consistent from one end of the tensile test specimen to the other in the compression molded samples, and, for the samples with 
"controlled milling", this orientation was longitudinal. 'Tho compression molded samples with "random milling" had modulus: values similar to those found in the transfer molded locations: with transverse fiber orientation. At $204^{\prime \prime} \mathrm{C}$, the tronds wore similar.

It is expected that the anisotropy in mechanical proportic:; would be greater for transfer molded samples than compression molded samples due to the strong flow in the transter moldiny process. A means of determining anisotropy is by comparing the longitudinal and transverse moduli within a sampl" (?). The ratio of the longitudinal Young's modulu, to the transverse Young's modulus gives the anisotropy rit 10.

Anisotropy ratios for compression and transfor molded :inmpl.... were determined. For the compression molded sinmplri, locations 1 and 2 were compared, as they are perpondululur tr, each other, as are locations 3 and 4 , and 5 and 6 . Fur thu: transfer molded samples, the fiber orientation result: wre used to determine the locations with longitudinal oricntation (tensile specimens 4 and 7) and transverse orientation (tensile specimens 3, 5, and 6). These were then comparud to each other. For both types of moldings, an overall avrerargr was found. The results are presented in Table 5.].

The average ratios indicate that the anisotropy is grenter for the transfer molded samples, as expected. It should be 
Table 5.1. Anisotropy Ratios for Molded Samples.

Compression Molded Samples

\begin{tabular}{|l|c|c|c|c|}
\hline Condition & $1 / 2$ & $3 / 4$ & $5 / 6$ & Average \\
\hline $\begin{array}{c}\text { Controlled Milling, } \\
163^{\circ} \mathrm{C}\end{array}$ & 1.01 & 1.07 & 1.05 & 1.04 \\
\hline $\begin{array}{c}\text { Controlled Milling, } \\
204^{\circ} \mathrm{C}\end{array}$ & 1.10 & 1.20 & 1.10 & 1.13 \\
\hline $\begin{array}{c}\text { Random Milling, } \\
163^{\circ} \mathrm{C}\end{array}$ & 1.01 & 1.07 & 1.12 & 1.05 \\
\hline $\begin{array}{c}\text { Rundom Milling, } \\
204^{\circ} \mathrm{C}\end{array}$ & 1.02 & 1.06 & 0.95 & 1.01 \\
\hline
\end{tabular}

\section{Transfer Molded Samples}

\begin{tabular}{|c|c|c|c|c|}
\hline $\begin{array}{c}\text { Condition } \\
\text { Converging sprues, } \\
163^{\prime} \mathrm{C}\end{array}$ & $4 / 3$ & $7 / 5$ & $4 / 6$ & Average \\
\hline $\begin{array}{c}\text { Converging sprues, } \\
204^{\prime \prime C}\end{array}$ & 1.17 & 1.07 & 1.20 & 1.15 \\
\hline $\begin{array}{c}\text { Diverging sprues, } \\
163^{\circ} \mathrm{C}\end{array}$ & 1.28 & 1.05 & 1.30 & 1.21 \\
\hline $\begin{array}{c}\text { Diverging sprues, } \\
204^{\circ} \mathrm{C}\end{array}$ & 1.12 & 1.21 & 1.14 & 1.16 \\
\hline $\begin{array}{c}\text { straight sprues, } \\
163^{\circ} \mathrm{C}\end{array}$ & 1.27 & 1.19 & 1.22 & 1.23 \\
\hline $\begin{array}{c}\text { straight sprues, } \\
204^{\circ} \mathrm{C}\end{array}$ & 0.88 & 1.46 & 1.20 & 1.18 \\
\hline
\end{tabular}


noted that while anisotropy did exist in the Young's moduli for the transfer molded samples, it was not substantial, especially when compared to short fiber reinforced composites, as shown in Table 1.2.

5.2.4. Comparison Between Experimental Data and 'Ihwul ot 14.11 Predictions

The Halpin-Tsai equations are commonly used to prollit the Young's modulus in the longitudinal and transveras diret ions. for different types of reinforcement. Table '..' llvw; th. Halpin-Tsai predictions for Young's modulus tor cont mumu. cords, particulate fillers, and short flber:i, usmu 1 lu. parameters found in the tested composite. I'h" "quntum numbers correspond to those found in the Literiture lindw (Chapter 3). The predictions are then compared to thw villu... obtained for the samples that were transfer mulum mull converging sprues at $163^{\circ} \mathrm{C}$.

The results indicate that none of the equation:; drrefurtuly predicted the Young's modulus. As expected, the chort i ibrr prediction is the best, but it still is not accuratr. 'lh. assumptions made in the equation are that the fituers ar: M:11 oriented in the test direction, have a uniform longth, "rr. regularly spaced, and are well bonded. In the composite, miny of these criteria are not met. However, this mould trend to cause the predicted result to be greater than the reperimential 
Table 5.2. Comparison Between Halpin-Tsai Modulus Predictions and Experimental Values.

\begin{tabular}{|l|c|c|c|}
\hline \multicolumn{1}{|c|}{ Reinforcement. } & $\begin{array}{c}\text { Fiber } \\
\text { Orientation }\end{array}$ & $\begin{array}{c}\text { Equation } \\
\text { Number* }\end{array}$ & $\begin{array}{c}\text { Modulus } \\
\text { (MPa) }\end{array}$ \\
\hline $\begin{array}{l}\text { Continuous cord } \\
\text { (Calculated) }\end{array}$ & $\mathrm{L}$ & 1 & 3580 \\
Particulate filler & $\mathrm{T}$ & 2 & 0.88 \\
(Calculated) & - & 3 & 0.88 \\
Short Fiber & & & \\
(Calculated) & $\mathrm{L}$ & 4 & 1.05 \\
Franklin Fiber $\star$ & $\mathrm{T}$ & 5 & 0.88 \\
(Experimental) & $\mathrm{L}$ & - & 1.99 \\
\end{tabular}

$I_{1}=$ Longltude direction

'I' = 'Trinsiverse direction

* Refers to the numbers given the equations in the I, terature Review (Chapter 3).

* Values taken from transfer molded samples (converging sprues, $163^{\circ} \mathrm{C}$, tensile locations 4 and 3 , respectively).

The following values were used in the equations:

$\mathrm{F}_{1}-1.79 \times 10^{\circ} \mathrm{MPa}$

$\mathrm{F}_{11}=0.83 \mathrm{MPa}$

$\phi_{1}=-0.02$

$\phi_{11}:=0.98$

$\mathrm{L} / \mathrm{D}=0$ (after molding) 
value, instead of the opposite. The most likely reason that the theory does not accurately predict the modulus is the nature of the whisker reinforcement. Whaskers have superior strength properties, so that even a low volume iruction ot fibers will still cause substantial modulus improvement. With short fibers, a much higher volume fraction is nooded, so the equation underpredicts the modulus at the low liner. concentration used in this project. Therefore, a molltim equation which would take into account the special propertal; of the whiskers would produce a more realistic probletion.

The Young's modulus of a sample with a known tibor of lentat un between 0 and $90^{\circ}$ may be predicted by use of liquat 1 on (1). This equation was used to predict the Young's; modulus; of a transfer molded tensile specimen with a core or lentat 1 on uml" of $-54^{\circ}$ and $a$ of $36^{\circ}$, where $\theta$ is the difference betworn thr angle of the fibers and $90^{\circ}$. The results are shown $1 \mathrm{n}$ 'I'abl. 5.3. This was the only location chosen for comparison beciulu. the others generally exhibited longitudinal or transver:ic fiber orientation. The predicted modulus is groater than thr. experimental value, due to the non-homogeneity of the fitur orientation. The composite must have unidirectiond fibrr orientation in order to obey Equation (7), and thre orsentition of the fibers in the molded composites used in this study was not unidirectional throughout the specimen. The fariation in fiber orientation from skin to core resulted in an overprediction of the composite modulus by Equation ( $\%$ ). 
Table 5.3. Prediction of Young's Modulus for Composite with Fiber orientation Angle $\theta$.

\begin{tabular}{|c|c|c|c|c|}
\hline $\begin{array}{c}\text { Tonsile Test } \\
\text { Specimen }\end{array}$ & $\begin{array}{c}\text { Orientation } \\
\text { Angle }\end{array}$ & $\theta$ & $\begin{array}{c}\text { Predicted } \\
\text { Mod (MPa) }\end{array}$ & $\begin{array}{c}\text { Experimental } \\
\text { Mod (MPa) }\end{array}$ \\
\hline 1 & $-54^{\circ}$ & $36^{\circ}$ & 1.79 & 1.63 \\
\hline
\end{tabular}

'The tollowing values were used in the equation:

$E_{1}=1.99 \mathrm{MPa}$

$\because \quad 1.50 \mathrm{MPa}$ 


\subsubsection{Effect of Franklin Fibers on Tensile properties}

The tensile properties of the unreinforced rubber are given in Table 4.1. When these are compared to the tonsile results that have been reported, it can be seen that the addition of Franklin Fibers causes an increase in tensile stromuth and Young's modulus, without significantly lnilumime the elongation at break. The increase in Yound':; molulu!; 1:; expected for fibrous reinfurcement, but the inrrerio in tensile strength and the behavior of the elongation at brouk are typical of the effects of particulate $11111 \%$ reinforcement. This suggests that whisker reintorcomont at:; as a combination of particulate filler and short libir reinforcements. The above effects are observod at low $1 \mathrm{H} \cdot \mathrm{H}$ loadings.

\subsection{Tensile set Results}

The tensile set is a measure of the elastic recovrry of it material after enduring a constant strain. It is drolund d,:

$$
\epsilon=\frac{\mathrm{L}-\mathrm{L}_{0}}{\mathrm{~L}_{0}}
$$

where $L$ is the distance between bench marks after the cimplo: has been stretched to a set elongation, held there for trin minutes, and then removed from the grips and relaxrd for tron minutes. $L_{0}$ is the initial distance betwern bench mark:s. Bartlett's test was used to determine a single standard 
deviation for each sample.

\subsubsection{Transfer Molded Samples}

The tensile set results for the samples molded with converging sprues at $163^{\circ} \mathrm{C}$ are presented in Figure 5.46 . The lowest set values were found at locations 3,5 , and 6 where the fiber orientation is transverse. The highest values were at positions 2 and 4 where the fibers were oriented longitudinally. The set value will be zero for fully elastic recovery, therefore, the more elastic the material, the lower the set. When the fibers are longitudinally oriented, they control the deformation, and their effect on properties decreases as their orlentation becomes more transverse (8). Also, when the fibers are oriented in the direction of the stress (longitudinal fiber orientation), they restrict the ablilty of the material to recover and return to its original configuration. Therefore, longitudinal fiber orientation results in a decrease in elasticity and an increase in tensile set. The results indicate lower set values at locations with transverse fiber orientation and higher set values at iocations with longitudinal fiber orientation.

The results for samples molded at $204^{\circ} \mathrm{C}$ with converging sprues are shown in Figure 5.47. The results were similar to those found at $163^{\circ} \mathrm{C}$. The values were generally higher at this temperature, due to the decreased efficiency in cross-linking. 


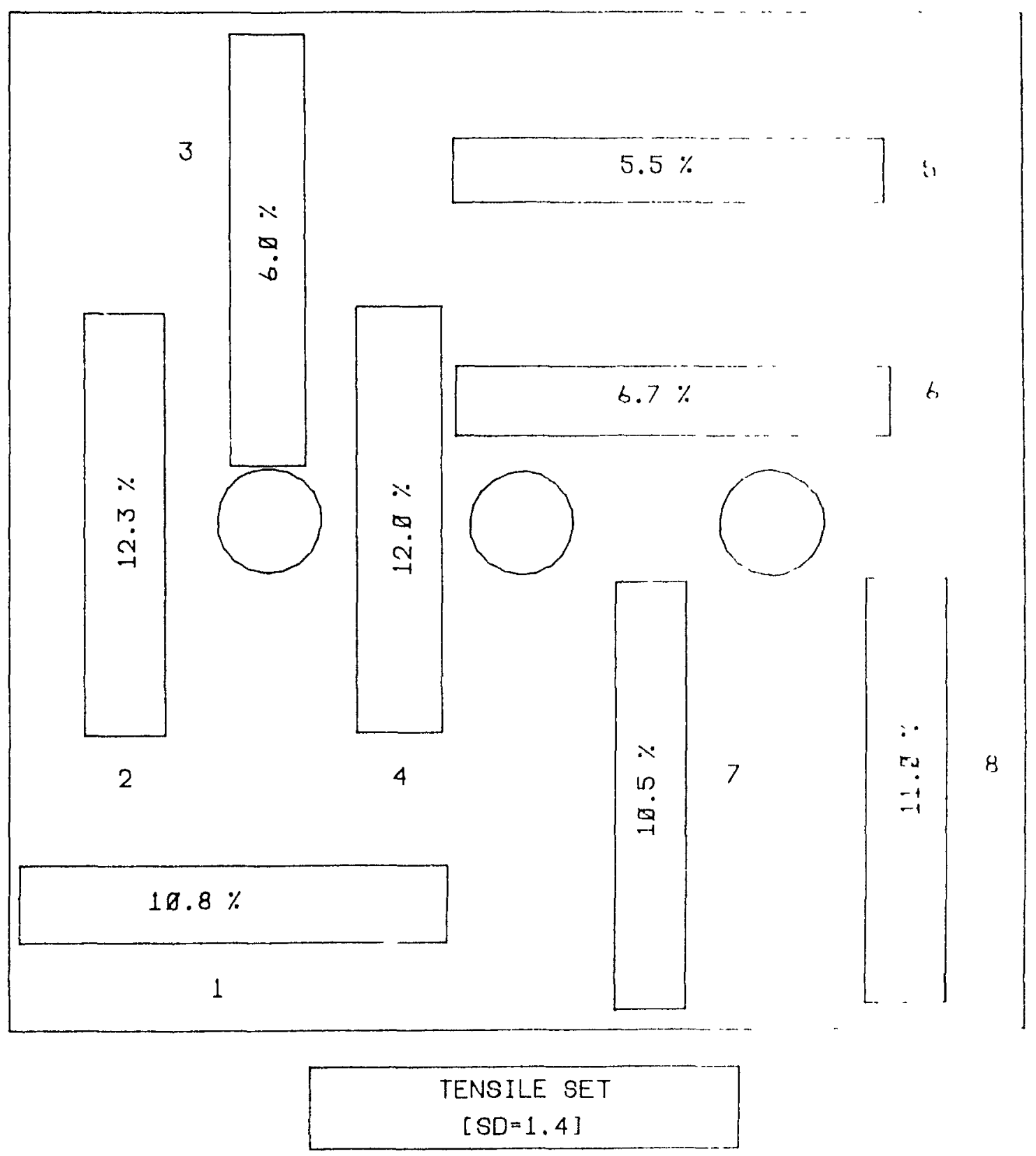

Figure 5.46. Tensile set Results for Samples Molded with Converging Sprues at $163^{\circ} \mathrm{C}$. 


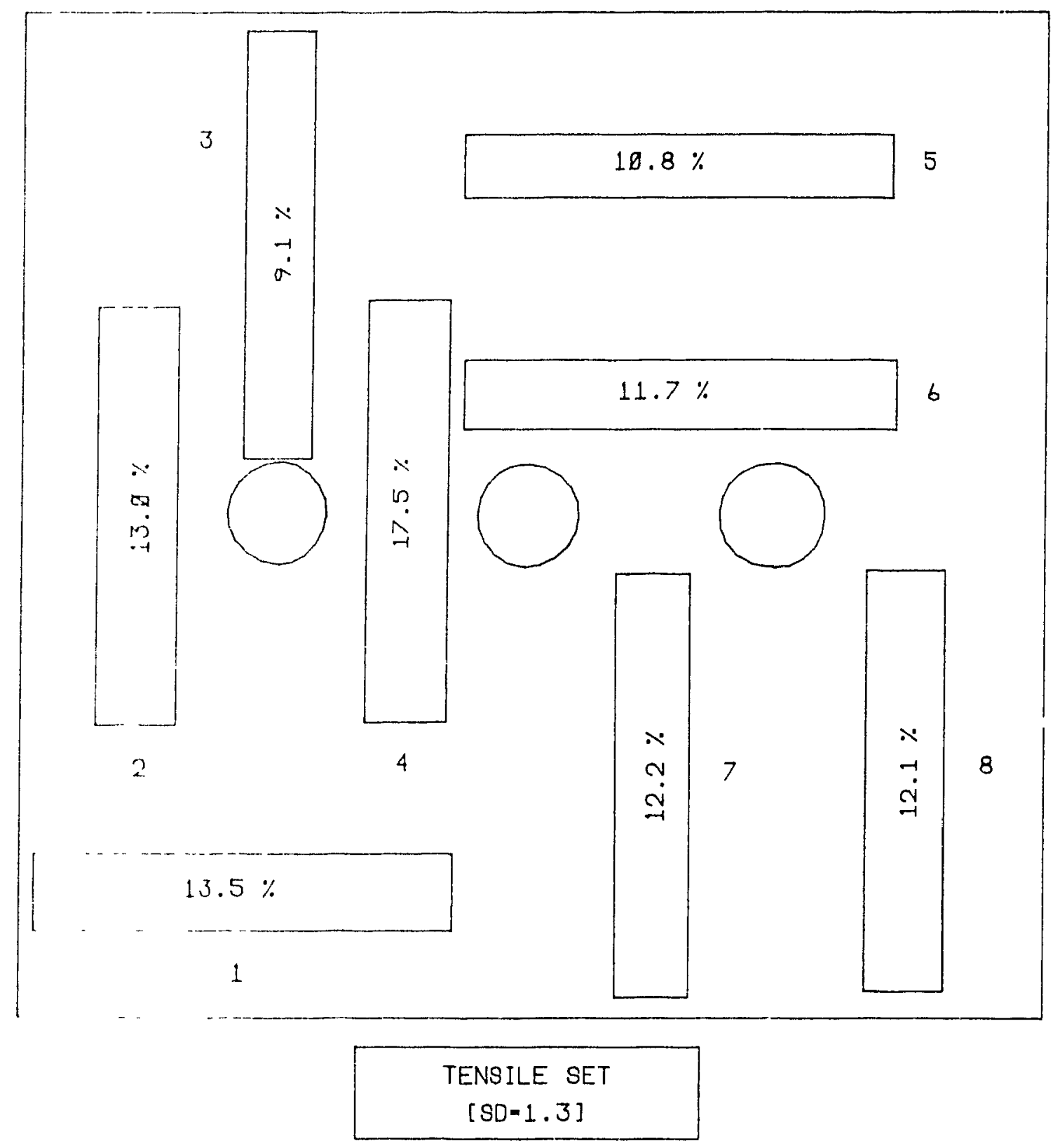

I'lgure 5.47. Tensile set Results for Samples Molded with Converging Sprues at $204^{\circ} \mathrm{C}$. 
Figures 5.48 and 5.49 present the results for samples molded with straight sprues at $163^{\circ} \mathrm{C}$ and $204^{\circ} \mathrm{C}$, respoctivoly. 'Tho variation of set with orientation and temperature which was; observed with converging sprues was also scen with struiyht sprues. A change in sprue design did not alter the orientation of the fibers; so, no variation in ten:il lo sot was: achieved with a different sprue design.

\subsubsection{Compression Molded Samples}

The samples Lhat were prepared with the "controller milling" procedure and molded at $163^{\circ} \mathrm{C}$ showed some anisotrupy in $1 \mathrm{hr}$ tensile set, as shown in Figure 5.50. At $204 \mathrm{~A}$, th. anisotropy was reduced, as seen in Figure 5.51. 'llht int. values were higher at the higher molding tomperratur., ,1: expected.

Figure 5.52 gives the results for the samples that uniorwint random milling and were molded at $163^{\circ} \mathrm{C}$. The sct values; wer. lower than those found in the samples with controllod mill $1 \mathrm{~mm}$, due to the random orientation of the fibers.

\subsubsection{Comparison Between Transfer and Comproision Moldim}

The set values were more anisotropic for the traniffr mulind samples, due to the greater anisotropy in thre fitur orientation. The highest set values were found for the 


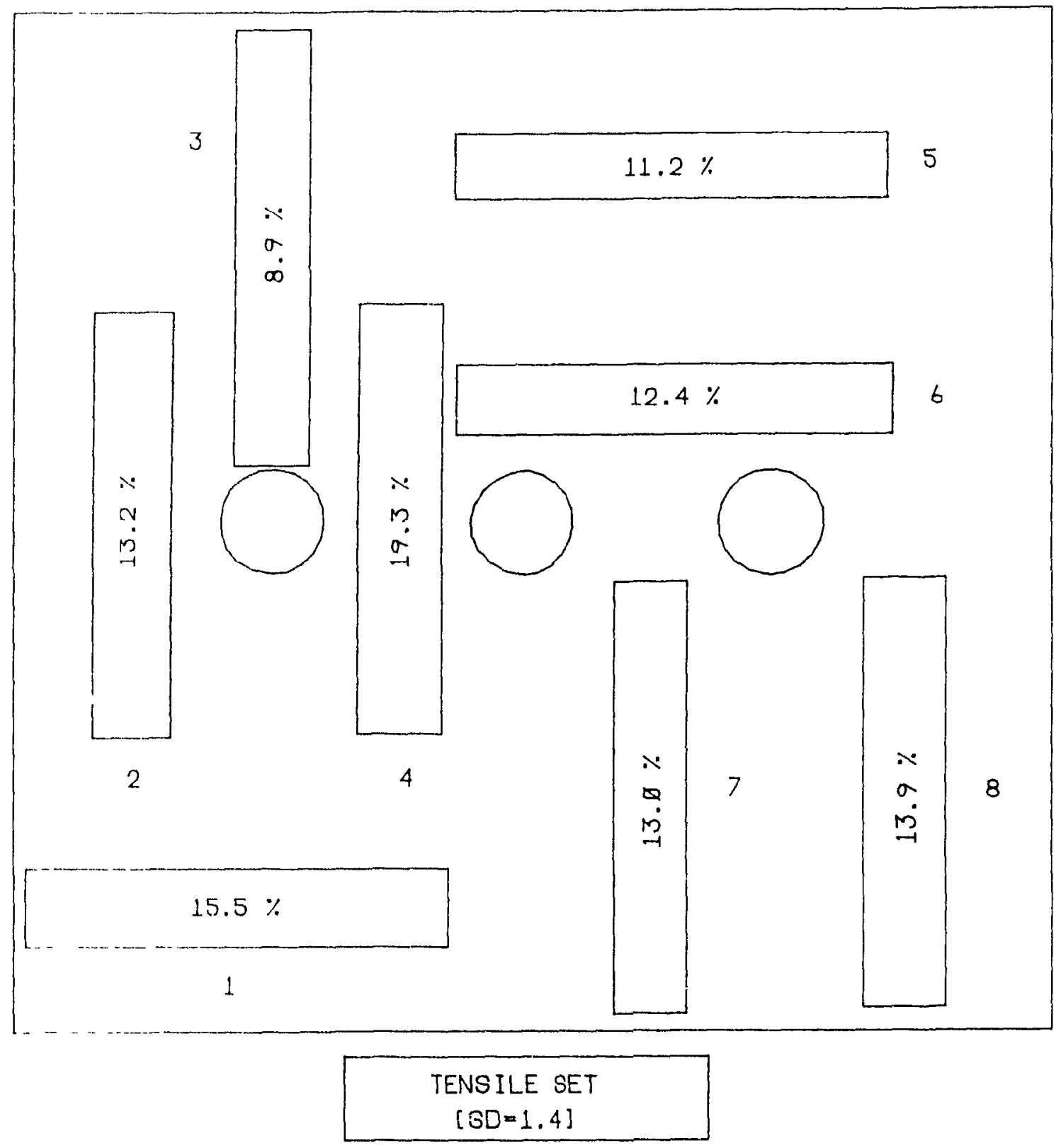

Figure 5.48. Tensile set Results for Samples Molded with Straight Sprues at $163^{\circ} \mathrm{C}$. 


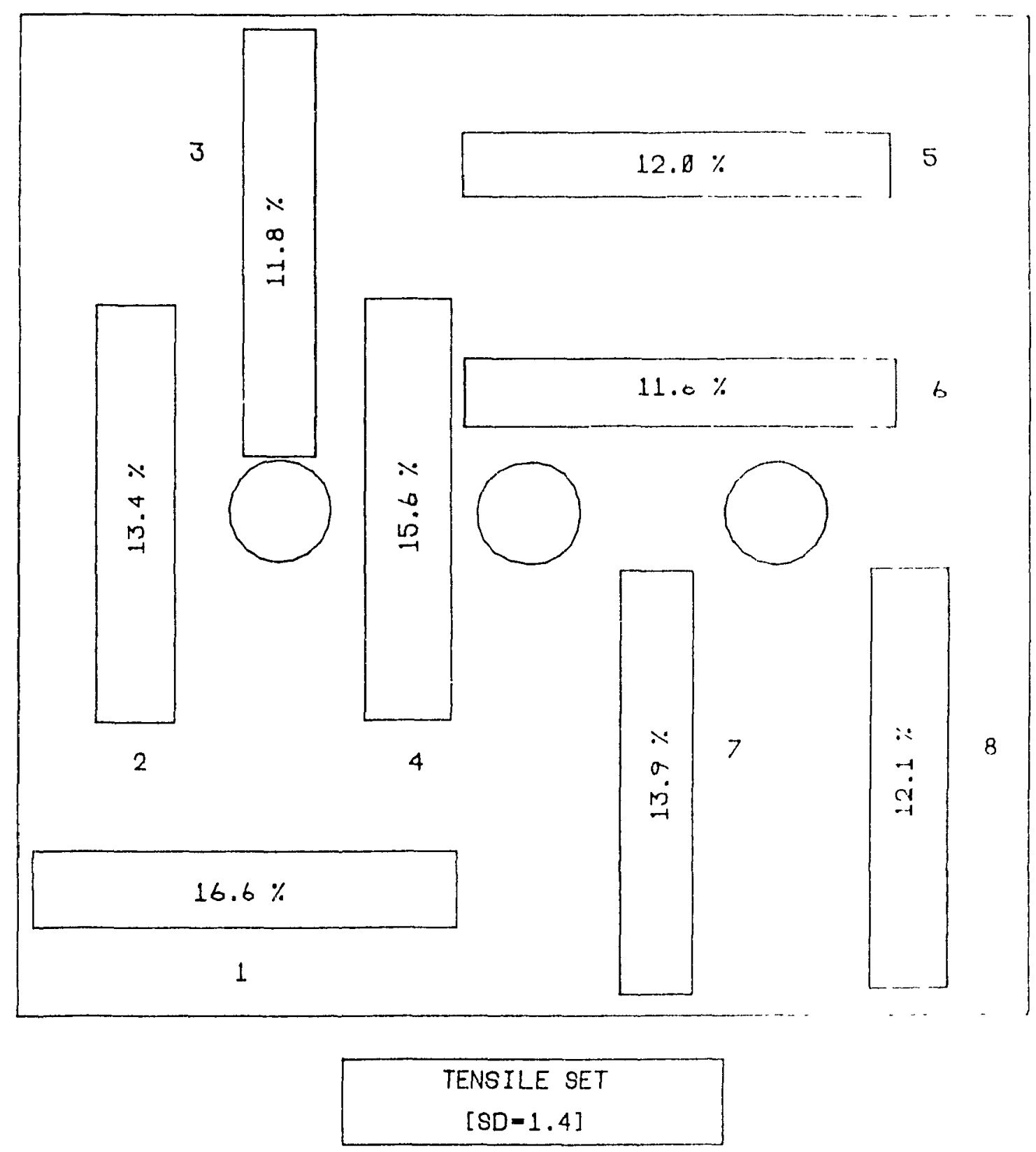

Figure 5.49. Tensile set Results for Samples Molderd inth straight sprues at $204^{\circ} \mathrm{C}$. 


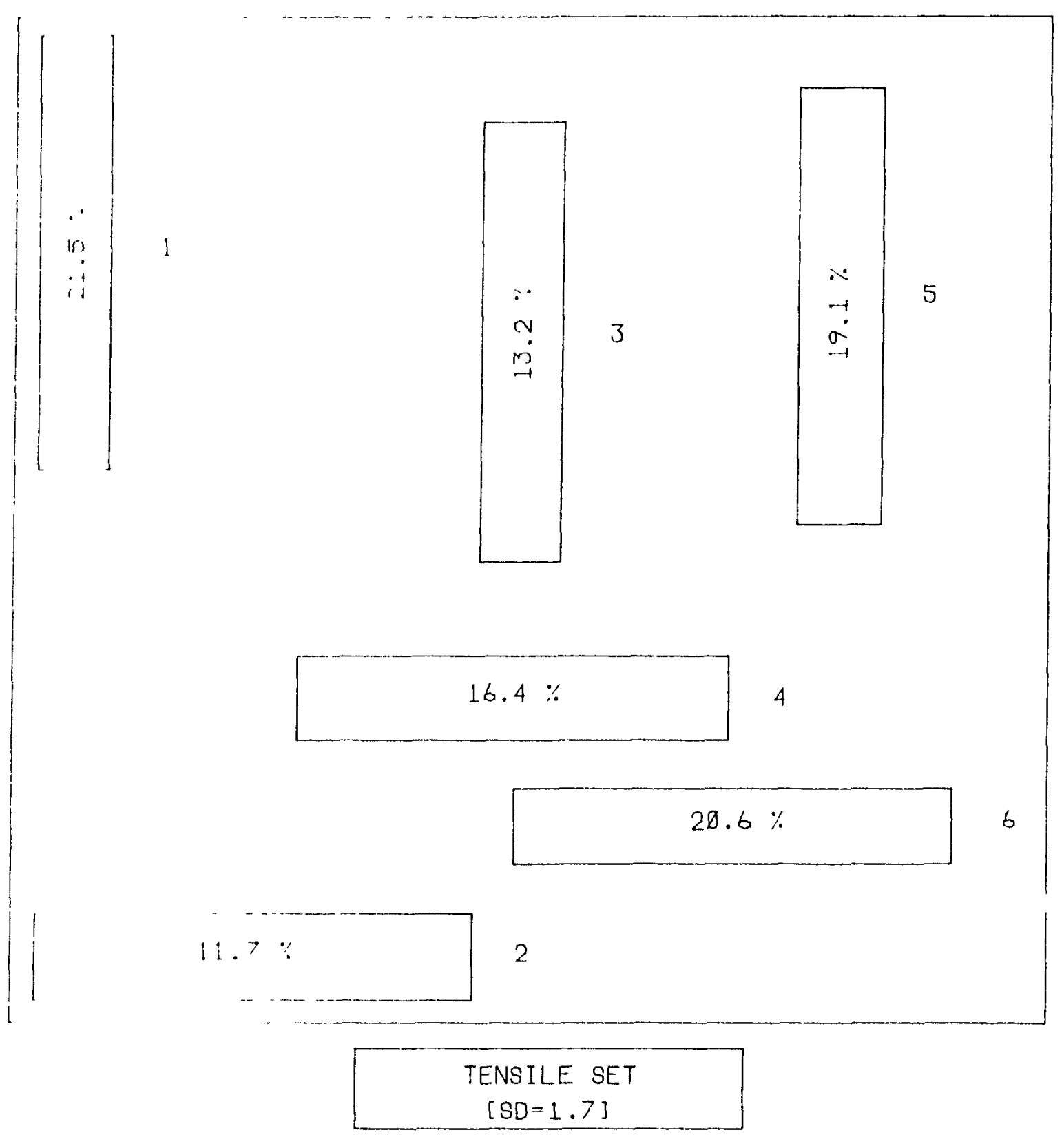

Figure 5.50. Tensile set Results for controlled Milling Samples Molded at $163^{\circ} \mathrm{C}$. 
1

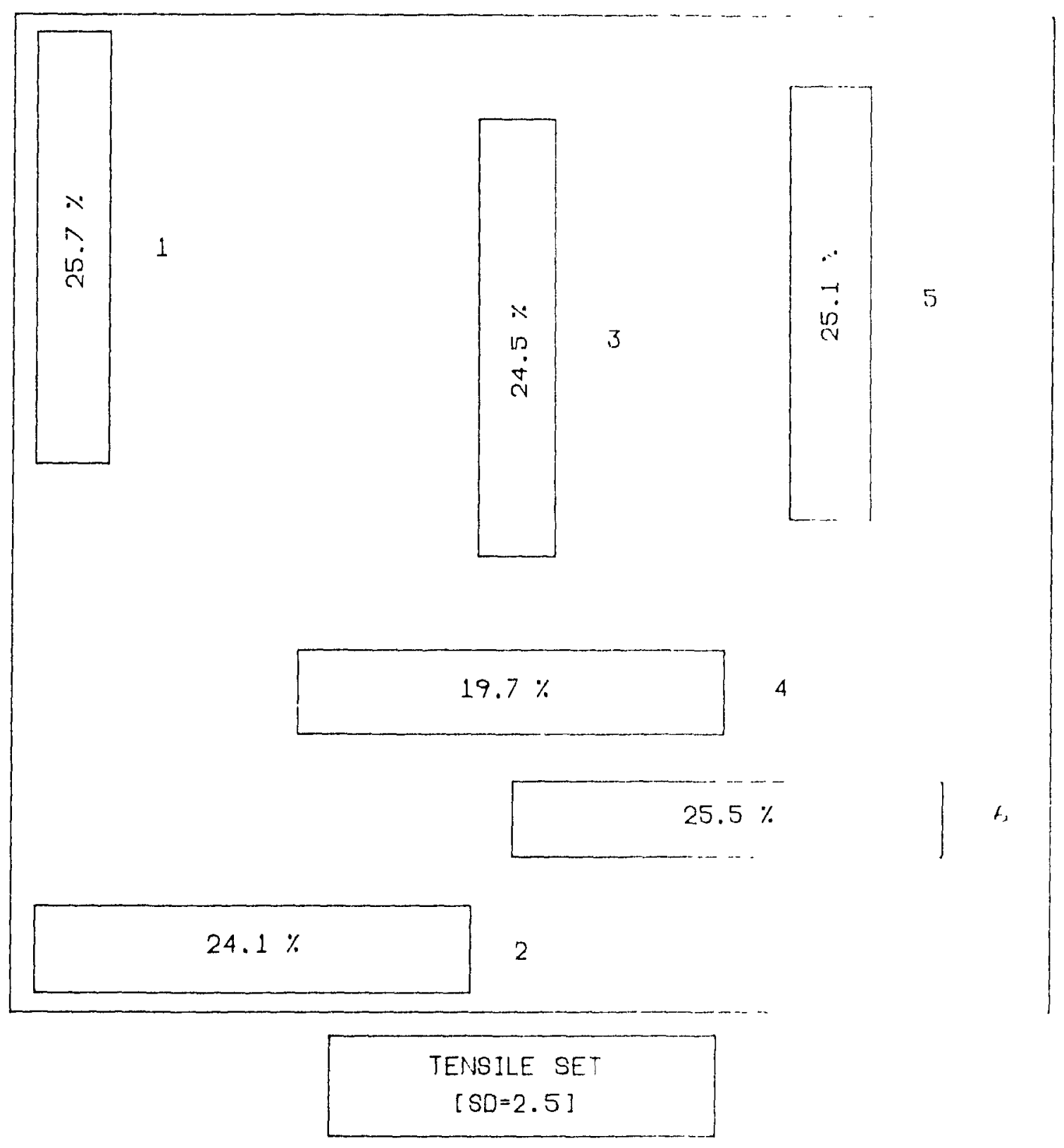

Figure 5.51. Tensile set Results for controlled lillinr Samples Molded at $204^{\circ} \mathrm{C}$. 

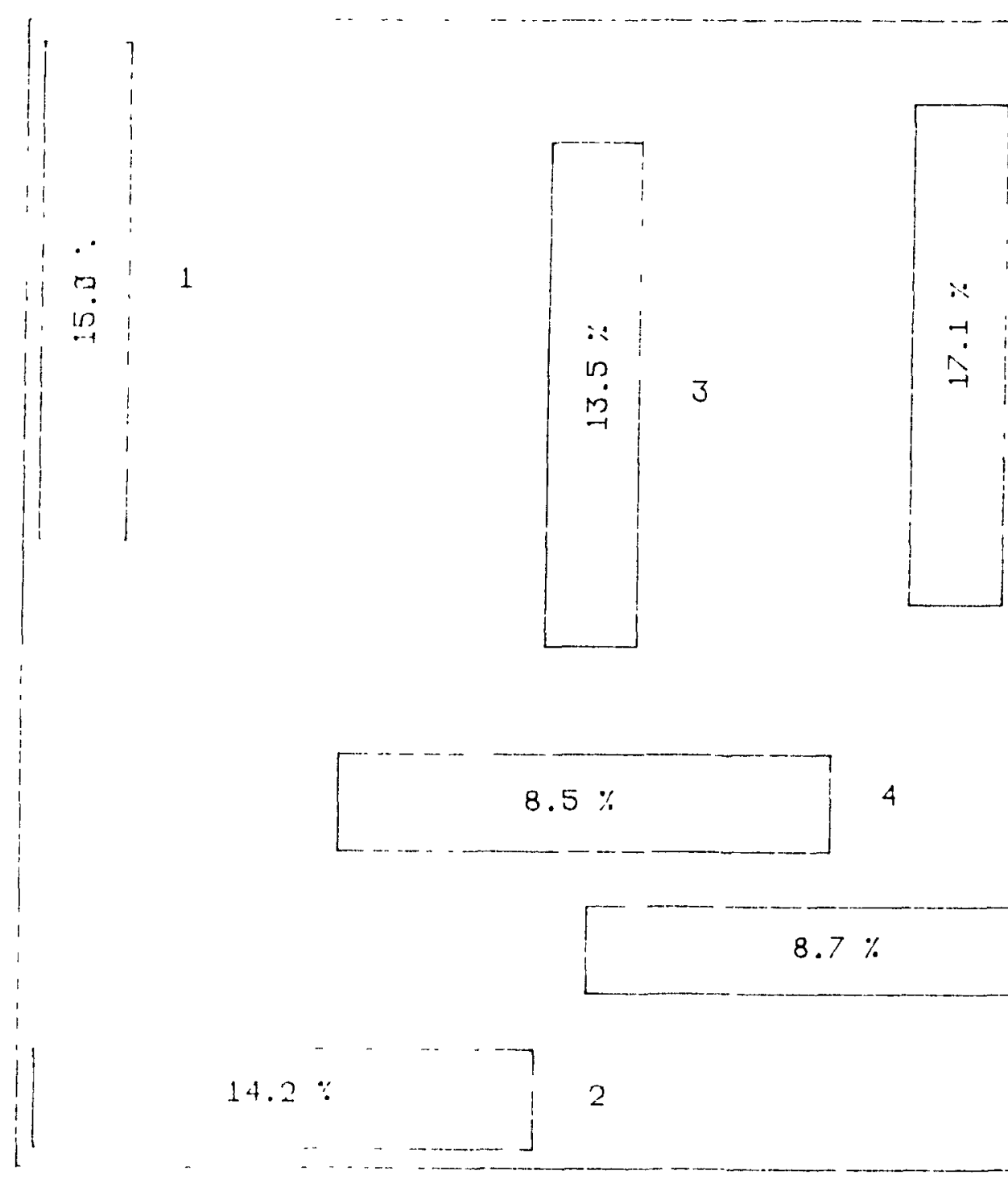

\section{5}

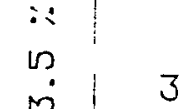

m

3
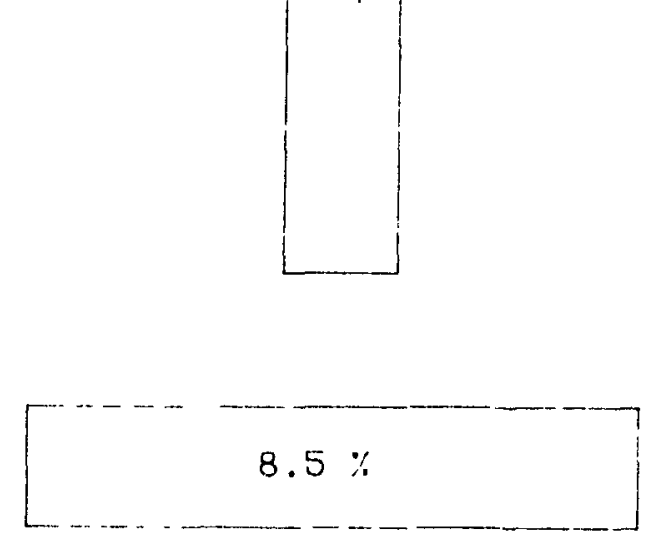

4

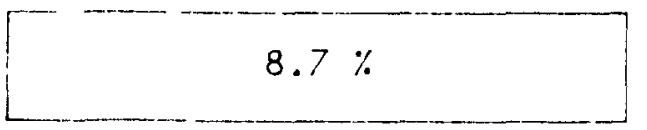

6

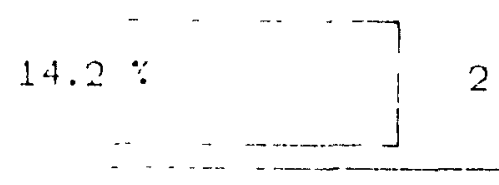

TENSILE SET

$[S D=1.8]$ 
compression molded samples with controlled milling which had uniform longitudinal fiber orientation. The tensile set was highly dependent on the fiber orientation. An increase in molding temperature caused an increase in the set for both molding procedures. 


\section{COHCLUS IONS AND RECOMMENDATIONS}

\subsection{Conclusions}

This project has shown that whisker-reinforced silicone rubber composites can be molded using compression and transfer molding. It was also shown that manipulation of processing parameters provides a mechanism of controlling fiber orientation and tensile properties. An image analysis system, leveloped in the laboratory, was helpful in obtaining a rapid and accurate evaluation of the fiber orientation and length distributions in the samples.

'The orlentation of the fibers is anisotropic and nonhomogeneous for the transfer molded samples. The fibers exhibit circumferential orientation at the core, regardless of sprue design or temperature. The milling procedure influenced the fiber orientation in the compression molded samples. The fiber orientation is anisotropic and homogeneous for the samples prepared with "controlled milling", regardless of temperature. The samples that were prepared with "random milling" yield random fiber orientation at both temperatures.

significant fiber attrition occurred for both molding procedures. The initial fiber length of 30 microns was reduced to a final length of approximately 12 microns. The 12 micron average length was found in all samples, regardless 
of molding procedure or milling technique. This suggosts that the initial mixing of the fiker: was responsible for the severe fiber breakage.

The tensile strength and elongation at break aro isotropic for the transfer molded samples and are independont of iprue design. The Young's modulus is anisotropic, and 1 s grouterit at locations with longitudinal fiber orientation. 'Iho compression molded samples with "controlled milling" oxhllit greater tensile strength and Young's modulus than those with "random milling". All tensile properties are homogeneous; und isotropic within the compression molded samples. An incrone" in molding temperature causes a decrease in strength and elongation for all molded samples. The Young's modulu!; is, not affected by an increase in temperature. The comprobinun molded samples with "controlled milling" have the grratri.; Young's moduli due to their homogeneous longiturdinal liber orientation. Differences in the state of cure may oudur it an increased mold temperature for the transfer molded simplo... The tensile set is sensitive to fiber orientation and temperature, =or all molded samples.

The Halpin-Tsai equations do not accurately prodict the Young's modulus of the composites. This is due to thr. inherent differences in dimensions and properties butwern whiskers and other forms of reinforcement. Substrantid] modulus improvement may be realized with whisker relnforcement 
at a much lower volume fraction than is required with short fiber or particulate reinforcement. Theoretical predictions for the Young's modulus of a composite with the fibers oriented at an angle between 0 and $90^{\circ}$ do not agree with the experimental results due to the non-homogeneity of the fiber orientation within the samples.

\subsection{Recommendations for Future Work}

The flber loading used in this project was very low, and may not have given optimum property improvement. Using several litferent fiber loadings would increase the understanding of how fiber concentration affects mechanical properties and would allow the user of this composite to find the optimum I l ber loading to obtain the desired property values.

It would be helpful to change the design of the transfer mulding operation so that the mold is placed vertically below the sprue. This might cause more uniform fiber orientation. 'Ihe three different sprue designs could then be compared to sce what type of fiber orientation resulted.

The amount of peroxide curing agent was kept constant in the samples, even when the curing temperature was changed. It would be useful to change the amount of peroxide to see if this effects the properties. 
It would be of interest to determine the manner in which the composites failed in tension. This could be achicved by viewing the fractured tensile specimens with a scanniny electron microscope. An analysis of the mode of failure of the composites would aid in determining the effect of the reinforcement.

Some discrepancies occurred in the high temperature trankitri molding, perhaps due to differences in curc from locition to location. It would be useful to do a complete study of the state of cure throughout the sample to verify this. As; woll, a dynamic mechanical analysis of the composite may bre hulpful in developing a broader understanding of the Frankl in Fiborsilicone rubber system. 


\section{REFERENCES}

1. P.J. Flory, Principles of Polymer Chemistry, Cornell University Press, Ithaca, New York, 1971, Chap. 11.

2. H.S. -Y. Hsich, R.J. Ambrose, Injection and Compression Molding Technology of Elastomers, Marcel Dekker Inc., New York, New York, 1987, Chap. 5.

3. E.L. Warrick, O.R. Pierce, K.E. Polmanteer, J.C. Saam, Rubber Chem. Technol., 52, 437 (1979).

4. M.G. Noble, Vanderbilt Rubber Handbook, R.T. Vanderbilt Corp., 1978, 216.

'. P.K. Pal, S.K. De, Rubber Chem. Technol., 55, 1370 $(1982)$.

6. D.K. Setua, S.K. De, Rubber Chem. Technol., 56, 808 (1983).

7. L.A. Goettler, K.S. Shen, Rubber Chem. Technol., 56, 619 (1983).

3. I.A. Goettler, Handbook of Elastomers, Marcel Dekker Inc., New York, New York, 1988, Chap. 7.

9. J.C. Halpin, J. Comp. Mater., 3, 732 (1969).

10. S. Abrate, Rubber Chem. Technol., 59, 384 (1986).

11. Specifications from United States Gypsum Company, Chicago, Illinois.

1.. J. Menough, Rubber World, 192 (1), 14 (1985).

13. S.R. Moghe, Rubber Chem. Technol., 49, 1160 (1976).

14. E.A. Dyzura, A.L. Serebro, N.D. Kiryushina, Int. Polym. Sci. and Technol., 13 (3), 8 (1986).

15. C.L. Tucker, Injection and Compression Molding Technology of Elastomers, Marcel Dekker Inc., New York, New York, 1987, Chap. 7.

11. A.I. Isayev, A.D. Azari, Rubber Chem. Technol., 59, $868(1986)$.

17. M.A. Wheelans, Rubber Chem. Technol., 51, 1023 (1978).

18. L.A. Goettler, R.I. Leib, A.J. Lambright, Rubber Chem. Tecnno: - , 52,838 (1979). 
19. A.Y. Coran, K. Boustany, P. Hamed, Rubber Chem. Technol., 47, 396 (1974).

20. J.E. O'Conner, Rubber Chem. Technol., 50, 945 (1977).

21. A.Y. Coran, K. Boustany, P.Hamed, J.Appl. Polymer sci..., 15, 2471 (1971).

22. P.C. Li, L.A. Goettler, P. Hamed, J. Elastomors and Plastics, 10, 59 (1978).

23. W.W. Paris, J.R. Dillhoefer, W.C. Woods, Rubber Chem. Technol., 55, 494 (1982).

24. Results of testing performed by the Lorl Corporation, Cary, North Carolina.

25. M.J. Bozarth, J.W. Gillespie, Jr., R.L. Mccullouch, Polymer Composites, 8 (2), 74 (1987). 